\title{
nct of 1958
}

NUCLEAR SAFETY QUARTERLY REPORT MAY, JUNE, JULY, 1968

FOR

NUCLEAR SAFETY BRANCH

of

USAEC DIVISION OF REACTOR

DEVELOPMENT AND TECHNOLOGY

OCTOBER 1968

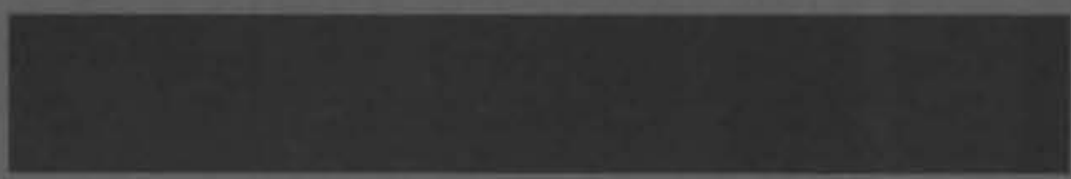

AEC RESEARCH \&

DEVELOPMENT REPORT

BATTELLE B NORTHWEST 


\section{LEGAL NOTICE}

This report was prepared as an account of Gavernment sponsared work. Neither the United States, ner the Commission, nor any person acting on behalf of the Commission:

A. Makes any worranty or representation, expressed of implied, with respect la the accuracy, com. pleteness or usefulness of the information contained in this report, or that the use of any information, apporatus, method, or process disclosed in this report may nat infringe privately owned rights; or

B. Assumes any liabilities with respect to the use of, of far damoges resulting from the use of any infarmation, apparatus, method, or process disclosed in this repart.

As vised in the obove, "person acting on behalf of the Commission" includes any employee or sontractor of the Cammission, or emplayee of such controctor, to the extent that such emplayee or con. Iractor of the Commission, or employee of such contracion prepares, disseminates, or provides access to, any information pursuant to his employment or contract with the Commistion, or his employment with such contractor.

\section{PACIFIC NORTHWEST LABORATORY \\ MICHLAND. WASHENGTON \\ operaled by \\ BATTELLE MEMORIAL INSTITUTE}

for the

UNITED STATES ATOMIC ENERGY COMMISSION UNDER CONTRACT AT(45-1)-1830 
NUCLEAR SAFETY QUARTERLY REPORT

MAY, JUNE, UULY, 1968

FOR

NUCLEAR SAFETY BRANCH

$0 F$

USAEC DIVISION OF REACTOR DEVELOPMENT AND TECHNOLOGY

By

The Staff of Eattelle-Northwest

FIRST UNRESTRITED OCT $2 \% 68$

October 1968

PACIFIC NORTHUEST LABCRATORY

RICHLAND, WASHINGTON 
Printed in the United States of America Available from

Clearinghouse for Federal Scientific and Technical Information National Bureau of Standards, U.S. Department of Commerce Springfield, Virginia 22151

Price: Printed Copy $\$ 3.00 ;$ Microfiche $\$ 0.65$ 


\section{NUCLEAR SAFETY QUARTERLY REPORT}

MAY, JUNE, JULY, 1968

FOR

NUCLEAR SAFETY BRANCH

$O F$

USAEC DIVISION OF REACTOR DEVELOPMENT AND TECHNOLOGY

By

The Staff of Battelle-Northwest

\section{FOREWORD}

This report is the sixth of a series in which Pacific Northwest Laboratory reports its nuclear safety-related studies being performed for the USAEC Division of Reactor Development and Technology.

\begin{tabular}{lll}
\multicolumn{3}{c}{ PREVIOUS REPORTS IN THIS SERIES } \\
BNWL-433 & January, February, March & \\
BNWL-537 & April, May, June & 1967 \\
BNWL-754 & July, August, September, October & 1967 \\
BNWL-8I6 & November, December, 1967, January 1968 & \\
BNWL-885 & February, March, April & 1968
\end{tabular}





\section{TABLE OF CONTENTS}

FOREWORD.

SUMMARY :

ENGINEERED SAFEGUARD STUDIES, • • • • • • • • $\quad$ • 2.1

Containment Systems Experiment - G. J. Rogers • . . 2.1

Fission product Aerosol Control - L. C. Schwendiman and $\mathrm{H}, \mathrm{H}$. Van Tuyl. . . . . . . 2.23

PRESSURE BEARING COMPONENT EVALUATION AND MONITORING STUDIES

Crack Detection in Pressure Piping by Acoustic

Emission - P. H. Hutton, R. N. Ord, C. E. Fitch

H. N. Pedersen, and J. C. Spanner . . . . . . 3.1

ENVIRONMENTAL STUDIES - R. F. Foster. • , • , . 4.1

Disposal of Reactor Off-Gas into Soil Systems -

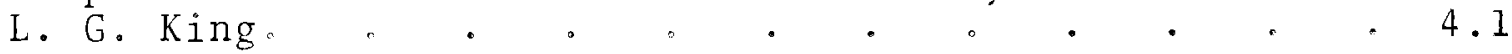

Simulation Modeling of Thermal Generation in

Selected River Systems - R. T. Jaske. • . . . 4.2

FIXATION OF RADIOACTIVE RESIDUES. . . . . . . . 5.1

Phosphate Glass Solidification. • . . . . . . 5.1

Spray Solidification . . . . . . . . . 5.5

Advanced Solidification Techniques..$\quad \cdot \quad \cdot \quad \cdot 5.12$

Development Studies on Solidification Processes . 5.15

Heat Transfer Studies. . . . . . . . 5.20

Waste from Chemical Processing . . . . . . 5.23

Low-Levei Waste Treatment . . . . . . . 5.29

Evaluation of Solidified Waste Products , , . 5.30 


\section{SUMMARY}

\section{ENG INEERED SAFEGUARD STUDIES}

\section{Containment Systems Experiment}

A series of leakage rate tests were performed on the CSE contalnment vessel using room-temperature air, heated-air, and steam-air atmospheres. The tests had the objective of relating the leakage characteristics of a containment system under possible postaccident conditions to the leakage rate determined by standard methods as required by Technical Specifications or operating licenses for nuclear stations.

Base-line tests were performed with room-temperature air at nominal pressure levels of 9,23 , and 35 psig. These tests were followed with heated-air and steam-air atmosphere, leakage-rate tests at nominal test conditions of 9 psig at $175^{\circ} \mathrm{F}$, 23 psig at $225^{\circ} \mathrm{F}$, and $35 \mathrm{psig}$ at $250^{\circ} \mathrm{F}$.

Results of the base-1ine tests showed good agreement between integrated leakage rates determined by the absolute and reference vessel methods; and the summation of collected leak flows at individual leak points amounting to 85 to $98 \%$ of the calculated leakage. Assuming laminar flow, variation of leakage rate with pressure was as predicted.

In both the heated-air and steam-air test series, a sub. stantial decrease in leakage occurred as temperature increased Additional, deliberately superimposed, leak points were introduced to provide reasonable tests of measurement sensitivity.

A large-scale fission-product transport experiment was performed at the quarter's end. Test conditions were a steamair containment atmosphere at $250^{\circ} \mathrm{F}$ and $48.5 \mathrm{psia}$, and airborne aerosol removal was by natural processes only. Test results are not yet available. 
A mathematical model for removal of elemental iodine by natural processes in a containment vessel was improved by incorporating the effect of the density gradient (resulting from molecular weight gradients) near the wall. Predictions with the model were compared with experimental results from CSE experiments in two, different size vessels, with reasonable agreement found.

Renovation of the CSE blowdown facility was nearing completion, and instrumentation is now being installed on the reactor simulator vessel.

Data from CSE blowdown experiments show significant deviations from predictions of existing mathematical models for foam level and effluent void fraction. A different theoretical approach was developed to predict the void fraction profile in the vesse1.

Optional, digital filtering techniques were developed and incorporated into the data processing codes for treating CSE blowdown data. A program for computing time derivatives of the vessel weight-load cell data was developed to eliminate the tedious manual graphical procedure for determining effluent mass flow during blowdown. A computer routine is being pro grammed to process neutron densitometer data to give effluent vold fraction without laborious manual calculation.

Core samples were taken from the CSE reactor simulator vesse1 wall in and near a large, ultrasonic test-defect indication. To date, results from examination of these core samples show that the sample from just outside the defect-indication region is free from defects and has normal tensile properties. The two, core samples from the defect indication region show numerous small void-or inclusion-defects elongated in the rolling direction at a location agreeing with the ultrasonic test 
indications. Tensile tests made on the core sample specimens show that the material around the flaws behaved in a ductile manner and exhibited reasonable strength.

Fission Product Aerosol Control

Absorption of methyl iodide by sprays of aqueous solutions of hydrazine and sodium thiosulfate was measured in a series of once-through spray runs. Separate collection of wall-film liquid and use of a specially designed drop-collector permitted comparative assessment of absorption by wall-film liquid and falling drops. The measured absorption was $1.5: 3$ times faster than predicted from stagnant film and drop theory.

The effect of chamber size on washout rate was estimated based on the washout model. For one set of conditions, nominally typical of those expected for a large scale containment system, the washout half-time using 5 wt dicted to be about $60 \mathrm{~min}$. This estimate utilized extrapolation from the experimental results using the droplet-wall removal model.

Further reaction kinetics data were obtained for the 1iquid systems of methyl iodide and 1,1-dimethylhydrazine, monomethylhydrazine, sodium sulfite, and sodium bisulfite. of these, sodium sulfite gave the most rapid rate.

A conclusion was reached that the radiation sensitivity of hydrazine and the formation of hydrogen as a product will be serious deterrents to its use in reactor sprays, unless selective timing of reactive sprays can be realized following the loss of flow accident, or satisfactory means to mitigate hydrogen explosive potential can be incorporated into the reactor design. 


\section{PRESSURE BEARING COMPONENT EVALUATION AND MONITORING STUDIES}

Crack Detection in Pressure piping by Acoustic Emission

Detailed study of acoustic emission wave propagation in reactor materials has continued. Emphasis is being placed on study in the frequency range of 0.5 to $3.0 \mathrm{MHz}$ and on the use of critical angle transducer orientation. Some success has been achieved in detecting signal variations between brittle and ductile material. There are also indications that what was earlier thought to be a variation in signal frequency content, as observed by lower frequency sensors, is actuaily a reflection of acoustic emission repetition rate or signal den. sity for increments of deformation and crack growth.

It appears that critical angle detection in the higher Erequency range (low $\mathrm{MHz}$ ) will improve the signal-to-noise ratio and provide a sharper wave front for improved source location resolution. One $\mathrm{MHz}$, PzT-5A transducers have been fabricated by using a ceramic mounting and backing material in place of the previously used epoxy to improve their high temperature longevity. These are currently in the testing process

A 1ow-noise, wide-band preamplifier has been fabricated and satisfactorily field tested for acoustic emission detec. tion. The performance is superior to previousiy used commercial preamplifiers, and the cost is about one third that of the commercial models.

Background-noise spectra measurements have been made on the Dresden I nuclear power reactor during start-up from cold flow to full power operation. For this reactor, it appears that an acoustic emission monitor system operating in the range of $750 \mathrm{kHz}$ to $3 \mathrm{MHz}$ would be relatively unhampered by reactor system noise interference. 


\section{FIXATION OF RADIOACTIVE RESIDUES}

During the report period, approximately $2,400,000 \mathrm{Ci}$ of radioactivity were processed in the sixth phosphate glass solidification run, and approximately 360,000 Ci were processed in the third spray solidification run. Phosphate glass Run PG-6 was made by using sulfate-free Purex waste 1 (PW-1) feed while SS- 3 was made with sulfate-containing Purex waste 2 (PW-2) feed.

The high rare-earth concentration (35 wt: as oxide) of $\mathrm{PW}-4 \mathrm{~m}$ waste tends to raise the melting point and increase nonhomogeneity of spray solidifier melts. Satisfactory phos. phate melts for the spray solidifier have only been achieved by adding sodium and iron to the point where the final melt resembled PW-I spray solidifier product. Some borosilicate systems have been investigated, of which several have been prepared that have "stick" temperatures above $700^{\circ} \mathrm{C}$ and me1ting points in the range 925 to $975^{\circ} \mathrm{C}$.

The water-nitric acid separation characteristics of an analog computer model of WSEP were verified by comparison with actual WSEP data. Data from a pot calciner run have also been used to adjust the parameters of the model to match data on solids entrainment and ruthenium volatility

Three, successful vacuum batch transfers of phosphate glass melts were made in engineering scale equipment to test advanced solidification techniques.

The vacuum distillation flowsheet for treating sulfate condensate resulting from phosphate glass solidification was tested with a simulated solution and tracer ruthenium. The overal1 decontamination factor was greater than $5 \times 10^{3}$.

Steady state cooling capacities of the two, wSEP product pot furnaces were calculated. The highest planned heat generation rate of $25 \mathrm{~kW}$ in a stainless steel pot is within the calculated furnace limits. 
- 


\section{ENGINEERED SAFEGUARD STUDIES}

CONTAINMENT SYSTEMS EXPERIMENT - $F_{3}$. J. Rogers

Containment Leakage Studies - M. E。 Witherspoon

A series of ambient air, hot air, and steam-air leakage tests were completed late in May. The objective of these tests is to relate the leakage of steel containment vessels as measured in a standard air test to the leakage of the same vesse1 in postaccident atmospheres. The results and subsequent analyses are important as a means of assessing the adequacy of current requirements for leak tightness as stipulated by the Division of Safety Standards. These tests supplement other leakage tests performed on the same vessel and summarized in previous reports. $(1,2)$

Base-line air-leakage rate tests at three nominal pressure levels $(9,23$, and 35 psig) were conducted to establish the nominal leakage rate of the vessel and the loss at each individual leakage point. The vessel was then retested with heated-air and steam-air atmospheres at the same nominal pressures and three nominal temperatures (175, 225 and $250^{\circ} \mathrm{F}$ ).

Calibrated thermocouples, a nickel-alloy resistance wire, a helium-tested reference tubing system, lithium chloride humidity sensors, and a heat exchanger and blower were within the contained volume as shown in Figures 2.1 and 2.2 .

\section{Base Line Air Tests}

The base-line air tests were performed with the results listed in Table 2.I (Test No. 1 to 3 ). The reference method value is the average of 24 single hourly observations. The absolute method is calculated with a perfect gas formula for conditions at the beginning and end of the 24 hour period, and it is also calculated by a linear regression analysis of 


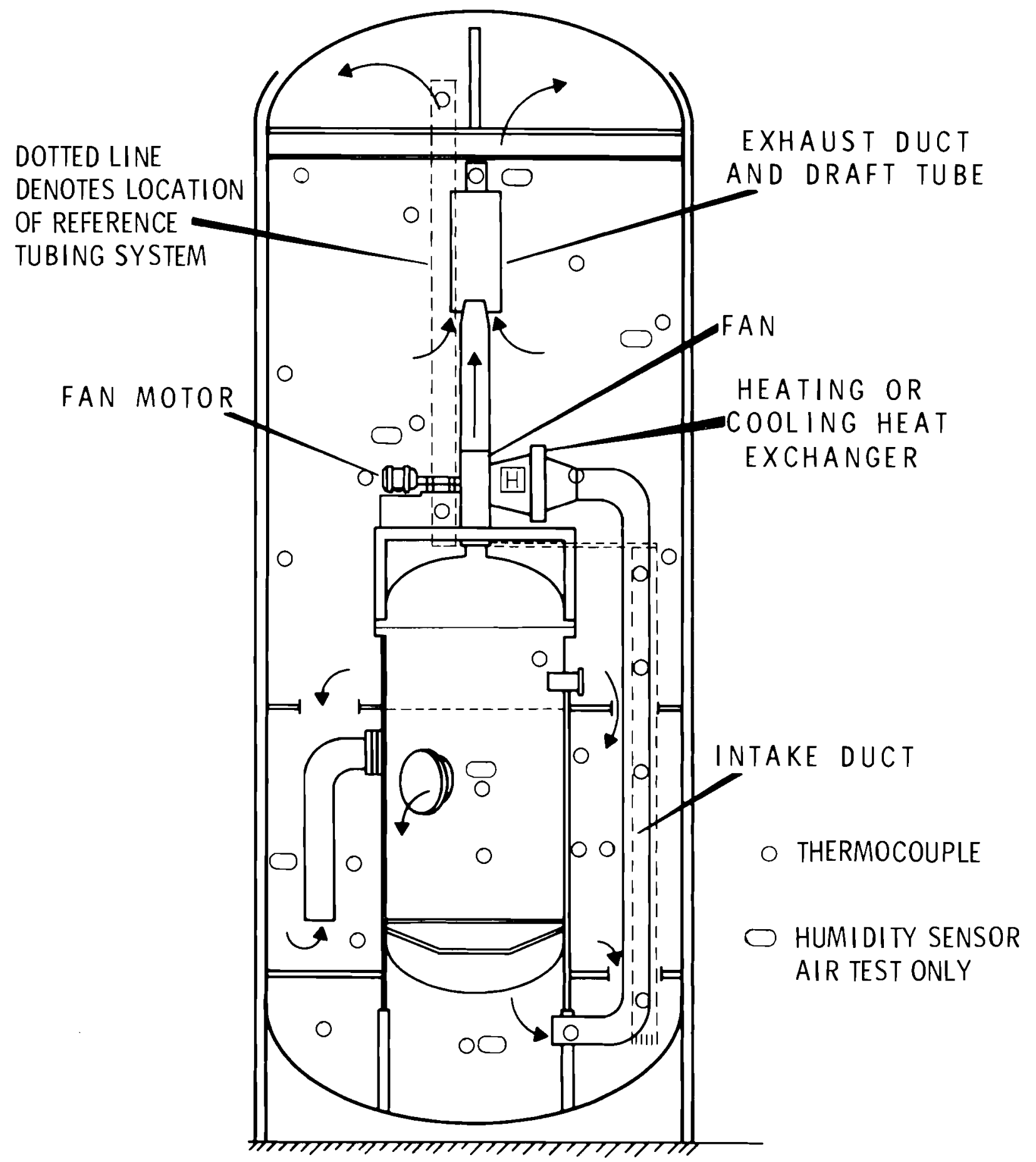

FIGURE 2.1. Equipment for Hot-Air and Steam-Air Leakage Rate Tests 


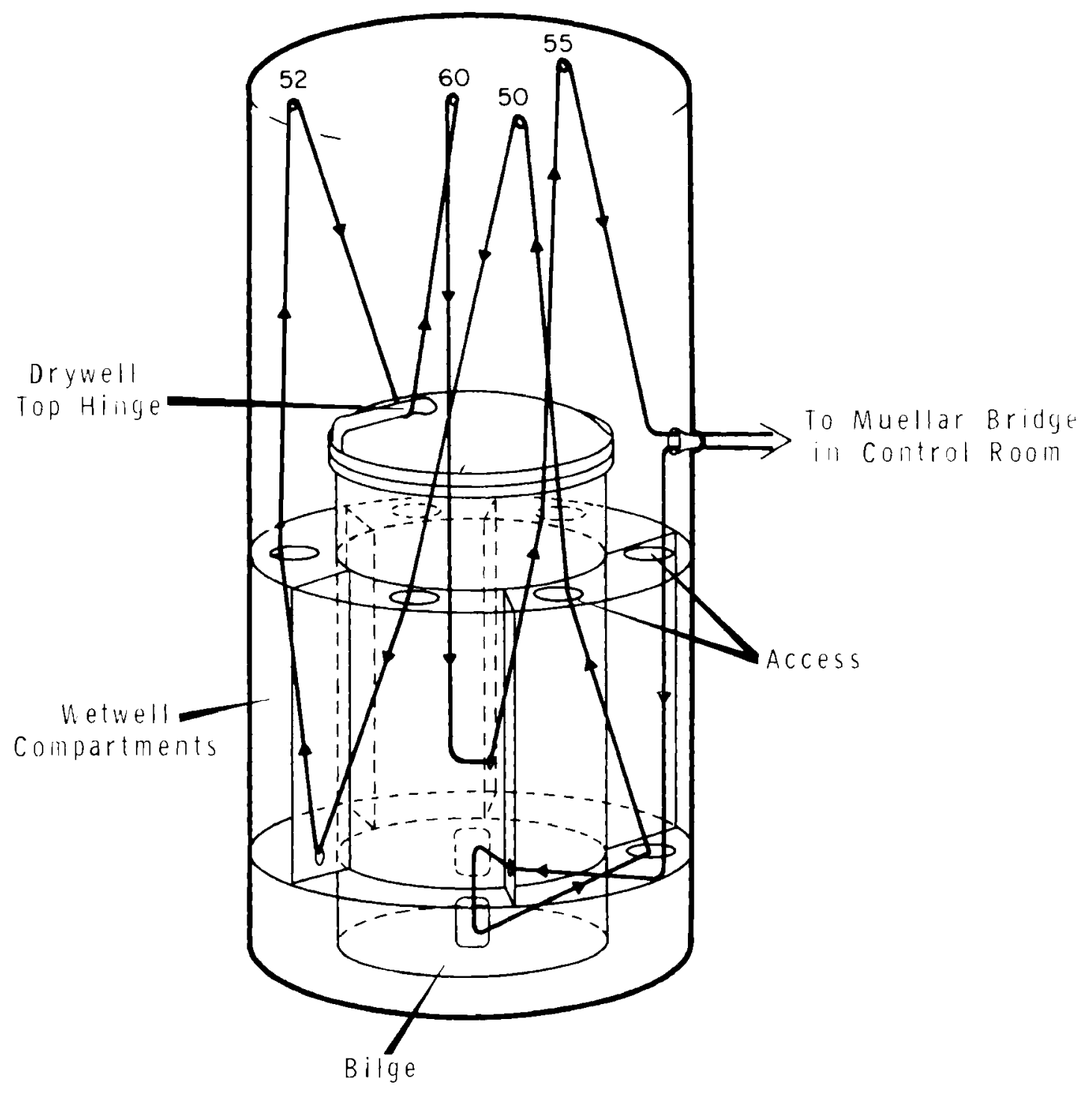

*All Points of Contact Insulated from Containment Shell

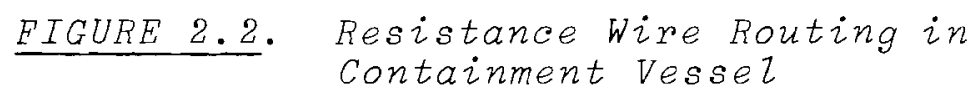


TABLE 2.1. Summary of Data; Hot-Air and Steam-Air Leakage Rate Series

\begin{tabular}{|c|c|c|c|c|c|}
\hline $\begin{array}{l}\text { T'est } \\
\text { No. }\end{array}$ & $\begin{array}{l}\text { Nominal } \\
\text { Conditions } \\
{ }^{\circ} \mathrm{F}, \text { psig } \\
\end{array}$ & $\begin{array}{l}\text { Reference } \\
\text { Method } \\
\end{array}$ & $\begin{array}{c}\text { Absolute } \\
\text { Method } \\
\text { (Wire) } \\
\end{array}$ & $\begin{array}{c}\text { Collected } \\
\text { Leakage } \\
\end{array}$ & Comments \\
\hline 1 & 75,35 & 0.408 & $\begin{array}{c}0.477 \\
(0.471 \pm 0.0098)\end{array}$ & 0.402 & $\begin{aligned} 0.477= & \text { base for down- } \\
& \text { ward extrapo- } \\
& \text { lation }\end{aligned}$ \\
\hline 2 & 75,23 & 0.393 & $\begin{array}{c}0.394 \\
(0.417 \stackrel{ \pm 0.0156)}{ }\end{array}$ & 0.349 & $\begin{aligned} 0.415= & \text { laminar extrap - } \\
& \text { olation from } \\
& 35 \text { psig }\end{aligned}$ \\
\hline 3 & 75,9 & 0.259 & 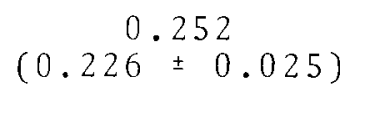 & 0.228 & $\begin{aligned} 0.258= & \text { laminar extrap- } \\
& \text { olation from } \\
& 35 \text { psig }\end{aligned}$ \\
\hline 4 & $175, \quad 9$ & $\ldots$ (a) & $\begin{array}{c}0.120 \\
(0.108 \pm 0.0176)\end{array}$ & 0.09 & $\begin{array}{l}\text { Leakage rates at indi- } \\
\text { vidual points diminished } \\
\text { during heat-lup }\end{array}$ \\
\hline $5 c$ & 225,23 & 0.220 & $\begin{array}{c}0.269 \\
(0.268 \stackrel{ \pm 0.01)}{ }\end{array}$ & 0.15 & $\begin{array}{l}\text { Superimposed additional } \\
0.1 \% \text { leakage }\end{array}$ \\
\hline 6 & 250,35 & 0.105 & $\begin{array}{c}0.124 \\
(0.147 \pm 0.012)\end{array}$ & 0.10 & $\begin{array}{l}\text { Superimposed 1eak } \\
\text { diminished }\end{array}$ \\
\hline $1 \mathrm{a}$ & 75,35 & 0.266 & $\begin{array}{c}0.289 \\
(0.301 \pm 0.033)\end{array}$ & 0.182 & $\begin{array}{l}\text { Includes original and } \\
\text { superimposed leakage } \\
\text { after cool-down }\end{array}$ \\
\hline 7 & $175,9^{(\mathrm{a})}$ &.- & $(-) 1.20$ & n i 1 & \\
\hline $8 \mathrm{a}$ & $\begin{array}{r}225,23 \\
(S / A)\end{array}$ & -- & $(-) 1.39$ & 0.285 & Superimposed add. 1eak \\
\hline $8 b$ & $\begin{array}{c}225,23 \\
(S / A)\end{array}$ & $-\cdots$ & $(-) 1.90$ & 0.05 & $\begin{array}{l}\text { Superimposed leak } \\
\text { diminished }\end{array}$ \\
\hline 9 & $\begin{array}{r}250,35 \\
(S / A)\end{array}$ & -- & $(-) 9.6$ & 0.48 & $\begin{array}{l}\text { Superimposed } \sim 0.5 \% \text { addi- } \\
\text { tional leakage }\end{array}$ \\
\hline $10 \mathrm{~b}$ & 75,35 & 0.47 & 0.532 & 0.255 & Ambient air retest \\
\hline
\end{tabular}

(a) Unstable control conditions put reference system temporarily out of order 
al1 24 hourly observations. The value in parentheses is the regression value with a $95 \%$ confidence interval (2 sigma).

The collected leakage column is the result of measuring individual leakage points with flow meters, summing them, and converting the sum to an equivalent percentage loss per day.

Agreement between the methods was considered reasonable and gave confidence that the instrumentation was performing satisfactorily. The results of a laminar extrapolation of the data at 35 psig to lower pressures agree well with calculated results. Comparison of collected leakage to calculated values of leakage indicate that 85 to $98 \%$ of the total leakage was collected.

\section{Hot Air Tests}

Test Number 4 shows that heating of the vesse1 to $175^{\circ} \mathrm{F}$ at 9 psig had the immediate effect of reducing the collected leakage from $20.23 \% /$ day to $0.09 \% /$ day. A corresponding drop is seen in the calculated leakage. The leakage at original leakage points continued to diminish in Test Numbers 5 and 6 (225 and $250^{\circ} \mathrm{F}$, respectively). The collected leakage in Test Number 5 includes additional, deliberately superimposed leakage points; these leaks also diminished during the $24 \mathrm{hr}$ period of the Number 6 test. A retest of the vessel after a cooldown (Test No. la) indicated that most of the leaks had not recovered their original leakage rate, and total leakage (including the superimposed leakage) was less than that at the beginning (Test No. 1).

\section{Steam-Air Tests}

Additional testing in steam-air atmospheres (Test No. 7 , $8 \mathrm{a}, 8 \mathrm{~b}$, and 9$)$ showed a further flow decrease at the superimposed leakage points. The atmosphere for these tests was 
established by beginning with one atmosphere of ambient air in the vessel, and adding steam until the desired condition was reached. Once the nominal test condition was attained, steam feed was halted and the vessel began a pressure decline down the saturation pressure curve. The method for calculation of the air fraction lost is the perfect gas law applied to the partial pressure of air. The ratios of steam to air are determined by letting the measured average temperature define the saturation pressure and by measuring the total pressure with a gage. Test Number 8 was an isothermal test with the same calculational procedure applied.

The collected leakage volume is the fractional percent of initial air contents leaking at the beginning of each test. These leaks were successfully collected by using flowmeters with condensate traps. Generally, all the individual leaks diminished as exposure time to the steam-air atmosphere increased,

The negative values for the steam-air calculations can be partially attributed to several unapplied corrections; accumulation of condensate resulting in a volume decrease, shrinkage of the vessel due to temperature decline (as much as $85^{\circ} \mathrm{F}$ in Test No. 9), shrinkage due to pressure drop(27 psi in Test No. 9), and an unknown measurement error caused by a time lag in the thermocouple system. Preliminary analysis indicates that the latter error is the most influential. The Test $10 \mathrm{~b}$ was a cold air retest of the vessel with all superimposed and original leaks included.

The trend of these data indicates that leakage rate effects caused by actual atmospheric weight and temperature are swamped by physical alterations of leakage paths because of the temperature and composition of the atmosphere. The results suggest that relatively small corrections and 
adjustments to aggregate leakage levels to account for changes in molecular weight and viscosity may be an unnecessary refinement. There are more gross effects which give conservatism to the estimate of leakage based on simple ambient air test with no corrections for atmosphere. Integrated leakage tests on steam-and air-atmospheres were unsuccessful because an accurate temperature measurement during a decline is difficult to attain. Further analysis and testing are needed to determine whether it is possible to get this measurement at all. $\underline{\text { Fission Product Transport Studies }}$

\section{Large-Scale Experiments - R. K. Hilliard}

One large-scale fission product transport test was made near the end of the quarter. In this experiment, CSE Run A-5, no active safeguards were used, and fission product transport within the containment vessel was due to natural processes only.

The primary objectives of this experiment were to obtain experimental data on FP behavior in the containment vesse1 in an environment similar to those expected after a Loss-ofCoolant Accident to a large PWR, and to compare the observed behavior with predictions based on mathematical mode1s. To achieve the latter objective, several secondary objectives were included:

- Rate of mixing of FP simulant materials in the atmosphere

- Characterization of the fluid dynamics (temperature and velocity gradients, steam-air ratios, and steam condensation rates)

- Measurement of FP aerosol properties in the containment atmosphere

- Determination of the FP leakage rate through selected leak points

- Visual observations of the atmosphere during the test. 
Test conditions were similar to those reported (3) for an earlier test, Run A-2, except that the vesse1 was insulated, and the atmosphere was $250^{\circ} \mathrm{F}, 48.5$ psia in Run A-5. Samples are being analyzed and no conclusions can be made at this time except that all test objectives appeared to be accomplished.

The next large-scale experiment will be a containment spray test that will demonstrate the efficiency of sprays for removing fission products from steam-air atmospheres.

Mass Transfer Mode1 for Natural Transport of Elementa1 Iodine - R. K. Hi11iard and J. G. Knudsen

The mathematical model discussed in a previous report (4) was improved by accounting for the effect on natural convection of the density gradient near walls caused by molecular weight gradients. The theoretical basis for this modification can be found in Jacob. (5) The model provides a method for predicting rates of transfer of gaseous fission products from steam-air atmospheres to containment vessel surfaces. Its advantage over existing mode1s $(6,7,8)$ is its ability to predict the gas phase mass transfer coefficient.

Assumptions, in addition to those used in earlier models, are: (1) flow patterns are caused only by natural convection due to heat transfer to vertical walls, and (2) the steam-air mixture is saturated at all locations. The simplification is made that the walls are at thermal equilibrium, though the model can be extended to cover the unsteady state.

The correlation recommended by McAdams (9) for turbulent heat transfer by natural convection, modified for density gradients caused by mass transfer of steam, is

$$
h_{i}=0.13 k_{f}\left(\frac{g}{\nu} \operatorname{Pr} S c\right)^{1 / 3}\left(1-\frac{M_{b} T_{i}}{M_{i} T_{b}}\right)^{1 / 3} .
$$


By analogy,

$$
\mathrm{k}_{\mathrm{c}}=0.13 \mathrm{D}_{\mathrm{v}}\left(\frac{\mathrm{g}}{v^{2}} \operatorname{Pr} \mathrm{Sc}\right)^{1 / 3}\left(1-\frac{\mathrm{M}_{\mathrm{b}}}{\mathrm{M}_{\mathrm{i}}} \frac{\mathrm{T}_{\mathrm{i}}}{\mathrm{T}_{\mathrm{b}}}\right)^{1 / 3} .
$$

All the terms are known except $\mathrm{T}_{i}$, the temperature at the interface. $T_{i}$ can be estimated by an energy balance:

$$
\begin{aligned}
\mathrm{q} / \mathrm{A} & =\mathrm{h}_{i}\left(\mathrm{~T}_{\mathrm{b}}-\mathrm{T}_{i}\right)+\frac{\mathrm{k}_{\mathrm{c}}}{\mathrm{RT}_{\mathrm{b}}} \Delta \mathrm{H}_{\mathrm{vap}}\left(\mathrm{p}_{\mathrm{b}}-\mathrm{p}_{i}\right) \\
& =h_{w}\left(\mathrm{~T}_{i}-\mathrm{T}_{0}\right)=h_{o}\left(\mathrm{~T}_{0}-\mathrm{T}_{\mathrm{a}}\right)
\end{aligned}
$$

The value of $\mathrm{T}_{i}$ can be calculated, for stated conditions of bulk gas temperature, $\mathrm{T}_{b}$, surrounding air temperature, $\mathrm{T}_{\mathrm{a}}$, and wall coefficient, $h_{w}$. Equation (2) is then used to calculate the mass transfer coefficient for elemental iodine or any other diffusing species for which the effective diffusivity is known. Assuming gas phase diffusion is limiting, the gas phase concentration calculated for a puff release is

$$
\frac{C_{g}}{C_{0}}=\exp \left[-\left(k_{c} \frac{A_{T}}{V}+k_{s} \frac{A_{W}}{V}\right) t\right] \text {. }
$$

Calculations for different cases of $\mathrm{h}_{\mathrm{w}}, \mathrm{T}_{\mathrm{b}}$, and $\mathrm{T}_{\mathrm{a}}$ showed that $k_{c}$ and $k_{s}$ are relatively independent of these parameters over the range of interest. Also, $k_{c}$ is about ten times greater than $k_{S}$. Thus, the concentration half-time depends chiefly on the ratio of total surface area to volume.

The predicted values of heat-and mass-transfer rates are compared in Table 2.2 with experimental values from tests in two sizes of vessels. Agreement is fair, but improvement could be made to the model if either: (1) liquid reaction rates and diffusion were considered, or (2) allowance was made for the portion of surface area that may have laminar boundaries. 
TABLE 2.2. Model Predictions Versus Experiments in the CSE

\begin{tabular}{|c|c|c|c|c|c|c|}
\hline \multicolumn{2}{|c|}{ Run Number } & ${ }_{{ }^{\circ} \mathrm{F}}^{\mathrm{T}_{\mathrm{b}}}{ }^{\mathrm{T}} \mathrm{i}$ & $\begin{array}{c}\text { Steam } \\
\text { Flux } \\
1 \mathrm{~b} \mathrm{hr^{-1 }} \mathrm{ft}^{-2} \\
\end{array}$ & $\begin{array}{c}k_{c} \\
\left(I_{2}\right) \\
\text { ft } \mathrm{hr}^{-1} \\
\end{array}$ & $\begin{array}{r}\mathrm{k}_{\mathrm{s}} \\
\mathrm{ft} \mathrm{hr}^{-1} \\
\end{array}$ & $\begin{array}{l}\mathrm{t}_{1 / 2} \\
\left(\mathrm{I}_{2}\right) \\
\min \\
\end{array}$ \\
\hline \multirow{2}{*}{$D-1^{(a)}$} & Prediction & 7.2 & 0.26 & 16.0 & 2.2 & 5.0 \\
\hline & Experiment & (c) & 0.375 & (c) & (c) & $8 \pm 1$ \\
\hline \multirow{2}{*}{$D-2^{(a)}$} & Prediction & 7.2 & 0.25 & 16.0 & 2.2 & 5.0 \\
\hline & Experiment & (c) & 0.340 & (c) & (c) & $10 \pm 1$ \\
\hline \multirow{2}{*}{$A-1^{(b)}$} & Prediction & 7.8 & 0.10 & 16.2 & 1.5 & 8.7 \\
\hline & Experiment & (c) & 0.096 & (c) & (c) & $16 \pm 2$ \\
\hline \multirow{2}{*}{$A-2^{(b)}$} & Prediction & 7.8 & 0.10 & 16.2 & 1.5 & 8.7 \\
\hline & Experiment & $5.4 \pm 2.0$ & 0.11 & (c) & (c) & $10 \pm 1$ \\
\hline
\end{tabular}

(a) CSE drywezl: $A_{T} / V=A_{W} / V=0.46 \mathrm{ft}^{-1} ; h_{\omega}=20 \mathrm{Btuhr}^{-1} \mathrm{ft}^{-2} \mathrm{oF}^{-1}$; $T_{b}=250{ }^{\circ} \mathrm{F}, T_{a}=110{ }^{\circ} \mathrm{F}$.

(b) Main CSE vessel: $A_{T} / V=0.293 \mathrm{ft}^{-1} ; A_{W} / V=0.19 \mathrm{ft}^{-1} ; h_{w}=38 \mathrm{Btuhr^{-1 }}$ $f t^{-2} o_{F}^{-1} ; T_{b}=180^{\circ}{ }_{F} ; T_{a}=110^{\circ} \mathrm{F}$.

(c) Not measured or not applicable 
A prediction for a large PWR with 4 -ft thick concrete walls and $A_{T} / V$ of $0.2 \mathrm{ft}^{-1}$ gave 23 min for the concentration half-1ife of elemental iodine. This rate would hold until the concentration is about $1.5 \%$ of its initial value. Thus, natural transport processes can be an important mechanism for attenuating the consequences of a major accident to a water reactor.

\section{Nomenclature}

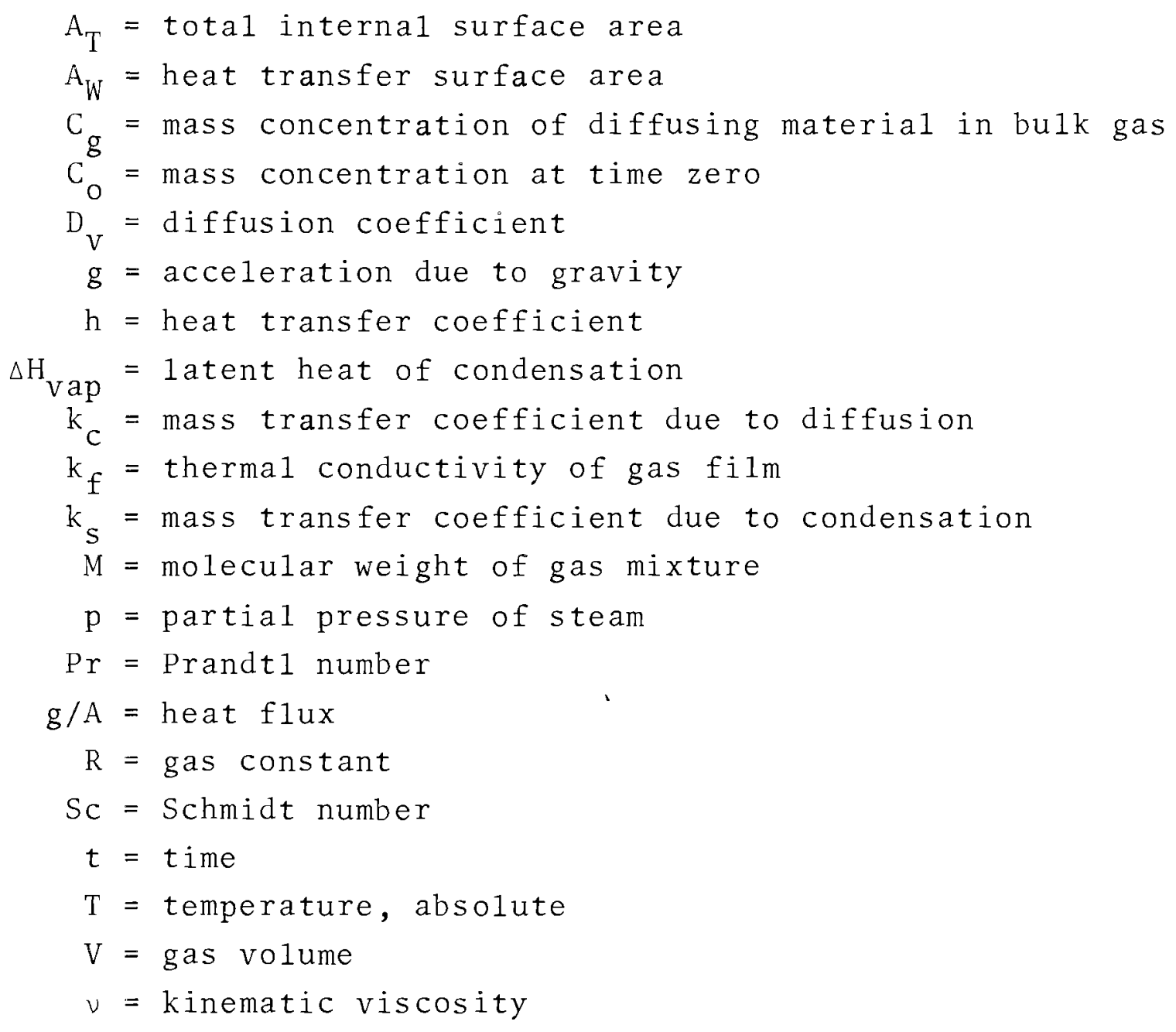

Subscripts:
a refers to outside air
b refers to bulk gas mixture
$i$ inside surface
o outside surface
w wall 
Coolant Blowdown Studies - R. T. Allemann

A reactor simulator vessel with a volume of $150 \mathrm{ft}^{3}$ and designed for operation at $600^{\circ} \mathrm{F}$ and $2750 \mathrm{psig}$ is being used in experiments to study loss-of-coolant accidents, The experiments have the objective of testing the validity of mathematical models used for predicting the consequences of reactor accidents. The vessel is mounted in a steel framework with the discharge nozzles directed horizontally. The blowdown apparatus is instrumented to measure internal pressures, temperatures, liquid level, void fraction of the fluid in the exit duct, mass of fluid remaining in vesse1, thrust reaction forces, shell stresses, and forces on reactor dummy core structures.

The main effort this quarter was directed toward the construction of a new, vessel supporting-structure to replace the system that failed last year. Installation of the vessel support system is complete. The instrumentation on the simulator vessel is being installed in preparation for resuming experimental work.

Void Fraction Profile in a Vessel During Coolant Blowdown - N. P. Wilburn

Knowledge of the void fraction profile in a nuclear reactor vesse1 during a loss-of-coolant blowdown is important in several ways: it determines the foam level in the vessel and, hence, influences the rate of heat transfer from the core; it determines rates of flow through the vessel internals; finally, and most important, it determines the properties of the effluent. These properties (stagnation enthalpy and pressure) are required as input to two-phase critical flow models. Heretofore, two empirical approaches have been used to obtain an approximation to these properties:

1. The fluid in the vessel was assumed to be a homogeneous mixture $(10)$ and, hence, had a constant void fraction profile. 
2. The void fraction profile was assumed to be linear in axial distance up the vessel, $(11,12)$ and effluent properties were computed from the void fraction at the withdrawal plane.

Moody (13) has obtained a theoretical description on the liquid-vapor action in a vessel. He assumed that:

- The bubbles were small enough so that the gas phase velocity was that which would be present in an infinite 1iquid.

- The effluent void fraction was a weighted average of that above and below the withdrawal plane.

- A pseudo steady-state integration of the resulting differential equations was possible.

Comparison of his results with data recently obtained from the Containment Systems Experiment (CSE) facility shows that the foam level and effluent void fraction predicted from his model deviate significantly from measured values.

A different theoretical approach, predicting the void fraction profile and then the effluent stagnation enthalpy from mass and energy balances around the withdrawal plane, has been developed. The partial differential equations that were written, described the mass and energy balances inside the vessel but neglected kinetic energy terms. Thermal equilibrium was assumed throughout. The gas-phase velocity was assumed to have reached a terminal value everywhere with respect to the local liquid velocity, and the difference was assumed to be either constant ( $2 \mathrm{ft} / \mathrm{sec}$ ) or given by Wilson's correlation with void fraction. (14) Two, first-order nonlinear partial differential equations for the void fraction and the gas phase velocity result. It was found that these equations could not be directly integrated by standard finite difference techniques because of a phenomenon akin to "shocking" in wave equations. 
However, a solution can be obtained by integration of the derived ordinary differential equations along the single set of characteristics by a Runge-Kutta or other technique. For the special case of constant pressure after an assumed initial depressurization, the void fraction and slope of the characteristic are constant on each characteristic and function of the initial void fraction. Thus, different initial values will cause intersection of the characteristics which is typical of "shocking".

The predictions of this model as to foam level and effluent void fraction will be compared with experiments using a vessel without internal resistances.

The results of this theoretical study indicate that the assumptions of a simple, linear void-fraction profile or the effluent void fraction being a weighted average of that above and below the withdrawal plane are not valid, or particularly good, when used to predict the effluent stagnation enthalpy.

\section{Processing of Blowdown Data - N. P. Wilburn}

Filtering. To reduce the random noise present in data collected from the blowdown facility and to eliminate undesired frequencies in the data (such as the $5 \mathrm{~Hz}$ vessel and support resonance), optional digital filtering of the data was incorporated into the 1108 data-processing code MPXDP. A third order recursive sine filter $(15)$ is used which has the following form:

$$
y_{n}=w_{0} x_{n}+\sum_{i=1}^{2 m} w_{i} y_{n-i}
$$

where

$$
\begin{aligned}
& y_{n} \text { is the filtered result } \\
& x_{n} \text { are the raw data } \\
& w_{i} \text { are weights }\left(\sum_{0}^{2 m} w_{i}=1\right) \\
& m \text { is the order of the filter. }
\end{aligned}
$$


The Nyquist frequency $f_{n}=(2 \Delta t)^{-1}$, where $\Delta t$ is time between samples, is the maximum, possible, frequency component present in the raw data $x_{n}$. Given $f_{n}$, a cutoff frequency $f_{c}$ is selected to filter the data. From $f_{c} / f_{n}$, the $w_{i}$ are computed. (15) The amplitude of all frequencies above $f_{c}$ is greatly reduced in $y_{n}$.

As $f_{c} / f_{n}$ becomes smaller, $w_{0}$ approaches zero; whereas, the other $w_{i}$ are of order 1 to 10 . Eventually, $w_{0} / w_{i}$ becomes of order $10^{-6}$; the rounding or truncation error in the digital computer becomes significant; and the output of the filter, $y_{n}$, diverges. This point occurs for $f_{c} / f_{n} \sim 0.05$ in a third order sine filter.

The problem can be circumvented by a two-step digital filtering process, similar to a two-section passive analog filter. The data are first filtered with $f_{c}=0.1 f_{n}$. Then, since the amplitude of the frequencies above $0.25 f_{n}$ are negligible, only every fourth output point $\left(y_{4 n}\right)$ need be retained. These are then filtered with $f_{c} / f_{n}^{\prime}>0.1$, but since $f_{c}^{\prime}$ is $0.25 f_{n}$, the effective cutoff frequency can be as low as $0.025 \mathrm{f}_{\mathrm{n}}$. Cutoff frequencies as low as $0.025 \mathrm{f}_{\mathrm{n}}$ are currently being used to filter the load-cell data $\left(f_{n}=50 \mathrm{~Hz}\right)$ where the $5 \mathrm{~Hz}$ resonance signal is 10 times that of the signal of interest.

Derivatives. The effluent mass flowrate from the vessel can be determined from the time derivative of the weight-load cell data (LC-1). To eliminate the tedious graphical procedures of derivative taking, a routine to determine derivatives of the data numerically has been included in the processing code MPXDP. The data are normally filtered first to eliminate high-frequency noise components amplified when derivatives are taken. Then the data are grouped into sets 
of $N$ points $(N=4$ to 20$)$ and a second order orthogonal polynominal fit to each set of data. The derivative is then computed at the midpoint of the set from an analytical differential of the polynominal.

Densitometer Data Reduction - R. T. Allemann

During blowdowns of the CSE reactor simulator vesse1, the void fraction of fluid in the discharge duct is measured by use of a neutron densitometer. This system includes a fastneutron generator and four, neutron detector chambers. The system depends on the moderation and scattering of the fast neutrons by hydrogen atoms in the fluid passing through the blowdown pipe. The neutron detector outputs do not give void fraction directly, and calibration of the system is necessary, as well as corrections to account for differences between calibration conditions and run conditions.

The neutron generator detector system is calibrated by filling the discharge pipe with a matrix of aluminum tubes, some of which are then filled with water to give different void fractions. The detector output is then plotted as a function of the fraction of water in the pipe. Since the detector is most sensitive to "slow" or moderated neutrons, its output is in turn a function of the amount of water or the void fraction in the discharge tube. The detector output is also a function of the neutron energy. Because the moderation is accomplished by the water, the energy of the moderated neutrons will be affected by the water temperature. There* fore, a temperature correction should be made to the detector output, particularly, if the fluid temperature changes during the blowdown. Also, a correction must be made for the fact that steam at high pressure and not air is the void fraction during the actual blowdowns. A final correction is made to account for changes in the neutron output of the generator. 
Since calculation of these corrections is quite laborious, a computer routine is being programmed to process the data directly, giving void fraction and quality with time.

$$
\text { Effect of Quality on Mass Velocity - R. T. Allemann }
$$

Some preliminary mass velocity and quality data from CSE blowdowns have been compared in Figure 2.3, with predictions given by several mathematical models at similar pressure. The salient point of these data is that the quality of the fluid is very low for bottom blowdowns with either initially saturated or subcooled liquid. It has been suggested that little slip is possible at low quality and that deviations from the homogeneous model result from nonequilibrium effects.(16) The CSE data agree with the trend predicted by the homogeneous model. The slip model equilibrium theories predict values of mass velocity that are too high. Even though these are plotted with quality values at the critical plane (i.e. the outlet), a correction to the inlet conditions for the Moody model still shows mass velocities higher than those measured. The Fauske model would probably not show better agreement in this low quality region.

Therefore, the preliminary data indicate that for the very low quality flows attained during bottom blowdown, a homogeneous model prediction gives better agreement than Moody $(17)$ or Fauske (18) model predictions. The variation of flow with quality, even at these low values of quality, is an important factor in making vessel blowdown calculations. Because of this importance, a more detailed analytical treat. ment is being made of the vapor-liquid action in the vessel.

Reactor Simulator Vessel Core Sample Analysis -

W. C. Townsend

The CSE reactor simulator vessel was being used for an experiment with a 6.8 in. break diameter and initial coolant 


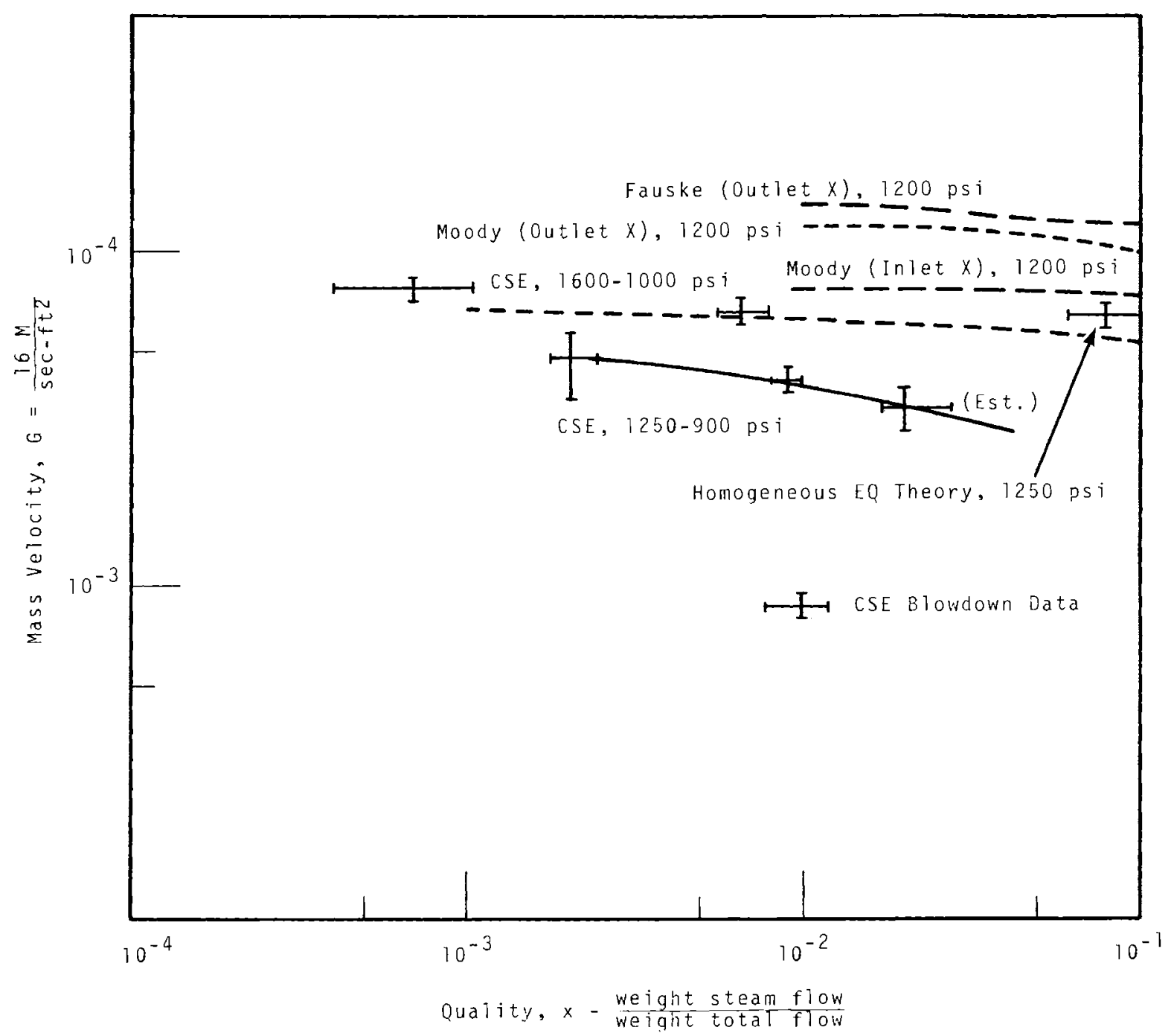

$\stackrel{N}{\infty}$

FIGURE 2.3. Effect of Measured Quality on Mass Velocity 
conditions of 2400 psig and $595^{\circ} \mathrm{F}$ when a structural failure occurred in the thrust support system. This failure subjected the vessel to a relatively severe loading condition. Although no significant damage to the vessel was evident, extensive nondestructive tests including radiography, penetrant, magnetic particle and ultrasonic tests were carried out on all portions of the vessel which had been subjected to large stresses either during the completed blowdown experiments or the thrust support failure accident. Tested portions of the vessel were:

- The supporting trunnions and leg brackets on the vesse1

- A previously noted but acceptable UT test defect indication in the top head

- The regions around the 8 in. blowdown nozzles loaded during blowdown experiments or the support failure accident .

U1trasonic tests showed some enlargement of the known tophead defect indication and a new defect indication below the bottom blowdown nozzle used for previous experiments. Detailed ultrasonic tests were made with smaller crystals to map the defect-indication area. These indicated that the defect was bounded by irregular areas (Figure 2.4) which indicated loss of back reflection. In some, areas an indication of depth to a defect was obtained (cross-hatched areas of Figure 2.4). The depth indications were noted to be approximately constant, which suggested that the defect indication resulted from a laminar type defect.

Three, core samples denoted A, V, and Y were removed from representative areas in the vesse1 wa11. The A sample was removed from apparently sound material, while the $V$ sample was removed from an area indicating defect depth. The Y sample was removed from an area having $100 \%$ loss of back reflection and no depth indication. The locations of the core samples are shown in Figure 2.4. 


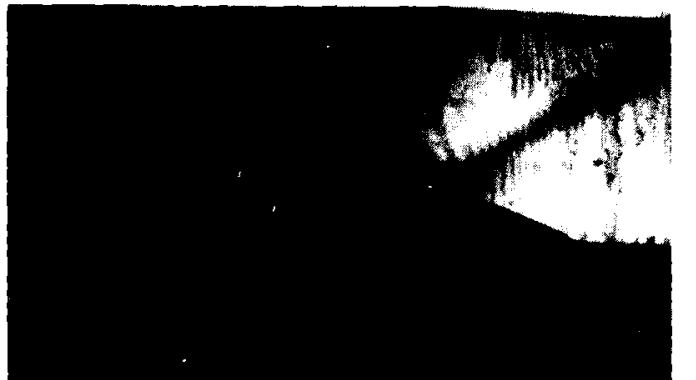

AREA OUTLINED WHERE LOSS OF BACK REFECTION OCCURS.

POINTS MARKED $\stackrel{4.2}{\diamond}$ SHOW THICKNESS OF VESSEL WALL

POINTS MARKED SHOW DEPTH TO DEFECT PLANE FROM OUTS IDE

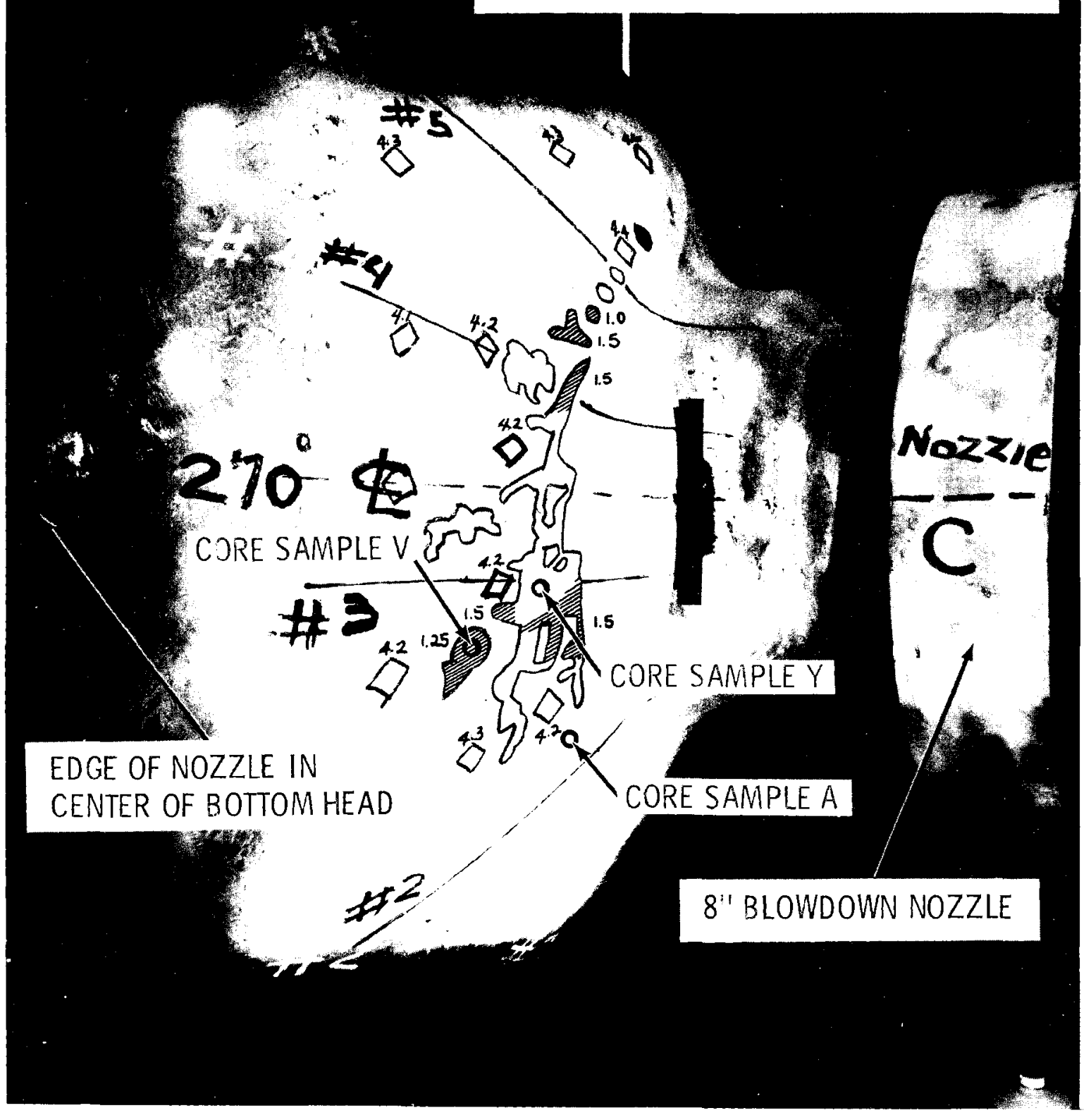

Neg 0680708

FIGURE 2.4. Defect Regions in Reactor Simulator Vessel 
A testing program is being carried out on the three, core samples to determine the material characteristics in the defect region and the nature of the defect indication.

The core-sample testing program is approximate 1 y $90 \%$ complete and includes the following tests:

$\begin{array}{ll}\text { Metallurgical examination } & \text { completed } \\ \text { Ultrasonic holography } & \text { completed } \\ \text { Ultrasonic } & \text { completed } \\ \text { Radiography } & \text { completed } \\ \text { Tensile } & \text { completed } \\ \text { Microprobe analysis } & \text { in progress } \\ \text { Fracture surface analysis } & \text { in progress }\end{array}$

Analyses of the results from those tests completed are being compiled for a composite interpretation and report. Preliminary results from one or more of the tests indicate:

- That the A sample does not have noticeable defects

- Agreement as to the location of the defect in the $V$ and $Y$ samples (This agreement includes radiographs, ultrasonics, photomicrographs, and visual measurements.)

- That the remaining material of each sample is still ductile

- That the fracture surface contains an apparently oxidized surface.

U1trasonic holography techniques were applied; however, the results are inclusive. Acoustic emission data were taken ouring the tensile tests, and have not yet been reduced.

Banding of metallic layers was evident from the photomicrographs taken during metallographic examination. The band spacing on the A sample was approximately $1 / 8$ in.; 0.004 in. on the $\mathrm{Y}$ sample. The $\mathrm{V}$ sample had approximately $50 \% \mathrm{with}$ the $4 \mathrm{mil}$ spacing, and the remaining section with the $1 / 8$ in. spacing. Banding is not uncommon and is not considered harmful. 
Photomicrographs of the $A$ and $V$ samples have been studied and compared with other photomicrographs of welded joints. The comparison suggested that the $\mathrm{A}$ and $\mathrm{V}$ core samples were removed from a previously welded area. Subsequent interpretation of fabrication reports indicates that $A$ and $V$ samples were possibly removed from a previous weld repaired region. From these reports, two large defect indication areas in the lower hemispherical head were weld-repaired. Although repair areas relative to the nozzles are not known, it is apparent that one of these is too near the welded joint (between the hemispheri. cal head and the cylindrical shell) to be applicable. The other weld-repaired region is at the proper circumferential position so that the $A$ and $V$ core samples could have been removed from this region.

Results of the tensile tests are given in Table 2.3. TABLE 2.3. Tensile Tests of CSE Reactor Simulator Vessel Core Samples

\begin{tabular}{|c|c|c|c|}
\hline & A & $\mathrm{V}$ & Y \\
\hline Gauge length, in. & 0.42 & 0.65 & 0.74 \\
\hline Yield load, lb & 1550 & 1560 & 700 \\
\hline Yield stress (avg), psi & 49,400 & 49,600 & 22,300 \\
\hline U1t. 1oad, 1b & 2,000 & 1940 & 960 \\
\hline U1t, stress (avg), psi & 63,750 & 61,800 & 30,600 \\
\hline Extension at ult., in. & 0.047 & 0.040 & 0.023 \\
\hline Strain at ult, (avg), $\%$ & 11.2 & 6.1 & 3.15 \\
\hline Extension at failure, in. & 0.175 & 0.105 & 0.0063 \\
\hline Strain at failure (avg), \% & 42 & 16 & 8,5 \\
\hline
\end{tabular}

The reduced diameter of these specimens was uniform and 0.200 in. The axis of the tensile specimens was perpendicular to the sur face of the simulator vessel surface; therefore, the plane at the defects is perpendicular to the axis of the specimens. 
Stress and strain calculations were based on the nominal test area and not the actual stressed area. The actual stressed area will be smaller because of the defects. Then, the stress and strain in the $V$ and $Y$ samples will be larger than reported in Table 2.3.

During the tensile tests, a small flaw was evident in the $V$ sample shortly after the yield stress had been reached. Undoubtedly, this was a prior defect. This flaw did not propagate but continued to open, and the material at the crack roots behaved in a ductile manner.

A large flaw about $1 / 8$ in. long was evident on sample $Y$ before testing. Another flaw appeared above the first at the yield stress. Considering the net area, the yield and ultimate loads are not unreasonable. Only the metal in the plane of the flaws reached the yield stress so that all deformation occurred there.

FISSIOIV PRODUCT AEROSOL CONTROL - L. C. Schwendiman and H. H. Van Tuy 1

Removal of Organic Iodides with Reactive Sprays L. C. Schwendiman and A. K. Postma

Following a serious reactor accident, volatile and gaseous fission products will be released to the containment volume. A possible method for reducing the airborne concentration of molecular radioiodine and methyl iodide is to immobilize these constituents by adding a reactive compound such as hydrazine to the spray.

During the current reporting period, a series of oncethrough spray runs was completed in which airborne methyl iodide was sprayed with dilute hydrazine. The results were compared with predictions based on an absorption model. The 
rate of washout of methyl iodide in a large containment vessel was predicted from the model and earlier experimental measurements.

The goal of the once-through experiments was to provide direct experimental measurements of the washout parameters $A$ and $B$ (amount of solute gas absorbed per unit volume of liquid per unit gas phase concentration, for wall film and drops, respectively). In each experiment, the wall film liquid was collected separately from the drops falling into the bottom of the chamber. Two, drop catchers (modified Erlenmyer flasks) were placed near the bottom of the chamber to collect falling drops with lmmediate isolation from the chamber atmosphere. These drop catchers were designed to preclude methyl iodide absorption by drop liquid subsequent to impact against any collecting surface. Humidified methyl iodide-free air was continually purged through the flask to prevent airborne methyl iodide from reaching the liquid surface. Ten cubic centimeters of $10 \%$ sodium thiosulfate solution was added to the flask to react rapidly with unreacted methyl iodide carried within drops into the catcher. Drops impacting against an inlet chimney were not collected, but instead drained away at the outside of the flask. Only those drops falling nearly vertically entered the flask. Gas phase concentrations of methyl iodide were measured using beds of activated charcoal operating in series. The results of these runs are shown in Table 2.4 .

The drop absorption coefficient, B, (Table 2.4), is the average of the values obtained for the two catchers used in each experiment. Drop sizes were measured from drops collected near the bottom of the $10 \mathrm{ft}$ tall chamber. Thus, the mass median diameter measured would probably represent drops larger than the average in the chamber because coalescence would cause an increase in size with increasing distance from the nozzles. 
TABLE 2.4. Results of Wall Film and Drop Absorption Experiments in once-Through Spray Runs

\begin{tabular}{|c|c|c|c|c|c|c|c|}
\hline $\begin{array}{l}\text { Run } \\
\text { No. }\end{array}$ & $\begin{array}{c}\text { Average } \\
\text { Temp, } \\
{ }^{\circ} \mathrm{C} \\
\end{array}$ & $\begin{array}{l}\text { Solution } \\
\text { Composition }\end{array}$ & $\begin{array}{c}\text { Wall } \\
\text { Flow Rate, } \\
\mathrm{cm}^{3} / \mathrm{sec} \mathrm{cm}\end{array}$ & $\begin{array}{c}\text { Drop Flow } \\
\text { Rate, } \\
\mathrm{cm}^{3} / \mathrm{sec} \\
\end{array}$ & $\begin{array}{l}\frac{\mathrm{A}}{\text { Wall Film }} \\
\text { Absorption } \\
\text { Coefficient }\end{array}$ & $\frac{B}{\text { Drop }} \begin{array}{c}\text { Absorption } \\
\text { Coefficient }\end{array}$ & $\begin{array}{c}\text { Mass Median } \\
\text { Drop } \\
\text { Diameter, } \mu\end{array}$ \\
\hline 13 & 89 & 2.15 wt: $\mathrm{N}_{2} \mathrm{H}_{4}$ & 0.138 & 47.8 & 6.27 & 1.06 & 320 \\
\hline 14 & 88 & $1.0 \mathrm{wt} \div \mathrm{Na}_{2} \mathrm{~S}_{2} \mathrm{O}_{3}$ & 0.125 & 42.4 & 4.78 & 1.45 & 320 \\
\hline 15 & 86 & $4.38 w t \% \mathrm{~N}_{2} \mathrm{H}_{4}$ & 0.143 & 52.4 & 8.55 & 1.95 & 320 \\
\hline 17 & 87 & 1 wt $\mathrm{Na}_{2} \mathrm{~S}_{2} \mathrm{O}_{3}$ & 0.151 & 55.2 & 4.4 & 1.23 & 320 \\
\hline
\end{tabular}

The temperature within the chamber decreased several degrees centigrade over the $7 \mathrm{~min}$ spray period. The spray solution was heated to the tank temperature before each test to reduce temperature variations.

The results obtained in these once-through runs in which drop catchers were employed are compared in Table 2.5 to the predictions based on stagnant film and drop theory. From Table 2.5 , it should be noted that the measured washout rates are 1.5 to 3 times faster than predicted. This ratio of measured to theoretical washout rate is somewhat lower than found in earlier recycle experiments. This difference may be due to absorption into the shallow pool which existed in the bottom of the chamber. In the recycle experiments, bottom pool absorption could not be separately accounted for; whereas, in the once-through runs, wall film and drop absorption were measured directly.

Reactor containment vesse1s are much larger than those used in the experiments carried out in this study. Hence, application of the small scale tests to large scale systems of practical interest must be based on knowledge of the scale factors that apply. We have attempted to show the effect of 


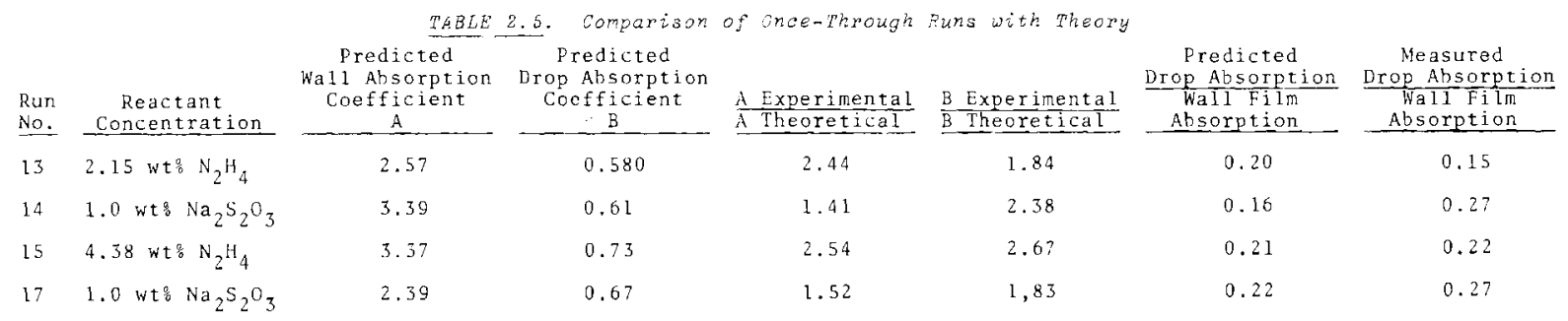

spray chamber size on methyl iodide washout rate by calculating the washout rate expected for cylindrical chamber from laminar flow theory.

In Figure 2.5 , the washout rate of methyl iodide in cylindrical spray chambers, with height to diameter ratios of 2.5 , is shown as a function of chamber size. The spray density was assumed to be $0.0068 \mathrm{~cm}^{3} / \mathrm{cm}^{2} \mathrm{sec}$, drop diameter was taken as $550 \mu$, and the wall flow rate was chosen as $0.1 \mathrm{~cm}^{3} / \mathrm{cm} \mathrm{sec}$. The first order rate constant was chosen as $6.55 \mathrm{sec}^{-1}$, the value predicted for 5 wt $\%$ hydrazine solution at $120{ }^{\circ} \mathrm{C}$.

The increase in washout half-time with increasing chamber size is a reflection of the importance of wall absorption, which is predicted to account for over $50 \%$ of the total, even for a cylinder $100 \mathrm{ft}$ in height. The curve shown is not high $1 \mathrm{y}$ sensitive to changes in the assumed conditions. For larger drops, the wall would be relatively more important, and the curve shown in Figure 2.5 would be steeper. For smaller drops or higher reaction rates, the curve would tend to level out, with the vessel size being of less importance.

Based on this calculation, we would expect a washout halftime of about $60 \mathrm{~min}$ for a vesse1 $80 \mathrm{ft}$ in height for 5 wt\% hydrazine, for the nominal spray conditions specified in Figure 2.5.

Physical Chemistry of Methyl Iodide Systems - R. A. Hasty and S. L. Sutter

The objective of this research is the determination of the physiochemical factors affecting the rate of spray removal of 


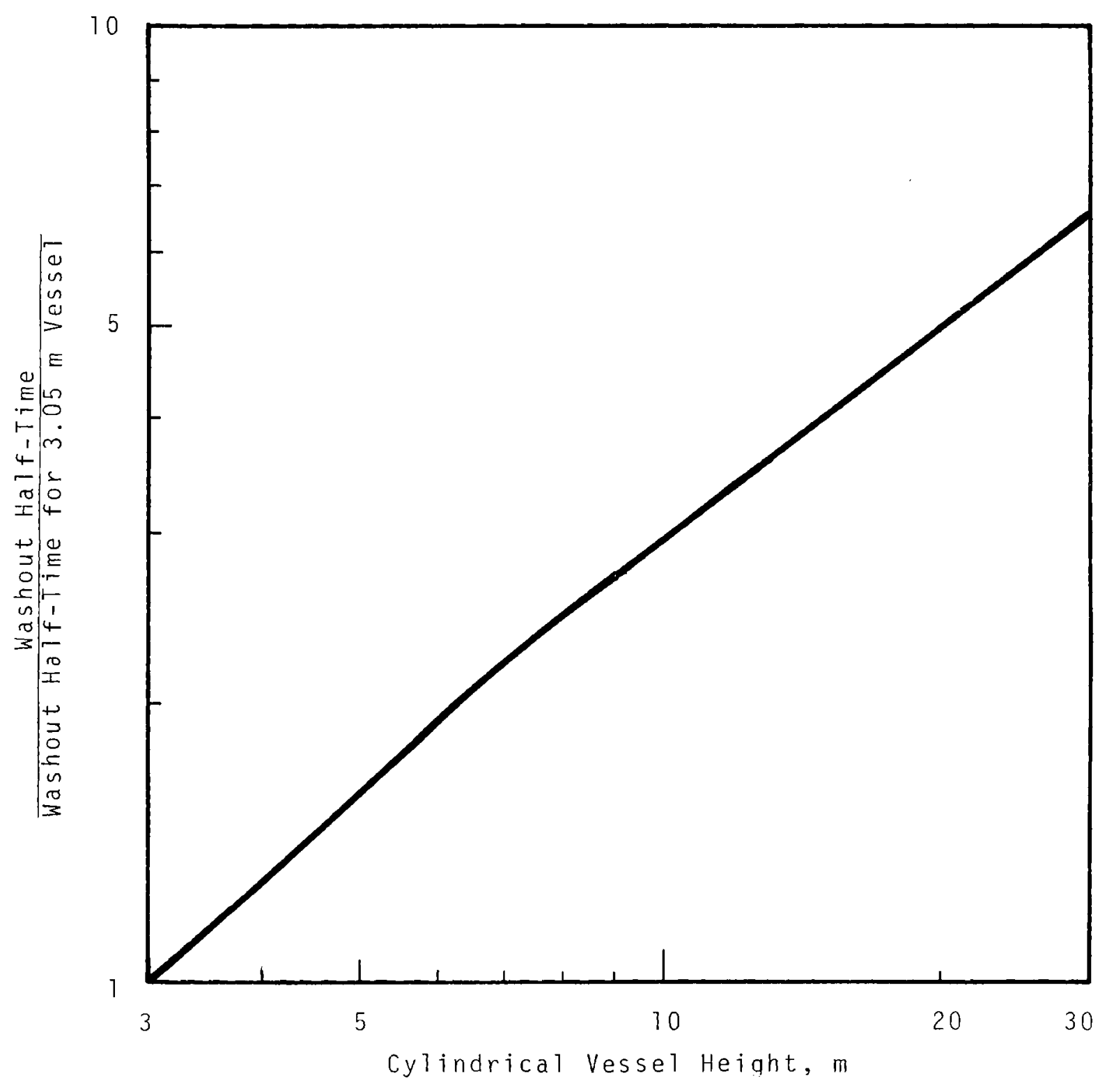

FIGURE 2.5. Predicted Effect of Vessel Size on Washout Rate for Methyl Iodide 
methyl iodide from reactor containment atmospheres. Earlier studies have demonstrated a complex relationship of the rate of removal of methyl iodide from the gas phase. Such a relationship is dependent upon the properties of the reactive solution used as the spray. (19) The rate of reaction of methyl iodide in the spray solution can be determined in the laboratory by the use of the "sparge removal technique", described in our last contribution (20) along with its utilization to determine the kinetic expression for the reaction of methyl iodide in hydrazine solutions. Since the technique can be applied to a number of chemical systems, we have determined the reaction rate constants for several reagents that can be used to react with methyl iodide. The reactants that have been studied or are currently being studied are 1,1-dimethylhydrazine, monomethylhydrazine, sodium sulfite, sodium bisulfite, and sodium thiosulfite. Kinetics of the reaction of methyl iodide with the latter reactant have been reported in the literature, but the study was over such a narrow temperature range (10 to $25^{\circ} \mathrm{C}$ ) that a re-examination of the earlier work and extension of the measurements to higher temperatures were considered worthwhile.

The results of the kinetic investigation of the five reactants examined are given in Table 2.6. The reaction of methyl iodide with sodium sulfite was interesting in that the reaction rate was affected by the ionic strength as well as by $\mathrm{pH}$.

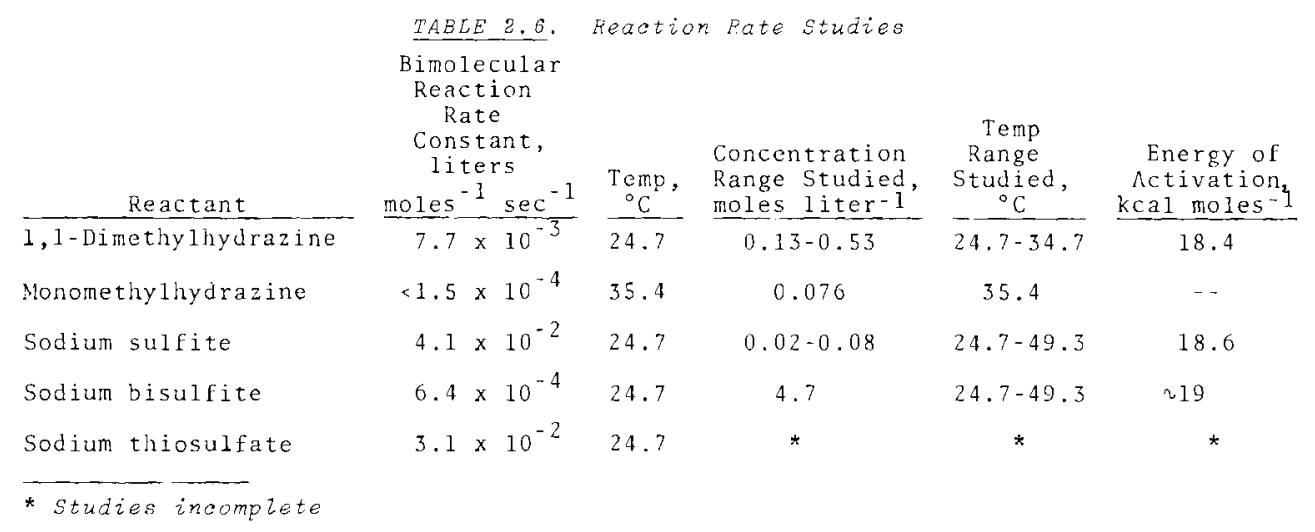


Earlier radiation stability research and studies made recently at ORNL have shown that hydrazine decomposes and releases hydrogen in copious quantities under the high radiation anticipated in a reactor accident. A second disadvantage recently disclosed was the impact that the use of any ammonia derivatives would have on the design of spray cooling heat exchangers. Current specifications call for copper alloy components that would be quickly corroded by ammonia derivatives. These observations have been reviewed and a conclusion reached that hydrazine as a spray additive for methyl iodide will not be acceptable to commercial reactor designers, even though it has many favorable features.

Research to demonstrate the value of hydrazine, per se, as an additive to sprays for removing methyl iodide is terminated. However, reaction rate data made available by these studies and the experience acquired in using hydrazine as a spray additive will be of considerable value in experimental verification of droplet removal models when liquid reaction rates limit the absorption process.

\section{REFEREIICES}

I. The Staff of Battelze-Northwest. Nuclear Safety Quarterly Report for January through March 1967, BNWL-433. Pacific Northwest Laboratory, Richland, Washington, July 1967.

2. The staff of Battelze-Northwest. Nuclear Safety Quarterly Report for Apriz through June 1967, BNWL-537. Pacific Northwest Laboratory, Richland, Washington, December 1967.

3. The Staff of Battelze-Northwest. Nuclear Safety Quarterly $\frac{\text { Report for July, August, September, and October, } 1967}{\text { BNWL-754, p. 2.1. Pacific Northwest Laboratory, Richland, }}$ Washington, June, 1968.

4. The Staff of Battelze-Northwest. Nuclear Safety Quarterly

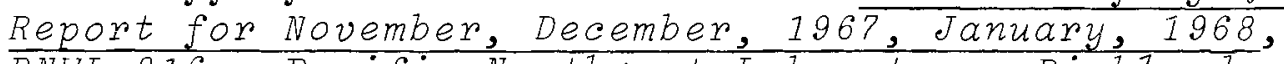
BNWL-816. Pacific Northwest Laboratory, Richland, Washington, September 1968. 
5. M. Jacob. Heat Transfer, John Wizey \& Sons, Ine., New York, 1949. vol. I, p. 592 .

6. R. K. Hizliard et al. Comparisons of the Containment Behavior of a Simulant with Fission Products Released from Irradiated UO2, BNWL-581. Pacific Northwest Laboratory, Richland, Washington, March 1968.

7. R, L. Ritzman, et ar. "Analytical Description of Fission Product Transport and Deposition in Containment Vessels," Trans. Am. Nuel. Soc., vol. 10, no. 2. November 1967.

8. G. M. Watson et ar. Effects of Containment Size on Fission Product Behavior, ORNL-4033. Oak Ridge National Laboratory, January 1967 .

9. W. H. MeAdams. Heat Transmission, MeGraw-Hizz Book Co., Inc., New York, N.Y., 1954. 3rd ed., p 173.

10. S. G. Margolis and J. A. Redfield. Flash: A Program for Digital Simulation of the Loss-of-Coolant Accidents, WAPD-TM-532. Westinghouse Electric Corporation, Pittsburgh, Pennsyzvania, May 1966.

11. J. A. Redfield, J. H. Murphy, and V. C. Davis. Flash 2: $\frac{\text { A Fortran IV Program for the Digital Simulation of a }}{\text { Multinode Reactor Plant During Loss-of-Coolant, WAPD-TM-666. }}$. Westinghouse Electric Corporation, Pittsburgh, Pennsyzvania, Apriz 1967 .

12. Quarterly Technical Report STEP Project, January-March 1967, edited by K. A. Dietz, IDO-17239. Idaho Operation Office, Idaho Falis, August 1967.

13. F.J.Moody. Liquid/Vapor Action in a Vessel During Blowdown, APED-5177. General Electric Company, San Jose, California, June $27,1966$.

14. J. F. Wilson, R. J. Grenda, and J. F. Patterson. "The Velocity of Rising Steam in a Bubble Two-Phase Mixture," Trans. Am. Nucl. Soc., vol. 5, no. 1, pp. 151. 1966.

15. H. Holtz and C. T. Leondes. "The Synthesis of Recursive Digital Filters," Jahrbuck der Chemil/Meyer, vol. 13, no. 2, pp. 262-280. August 1966.

16. R. E. Henry. A Study of One-and-Two-Component Two-Phase Critical Flow at Low Qualities, University of Notre Dame, 196?. (Ph.D. thesis) 
17. F. J. Moody. "Maximum Flow Rate of a Single Component, Two-Phase Mixture," J. Heat Transfer, vol. 87-C, p. 134. 1965 .

18. H. K. Eauske. Contribution to the Theory of Two-Phase, one-Component Critical Flow, ANL-6633. Argonne National Laboratory, Lemont, Iliinois, 1962.

19. R. A. Hasty. "Reaction of Hydrazine and Iodomethane. Removal of Iodomethane from a Gas Phase in Contact with Alkaline Hydrazine Solution," J. Chem. Eng Data, vol 13, pp. 134-138. 1968 .

20. R. A. Hasty, "Physical Chemistry of Methyl Iodide Systems," Nuclear Safety Quarterly Report, February-Apriz, 1968, for Nuclear Safety Branch of USAEC Division of Reactor Development \& Technology, BNWL-885. Pacific Northwest Laboratory, Richland, Washington, p. 2.49. october 1968 . 


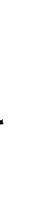




\section{PRESSURE BEARING COMPONENT EVALUATION AND MONITORING STUDIES}

CRACK DETECTION IN PRESSURE PIPING BY ACOUSTIC EMISSION P.H. Hutton, R. N. Ord, C. E. Fitch, H. No Pedersen, and J. C. Spanner

Introduction

Development of new and more discerning techniques for nondestructively testing reactor pressure boundaries to assess their integrity is of general interest to the nuclear industry for further enhancement of nuclear safety. One such technique showing considerable promise is based on detection of "acoustic emission" or elastic waves generated in metal by the energy released as it plastically deforms and fractures. This technique has potential application for integrity surveillance during both hydrostatic testing of a reactor system and online operation. It is, however, limited to detection of a dynamic condition--i。e., it will not detect a static flaw or discontinuity.

The USAEC, Division of Reactor Development and Technology has sponsored development work at Battelle's Pacific Northwest Laboratory, starting in February 1966, directed toward deve1opment of the technology and equipment needed to apply this new surveillance technique routinely to reactor systems. In the interest of increased overall effectiveness of development work, a coordinated effort has been established between this program and acoustic emission plant application work being done by Phillips Petroleum Company at the Idaho Test Site.

Test work has been concentrated on low-alloy carbon steel and Type 304L SS. 
Discussion

Task 1 - Acoustic Emission Signal Analysis and

Characterization

It has long been realized that maximum, reliable utilization of acoustic emission signals will require a knowledge of acoustive wave generation, and propagation in the finite media of the various reactor pressure system materials. It has been suspected, but not fully confirmed, that signals of a much higher frequency than those commonly detected in acoustic emission tests form the basic signal generated during the deformation and fracture of metals. Analysis of these high frequency signals can provide more knowledge of metallurgical behavior effects on acoustic emission, and thus enhance flaw detection, location, and description capabilities. A recent reactor background noise study (discussed later in this report) has provided added impetus to investigating the higher frequency acoustic emission.

Experiments were conducted to study ultrasonic wave behavior in a finite plate geometry using wide-band, shortduration ultrasonic pulses. Short-duration, high-frequency, acoustic emission signals should experience behavior compar. able to the ultrasonic pulses in a plate, and this technique provides an easy, inexpensive means of generating preliminary guide data. By observing and analyzing the ultrasonic signals, the expected behavior of acoustic emission signals will be more clearly understood.

A 3 ft $x 4 \mathrm{ft} \times 1 / 2$ in. thick plate of A-212B steel was used for these initial studies. It was anticipated that sig * nals produced by grain failure in tension, and in shear could be approximated by introducing the ultrasonic signals normal to the plate edge with longitudinal and shear transducers. To more easily separate and study the response waves that 
travel in the plate, a receiver was mounted with a fixture to provide critical-angle adjustments for various propagation modes. Water couplant contained in a latex membrane was used to immerse the receiver, and alcohol was used between the latex membrane and the plate to avoid undesirable oxidation.

The critical angles favoring selective detection of longitudinal, shear, and Rayleigh wave transmission modes were chosen for initial studies. With a longitudinal transmitter mounted on the edge of the plate and the receiver set at the longitudinal critical angle, the first signal to the receiver will be a pure longitudinal wave. This signal should be free of other interference provided that energy from preceding transmitted pulses has completely decayed. The observed signal is the first longitudinal, and the subsequent signals are due to mode conversion from longitudinal to shear at an angle $\theta_{s}$ in the plate, where

$$
\theta_{s}=\sin ^{-1} \frac{V_{s}}{V_{1}} \text {, }
$$

provided the longitudinal wave mode converts at an angle of 90 degrees.

The time separation $(t)$ of each subsequent pulse is calculated from the relationship

$$
t=\frac{T}{V_{s}}\left(1-v_{s}^{2} / V_{1}^{2}\right)^{1 / 2}
$$

where $\mathrm{T}$ is the plate thickness. For the test situation, $\mathrm{T}$ was $1 / 2$ in., $V_{s}=1.28 \times 10^{5} \mathrm{in.} / \mathrm{sec}$, and $V_{1}=2.34 \times 10^{5}$ in./sec. With these values, $t$ calculates to be $3.27 \mu \mathrm{sec}$, which agrees with Figure 3.1 (Time scale $=4 \mu \mathrm{sec} / \mathrm{cm}$ ).

The signal observed at the shear critical angle for the above transmitter arrangement is shown in Figure 3.2. Since the transmitter is a longitudinal polarized transducer, 


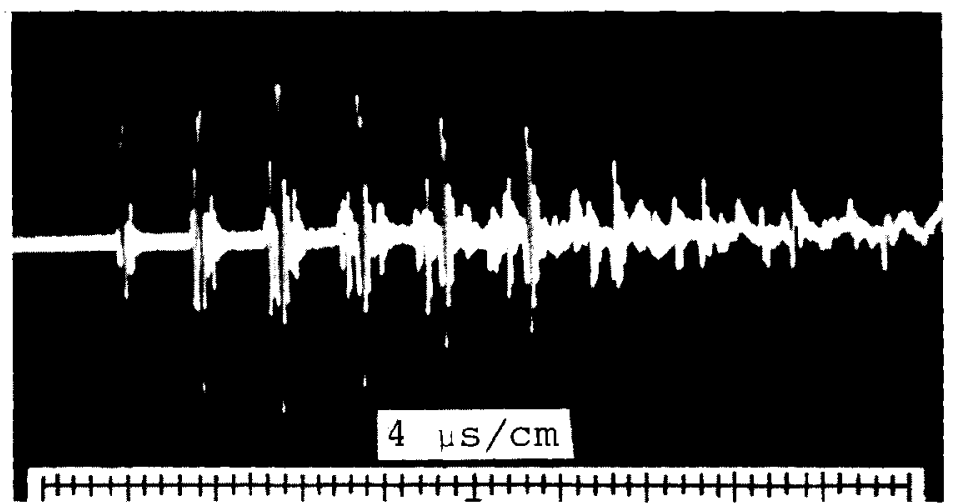

EIGURE 3.1. Longitudinal Critical Angle Signals for $1 / 2$ in. Plate Using Longitudinal Transmitter

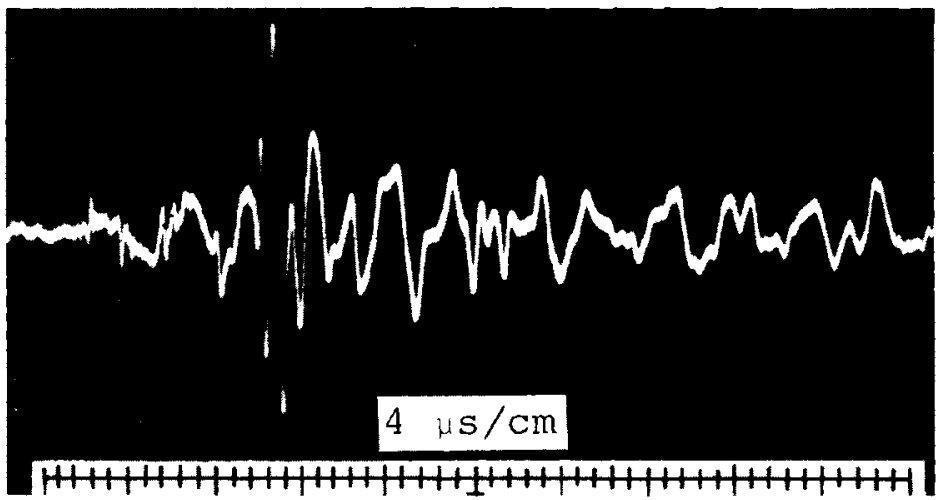

FIGURE 3.2. Shear Critical Angle Signals for 1.2 in. Plate Using Longitudinal Transmitter 
response at the shear critical angle should not be expected. However, with the transmitter being a lead zirconate titanate (PZT) ceramic element, polarization in one mode of vibration is not entirely possible. Consequently, some shear energy is generated. These signals are evident at the very beginning of the trace (Figure 3.2) and are the very small, high frequency pulses preceding the main energy pulse. The reason for more than one shear mode signal is not clear but may be due to material anisotropies. (The pulse arriving with the fastest time was used for shear wave velocity determinations.)

As the receiver angle was further increased to the Rayleigh angle, the major peak shown in Figure 3.2 increased in amplitude and was essentially the only high frequency pulse remaining. From this, it is implied that the major peak in Figure 3.2 was caused by Rayleigh waves. Also, it is of interest that the main signal observed when the receiver angle was reduced to zero (or normal incidence) was from the Rayleigh wave. This normal incident receiver orientation is the cus tomary way in which acoustic emission signals are detected and generally the indicated propagation velocities are near theoretical Rayleigh velocities. However, in some cases a significant variation has been observed. The question arises as to how signals are even detectable with normal incidence receiver orientation since the main polarization direction is perpendicular to the direction of wave propagation. This is possible because the ceramic transducers have relatively strong low-frequency radial and circumferential modes that respond to waves propagating parallel to the plate surface. Though these radial modes do have advantages for some acoustic emission detection applications, they also tend to complicate analysis of wave disturbances using wide band electronic systems because of sensitivity to more than the thickness mode polarizations (Figure 3.2). This raises a further question which will 
hopefully be answered by this work--i,e., might not signals which are marginal when defected with a normal incident receiver be greatly enhanced by critical angle detection?

The next experiment used a shear polarized PZT transmitter also mounted at the plate edge. This arrangement was expected to produce signals similar to those from shear failures. When the receiver transducer was again set at the longitudinal wave critical angle, small amplitude signals very much like those in Figure 3.1 were observed which indicated that some longitudinal waves were generated by the shear poled PZT element.

At the shear critical angle, the signal shown in Figure 3.3 was observed. The signal arriving first in time was the direct transmitted shear. As before, the Rayleigh surface wave signal was also substantially present in addition to contributions from the other unexplained signals discussed for Figure 3.2. As the receiver angle was further increased to the Rayleigh critical angle, the shear mode tended to disappear as the Rayleigh mode dominated. Also, as can be seen in Figure 3.3, low frequency radial and circumferential modes were present, making wide band signal interpretations difficult.

From the previous study, it appeared that information pertaining to whether actual acoustic emission signal originates from tensile or shear failure of crystals, could be determined. If a crack mechanism occurs in tension, it should stimulate strong longitudinal waves and possibly low-amplitude shear. Conversely, if cracking occurs in shear, then this mode should dominate. As can be seen in the preceding figures, the higher frequencies contain most of the pure longitudinal, shear, and Rayleigh mode information. Also it is believed that the higher frequencies may eventually tell more about other subtle failure mechanisms. 


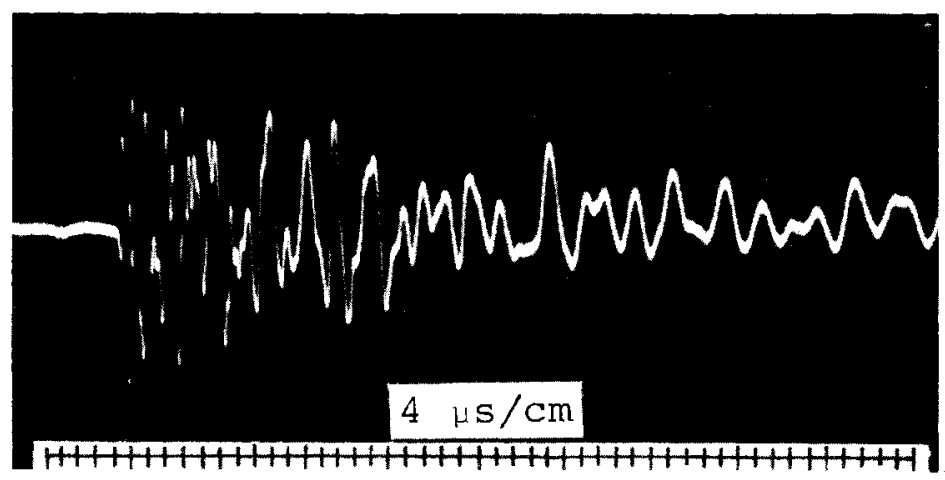

\section{FIGURE 3.3. Shear Critical Angle Signals for 1/2 Plate Using Shear Transmitter}

Initial work attempting to detect higher frequency acoustic emission signals using a wide band electronic system was unsuccessful because the high frequency noise tended to mask the desired information. To overcome this, a narrow band electronic system was introduced. Optimum frequency "windows" for acoustic emission signal detection have not yet been defined; however, transmission of frequencies in the 0.5 to $3.0 \mathrm{MHz}$ range over long path lengths is of obvious practical importance when recently acquired reactor noise data are considered. To select optimum, narrow frequency bands for emission detection, a parametric study must be undertaken.

Available amplifiers, tuned in the $5 \mathrm{MHz}$ frequency range, were used for some initial studies; more versatile, tuned amplifiers are on order. To keep the experiments within the capabilities of laboratory tensile equipment, small $1 / 8$ in. thick strips of metal were used. Preliminary work was done with single-edge notch specimens of Type 304L SS and Type A-212B carbon steel.

Smal1 0.125 in. diam $5 \mathrm{MHz}$ PZT-5 transducers were mounted with special fixtures to facilitate changing the receiver angle. 
One transducer with a narrow-band amplifier was positioned near the notch and was used to trigger the oscilloscope. Another, positioned farther down the strip, had its signal amplified and fed to the oscilloscope vertical display. Signals received on the oscilloscope for longitudinal, shear, and Rayleigh critical angles were recorded photographically. Because the transducers were small, their simultaneous response to shear and Rayleigh modes appeared to be equally favorable at either critical angle; therefore, data were taken at only two angles--the longitudinal critical angle and an angle between the shear and Rayleigh.

Typical acoustic emission signals for $304 \mathrm{~L}$ SS at the longitudinal angle are shown in Figure 3.4, and typical shear-Rayleigh signals are shown in Figure 3.5. As expected, many successive signals arrived at the longitudinal angle; however, contrary to expected results by the earlier plate work, more than one successive signal also appeared in many of the shear-Rayleigh emission pulses. Earlier work did show more than one shear signal, but the spacing between these would be smaller in the strip material because of smaller path lengths and sample thick. ness. (This spacing would be condensed in the first portions of signals shown in Figure 3.5.) One explanation for these multiple signals is that more than one emission may occur in a very short time period for one metallurgical event. Present state-of-the-art does not adequately describe fracture mech. anisms as related to specific acoustic emission, and complete interpretation of observed signals is not yet possible. Some work was done with oil-tempered tool steel, and signal differ. ences (as compared to the more ductile materials) were observed.

The above results are obviously very preliminary. Continued investigation is planned to define the optimum trans. ducer angle, to relate high-frequency signal changes to material characteristics, and to determine the optimum tradeoff point between material attenuation of high frequencies versus proximity to reactor noise of lower frequencies. 

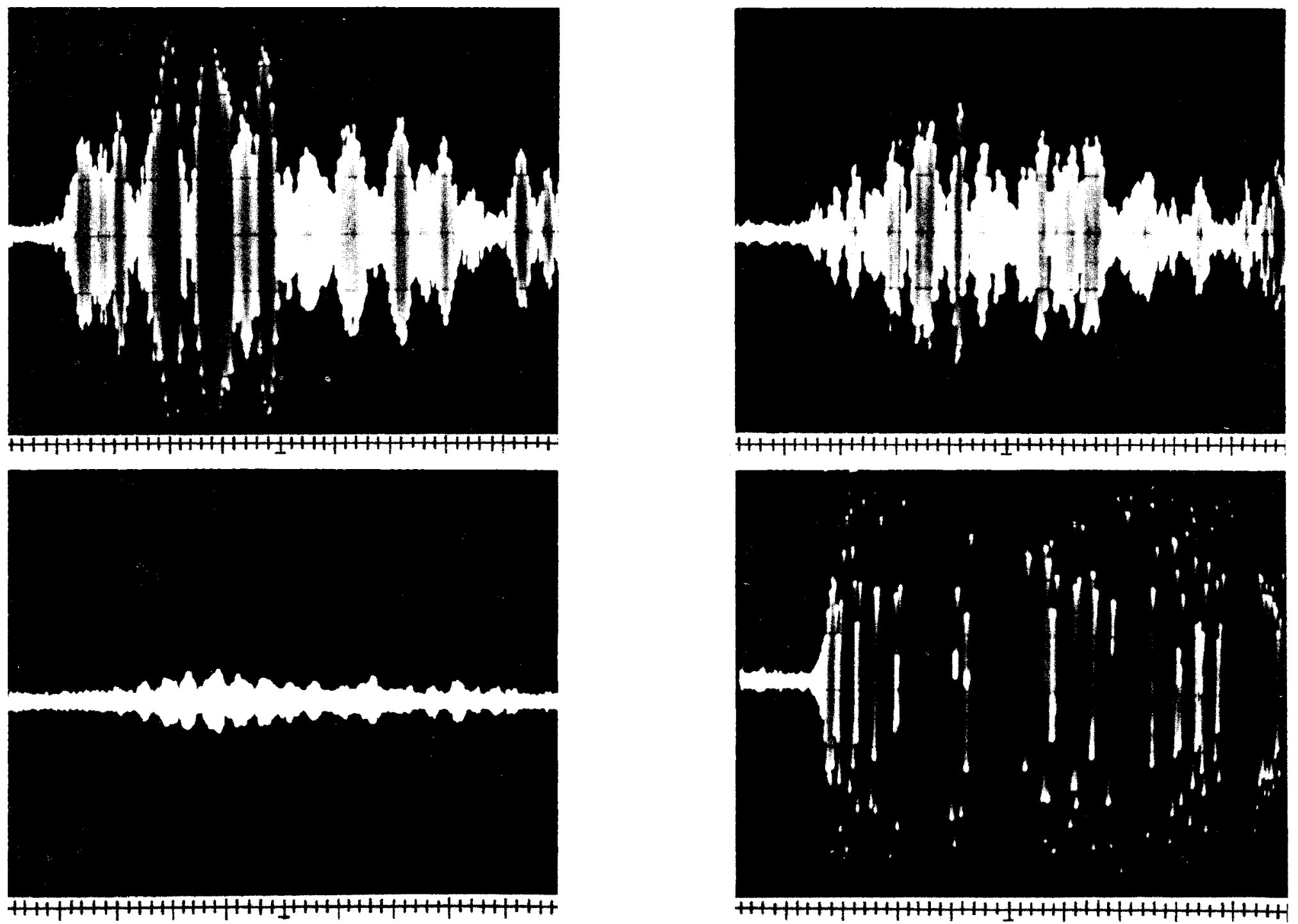

0
0
0
0
0
1
0
0
0

EIGURE 3.4. Typical Longitudinal Critical Angle Acoustic Emission Signals for 

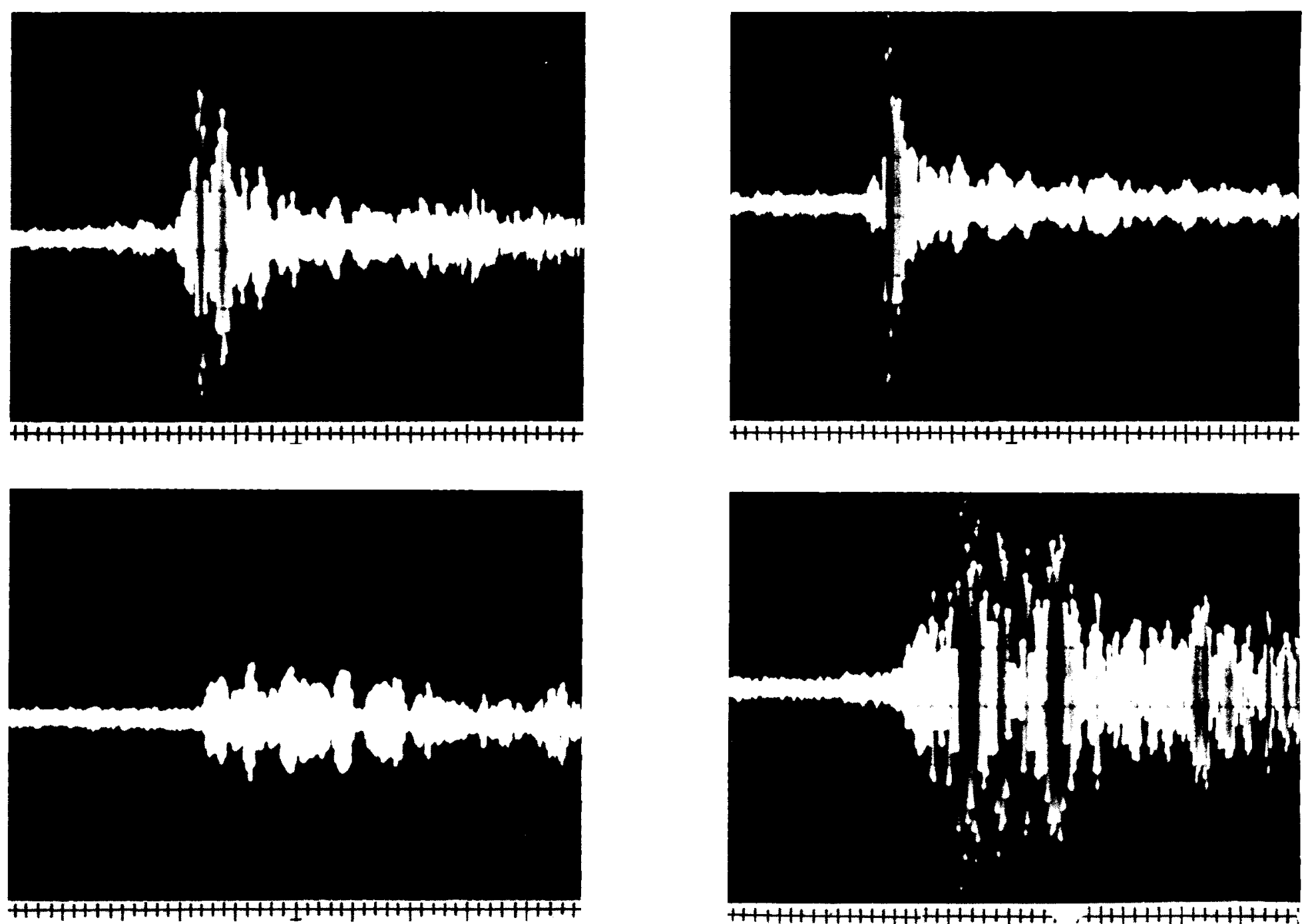

FIGURE 3.5. Typical Rayleigh-Shear Critical Angle Acoustic Emission Signals for $304 L$ SS Strip 
Task 2 - High Temperature Transducer Development

Preliminary laboratory test work has shown that detection of acoustic emission using critical angle transducer orientation and operating in a higher frequency range (1ow $\mathrm{MHz}$ ) has the potential for significant improvement in the quality of information obtained. It appears that this will improve the signal to noise ratio, minimize transmission-velocity variations, and sharpen the wave front definition.

Figure 3.6 shows a sample of the results obtained in this preliminary work. The three transducer arrangements were installed on a steel single-edge-notch test specimen, together with a fourth transducer used to trigger the oscilloscopes. Orientation of the trigger transducer and the other transducers was such that source of the observed signal could be positively identified by position on the scope screen. This provided an easy and reliable means of identifying the signal as originating from the flaw rather than from the tensile machine or grips. All three traces were generated by the same acoustic emission event. The top trace is the response of a "standard" $1 \mathrm{MHz}$ transducer, arrangement such as has been used to date for test work. The bottom two traces were produced from a 2 and $5 \mathrm{MHz}$ transducer oriented at the shear wave critical angle. Oper. ating at the higher frequencies permits reduction of background noise by filtering or narrow band amplification, with the wave front becoming more sharply defined. This latter effect enhances the accuracy of source location by improving the accuracy of determining time relationships among various transducers. Use of the critical angle transducer orientation is beneficial in that it favors reception of a selected propagation mode which, in turn, tends to standardize the propagation velocity involved. 


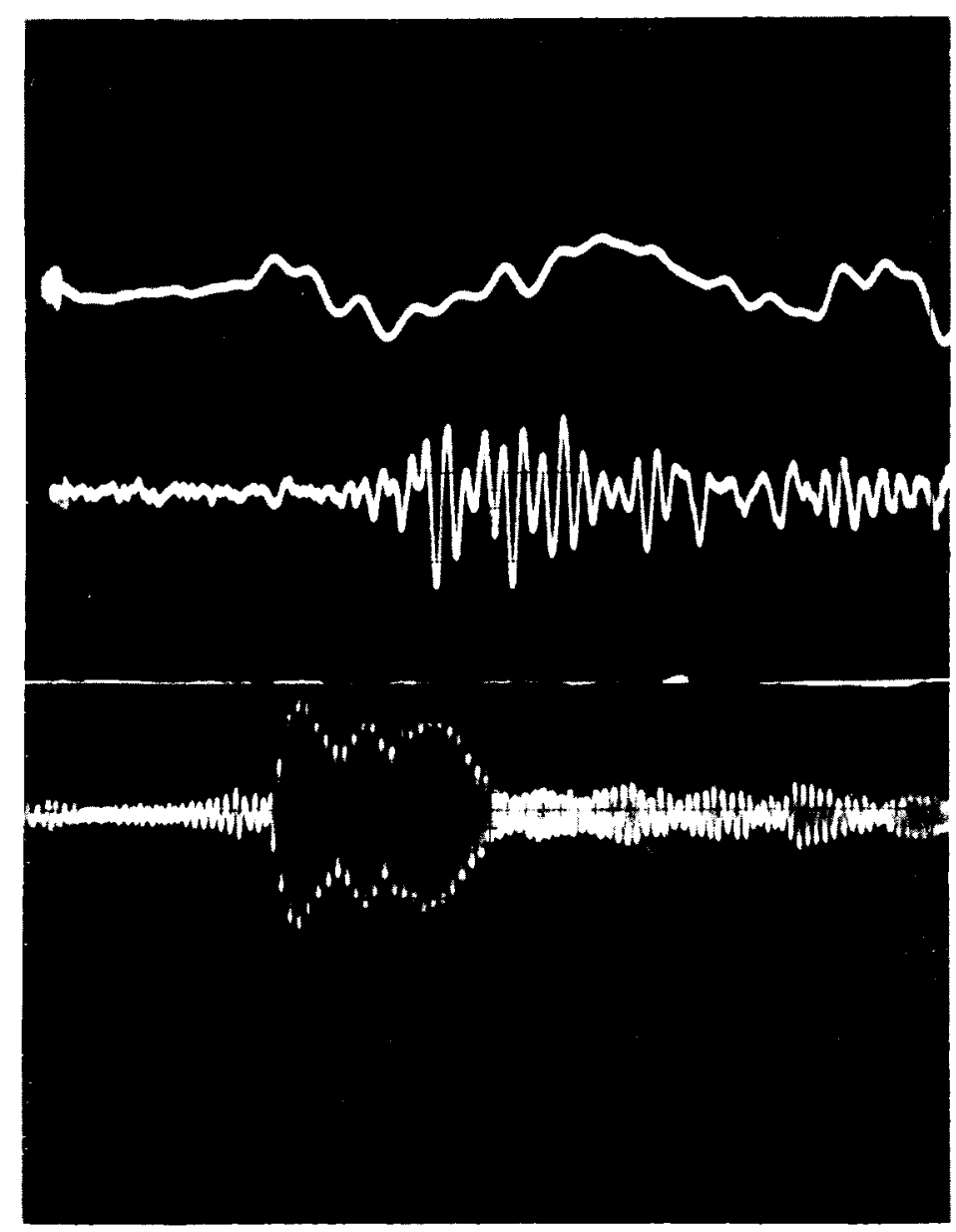

$1 \mathrm{MHZ}$ TRANSDUCER VERTICAL MOUNT

$20 \mathrm{kHz}$ HI-PASS FILTER

RTV-116 SILICONE RUBBER COUPLANT

$2 \mathrm{MHZ}$ TRANSDUCER

SHEAR ANGLE MOUNT

$500 \mathrm{kHZ}$ HI-PASS FILTER

WATER COUPLANT

$5 \mathrm{MHZ}$ TRANSDUCER

SHEAR ANGLE MOUNT

4-1/2 - 5-1/2 MHZ NARROW BAND

AMPLIFIER

WATER COUPLANT

$2 \mu$ SEC/CM SWEEP RATE IN ALL

CASES

PZT-5A TRANSDUCER CRYSTALS

FIGURE 3.6. Effect of Transducer Frequency and orientation on Response to the Same Acoustic Emission Signal 
These results are of particular interest because of their compatibility with the results of nuclear reactor noise measurements discussed under "Task 6 - Application Engineering."

Some of the more apparent facets of this technique yet to be resolved include determination of the maximum useable frequency for effective propagation in materials of interest, development of an omnidirectional, critical angle transducer, and determination of a coupling method suitable for field use.

Several $1 \mathrm{MHz}$, PZT-5A transducers, fabricated by use of a ceramic backing material, are being tested for their ability to withstand extended exposure to high temperature (600 to $650^{\circ} \mathrm{F}$ ) environment. The epoxy material previously used in fabricating these transducers is not satisfactory for longterm high-temperature applications because it gradually deteriorates with time at temperature. Sensors of this type were used in noise studies on the Dresden I reactor and after about three weeks of service, although they were still functional, the damping effect of the backing had obviously deteriorated.

Task 3 - System Analysis Study

No further work has been done this quarter. Task 4 - Monitor System Development

A low-noise, solid-state wide-band preamplifier has been fabricated and field tested with satisfactory results. Bandwidth of the current design is $1 \mathrm{KHz}$ to $31 / 2 \mathrm{MHz}$ with a noise level of $16 \mu \mathrm{V}$ referred to input, which is only about a factor of two above the noise level of the best commercial preamplifier yet found over a much narrow bandwidth ( 1 to $300 \mathrm{KHz})$. The new preamplifiers have been built and tested in both $X 10$ and $X 100$ versions. Figure 3.7 shows the compact size of the instrument. 


\section{ACOUSTIC EMISSION \\ Low Noise, Broadband Preamplifier Developed for Acoustic Emission Detection}
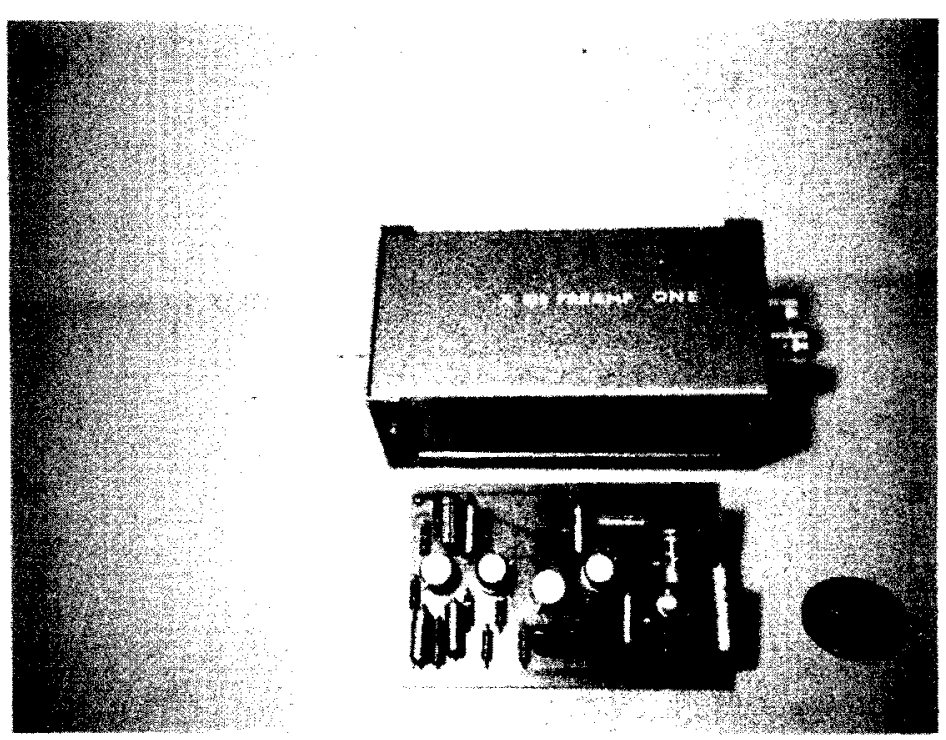

FIGURE 3.7. Low Noise, Broddband, Preamplifier Developed for

Acoustic Emission Detection

Task 5 - Cooperative Work With Phillips Petroleum Company

Task 6 - Application Engineering

Tasks 5 and 6 are discussed together because one of the major efforts on the acoustic emission program this quarter was a cooperative study of background noise at the Dresden I nuclear power reactor by Phillips Petroleum Co. (PPCo.) and Battelle-Northwest (BNW). Dresden $I$ is a part of the Commonwealth Edison Co's. electrical power generation network located near Morris, Illinois. Arrangements were made by PNL to install transducers at selected locations on the reactor at selected locations on the reactor system in late May, 1968 . 
BNW installed sensors and supporting electronics at four locations on the Dresden I pressure system (Figure 3.8). These locations were: 1) 22 in. west recirculation header, 2) a control rod thimble external to the reactor, 3) 6 in bypass line on the "D" secondary steam generator, and 4) top head of the reactor vessel (two sensors).

In addition to the sensors installed by BNW, PPCo. installed three sensors on the 22 in. west recirculation header to obtain independent information. One of these sensors was provided by BNW; the other two commercial sensors came from ppCo.

One of the BNW sensor channels on the vessel head was nonfunctional, apparently because of a broken wire at the preamplifier. The second sensor at this location provided only limited data because the preamplifier failed after two days of reactor operation due to the environmental temperature exceeding component limits. PPCo. experienced early deterioration (approximately two days at temperature) of their two commercial sensors because of temperature effects.

The BNW measurement system is illustrated in Figure 3.9, with the transducer response characteristics shown in Figure 3.10.

Noise measurements were made on all functional points at various stages from initial start-up (full cold recirculation flow) to about $90 \%$ of full power ( 190 MW electrical). The data obtained are summarized in Figures 3.11 through 3.14. This is a valid representation of the data because with the flow essentially constant, there was no significant change in the noise spectrum on the primary recirculation system from cold conditions to full power level. The total flow through the vessel was approximately 26 million pounds per hour. Each 22 in, header carries essentially half of 


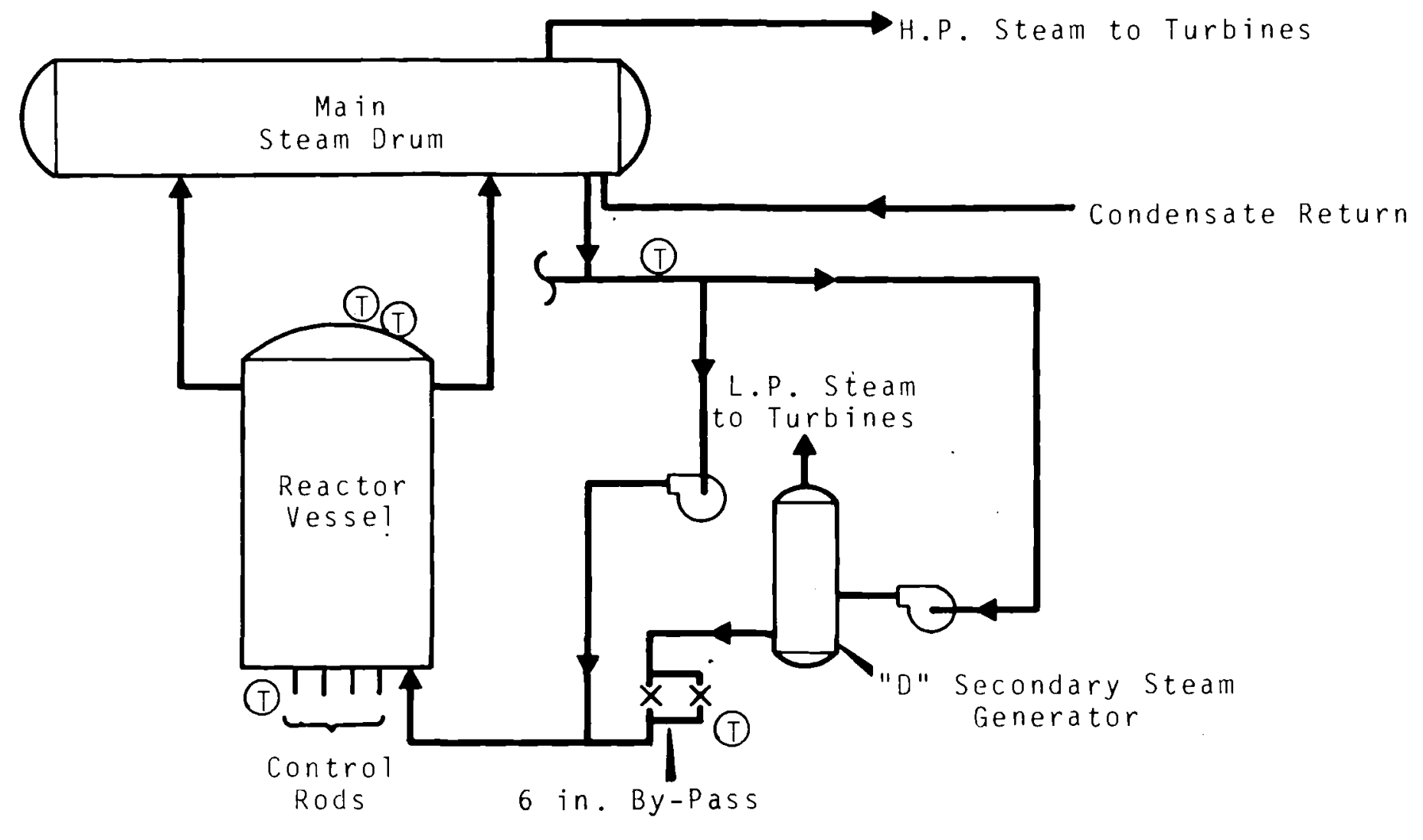

(T) Transducers for Noise Measurement

FIGURE 3.8. Partial Schematic of Dresden I Nuclear Power Reactor System Showing Transducer Locations for Noise Measurements 


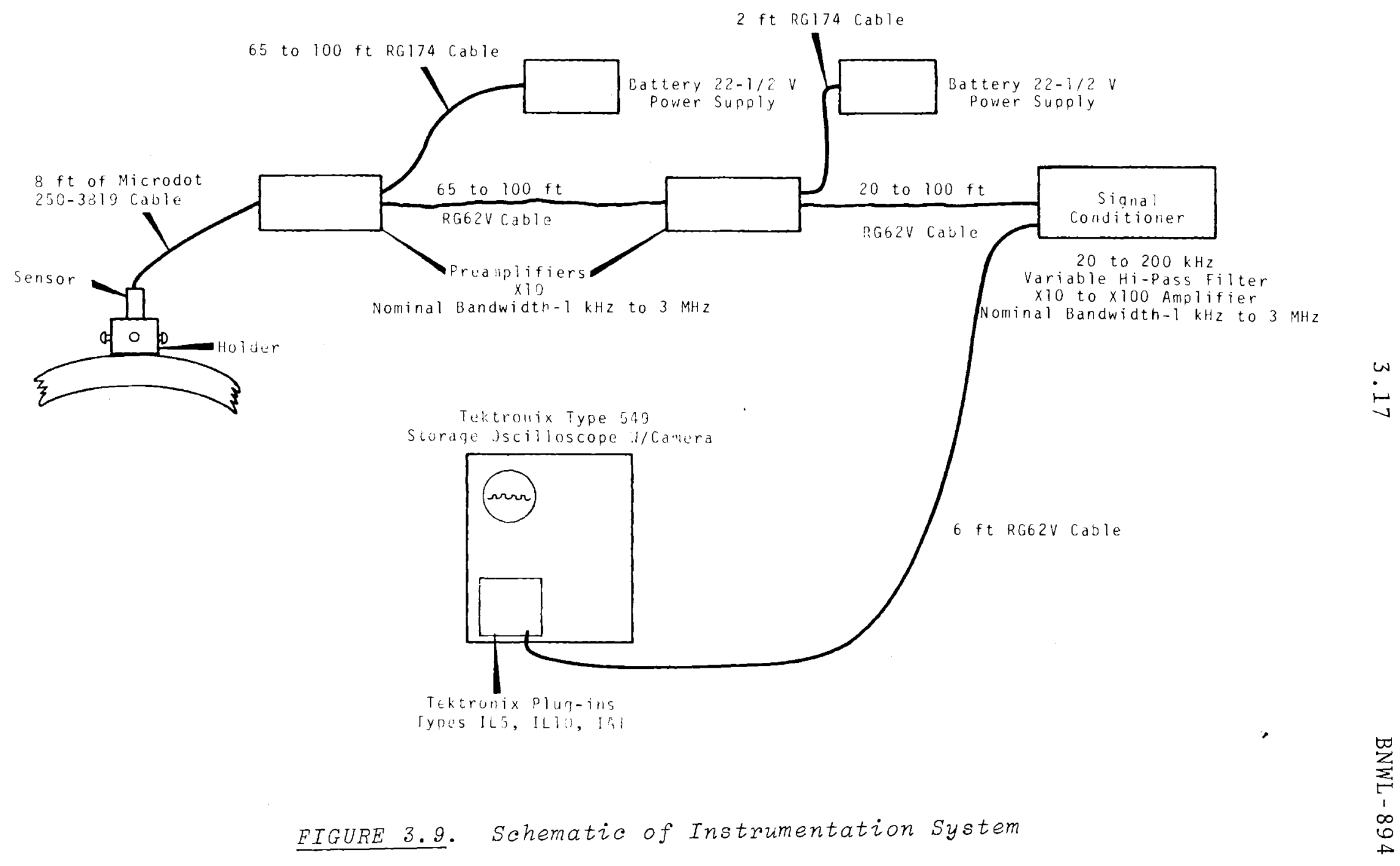




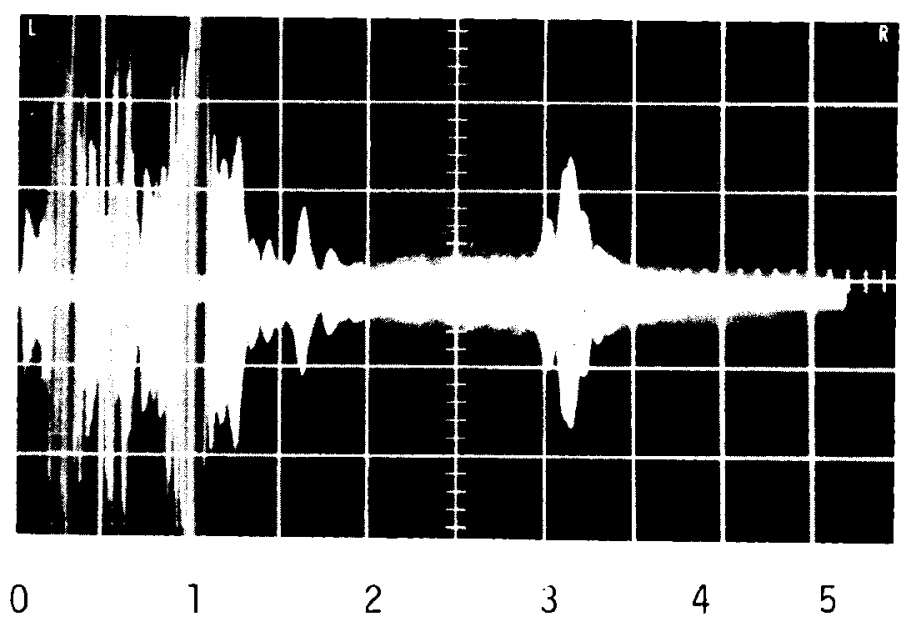

Frequency, $\mathrm{MHz}$

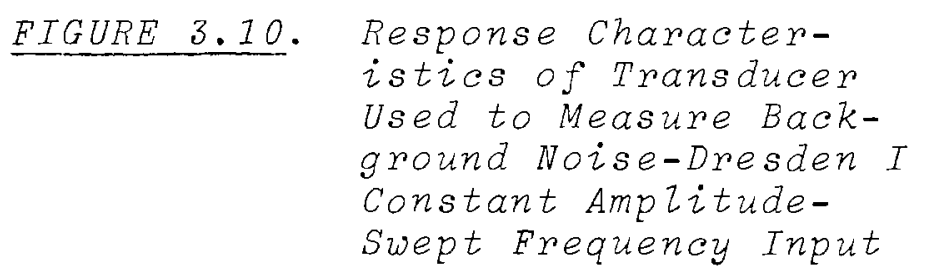

this or 13 million pounds per hour for a corresponding flow velocity of $25 \mathrm{ft} / \mathrm{sec}$. As shown in Figure 3.13 , there were two different flow conditions, and in turn, two different noise spectrums for the 6 in. by-pass line. Unfortunately, there were no apparent feasible means of determining with any accuracy what the flow values were in either case. The total recirculation flow splits about equally among four secondary steam generator systems. During start-up, flow to the secondary steam generators is controlled by manipulating a main 18 in. valve and a 6 in. by-pass around this valve (where one of the transducers was located) downstream of the heat exchanger, together with a 6 in. Iine that completely bypasses the heat exchanger. The control parameter is steam generator output, with no direct measure of the specific flow in the various parts of this system. For a brief period early in the start-up cycle, the main valve was throttled; this 


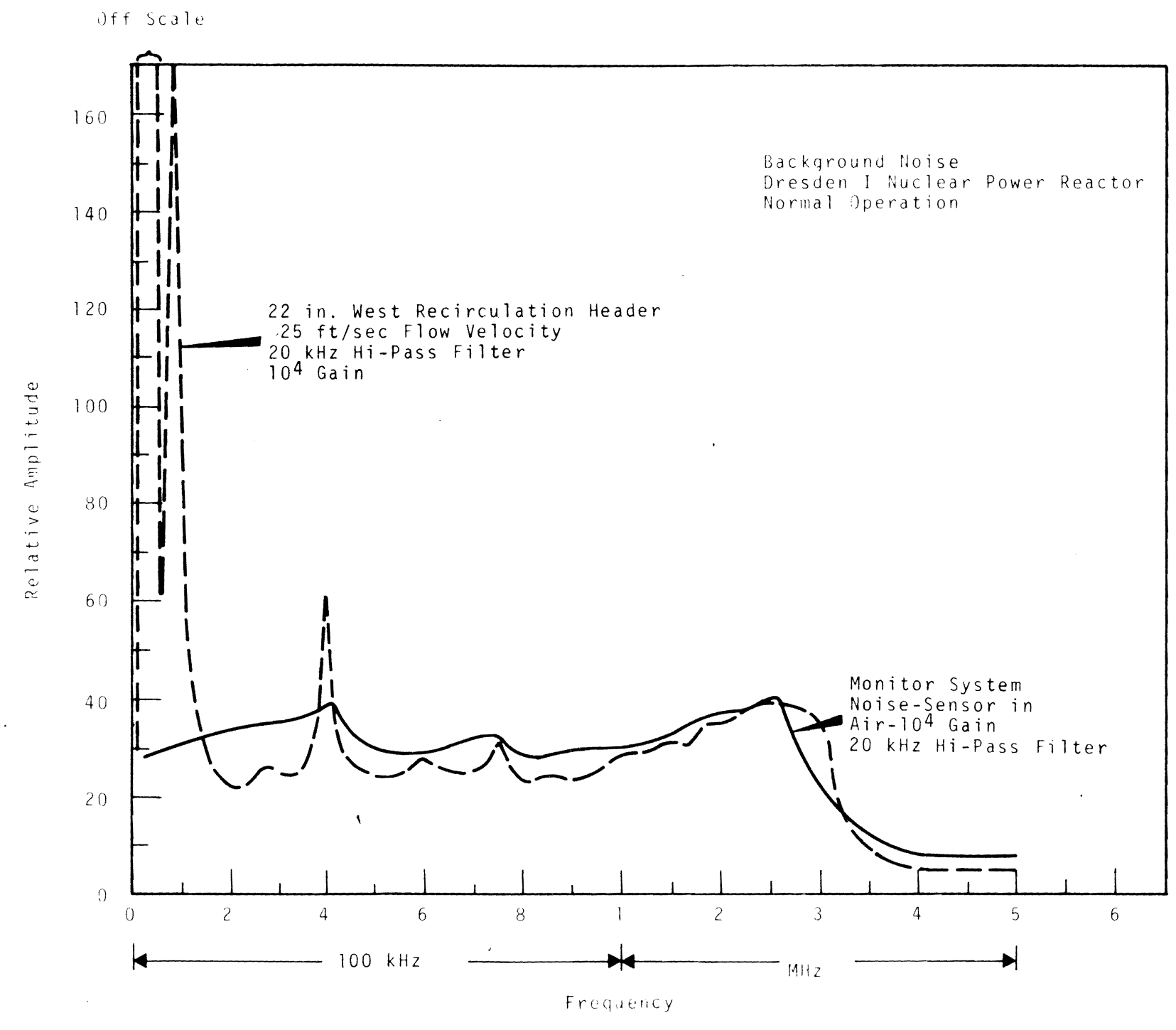

FIGURE 3.11. Noise Spectrum 22 in. West Recirculation Header 


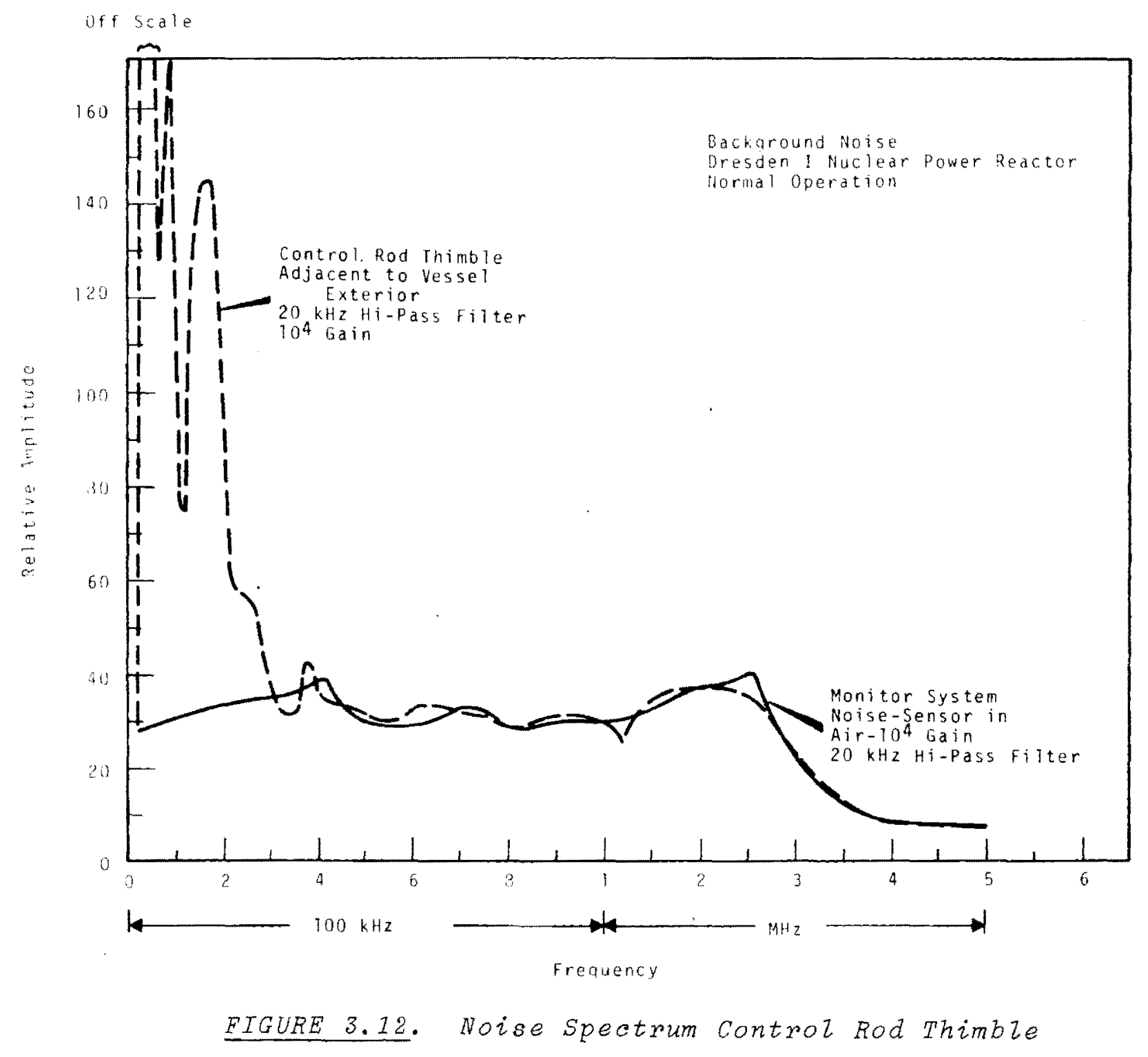




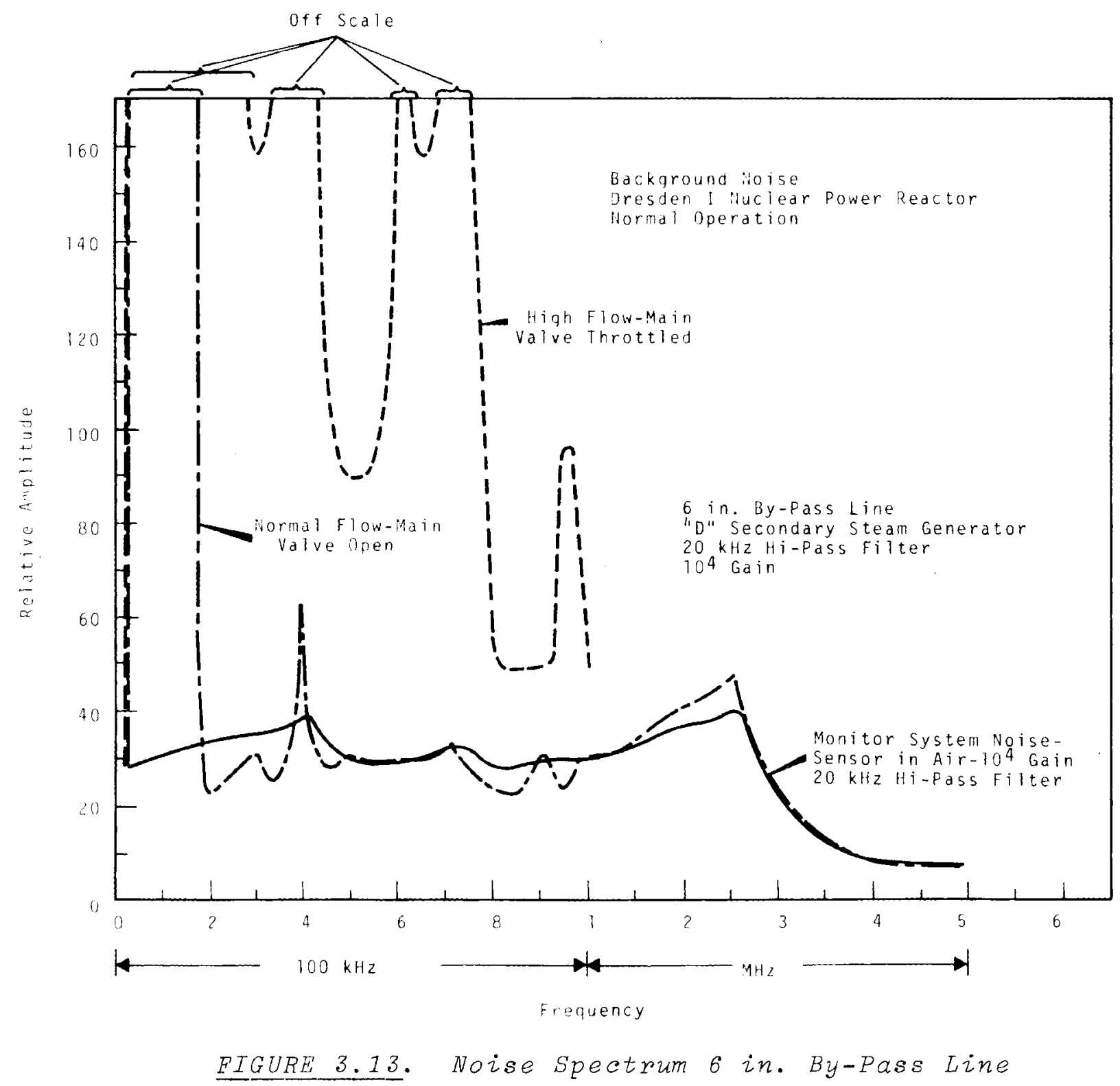

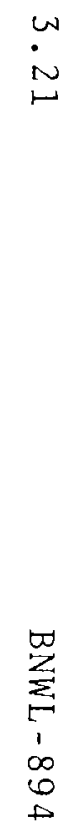




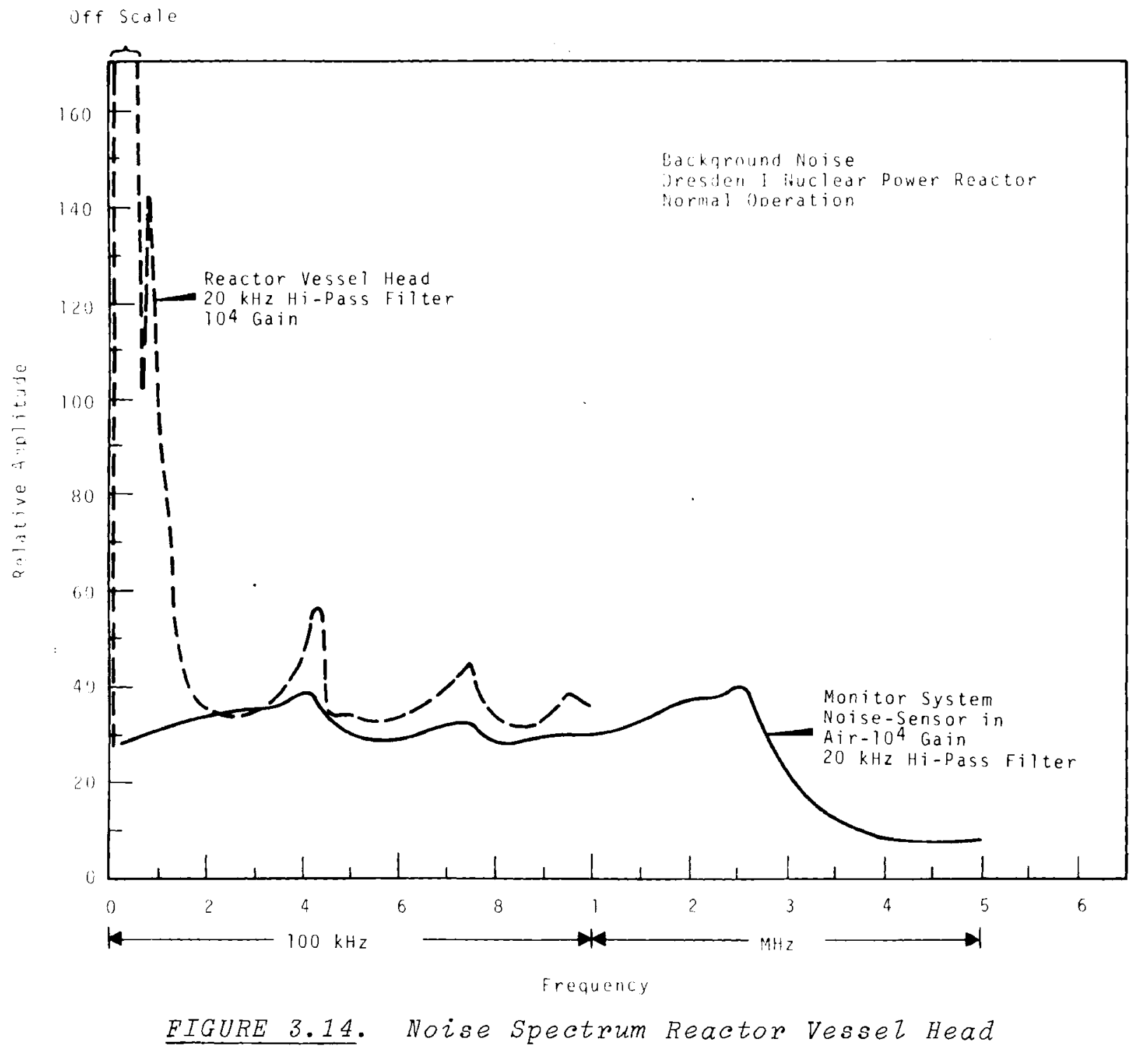


increased the flow through the 6 in. by-pass. The upper curve in Figure 3.13 was the resulting noise spectrum out to $1 \mathrm{MHz}$. No analysis beyond $1 \mathrm{MHz}$ was obtained for this condition; however, the spectrum falls off quite rapidly toward $1 \mathrm{MHz}$. When the main valve was opened, the noise spectrum assumed a shape very similar to that of the other points.

The noise distribution measured on the head of the vesse1, shown in Figure 3.14, was measured only out to $1 \mathrm{MHz}$ because of the unexpected early failure of the preamplifier in this location.

Figure 3.15 shows the information from which the measurement-system electronic-noise spectrum included in the previous curves was derived. These data were generated by using the total measurement system including a transducer cushioned with the face open to air during the measurements. This was done at the Dresden site and again in the laboratory with consistent results.

Typical spectral data traces for the various locations are presented in Figures 3.16 through 3.19. A relative amplitude scale is used in presenting all of the spectral distribu. tion information. Since the information is random in nature, a more accurate measure of absolute amplitude can be derived from the video traces of the actual signals as given in Fig ures 3.20 and 3.21 . As the spectral curves show, the bulk of the noise at all locations is contained in the frequency range from dc to $200 \mathrm{kHz}$ with the exception of the high flow case for the $6 \mathrm{in.}$. by-pass line. In this latter case, significant noise components are evident on out to the $900 \mathrm{kHz}$ to $1 \mathrm{MHz}$ range but this was not reflected in noise data obtained from the other points on the system. The preliminary conclusion drawn from this is that an acoustic-emission monitor system operating in the $750 \mathrm{kHz}$ to $3 \mathrm{MHz}$ range would be relatively 


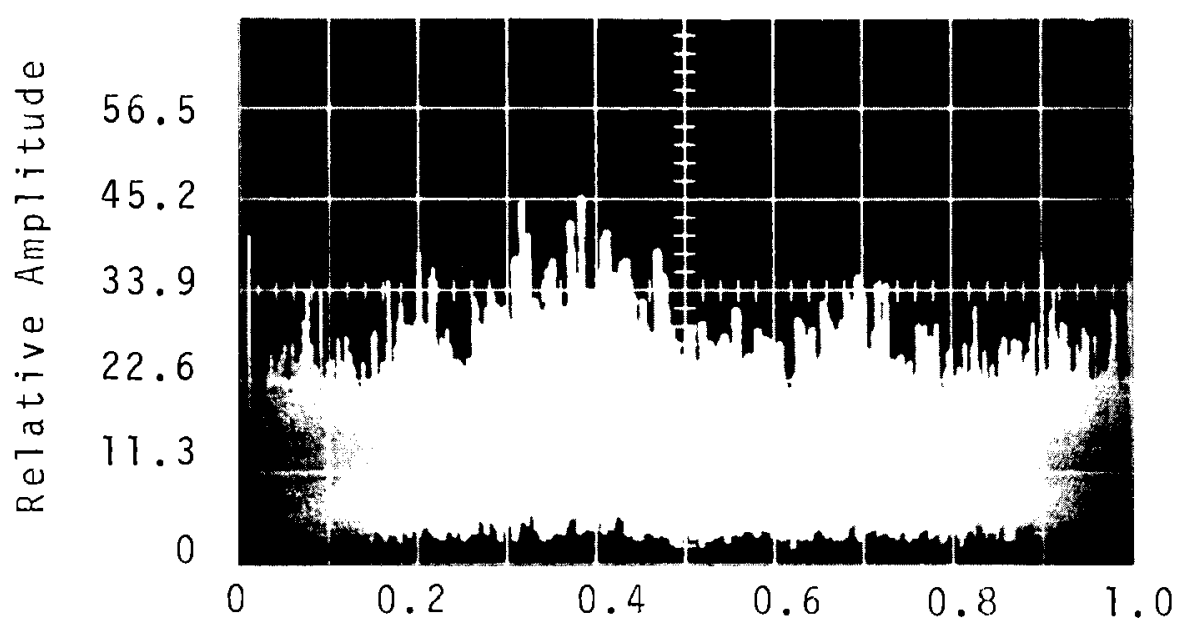

Frequency, $\mathrm{MHz}$

Tektronix Type IL5 Analyzer

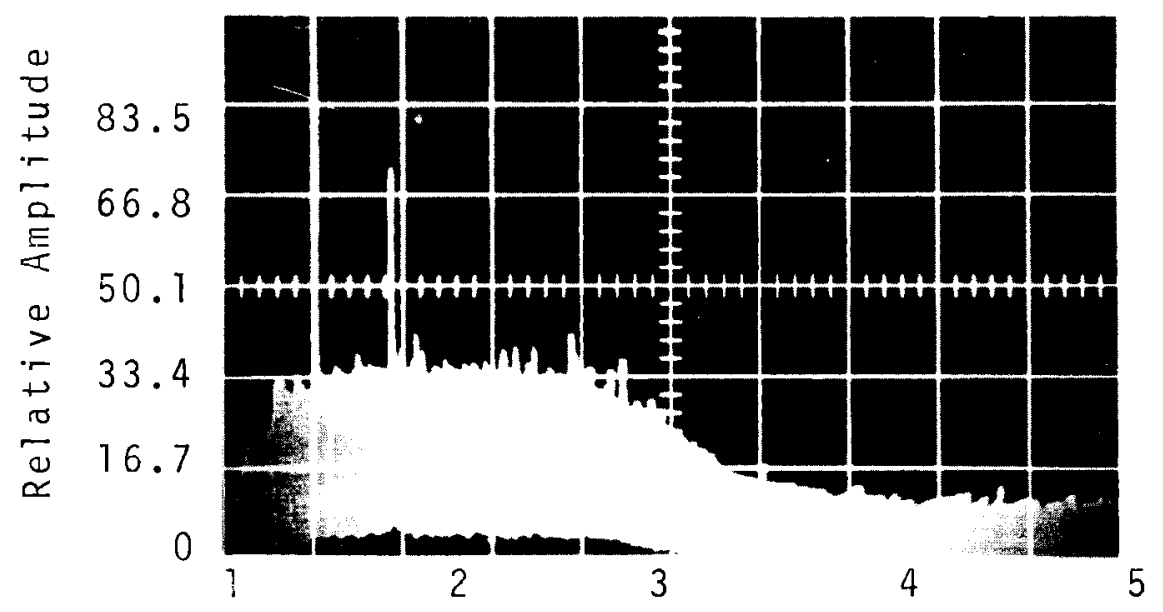

Frequency, $\mathrm{MHz}$

Tektronix Type ILlo Analyzer

$20 \mathrm{kHz}$ Hi-Pass Filter Used in Both Cases 104 Gain

FIGURE 3.15. Measurement System Noise Spectrum Transducer in $A i r$ and Connected to Electronic System Used for

Reactor Noise Measurements 


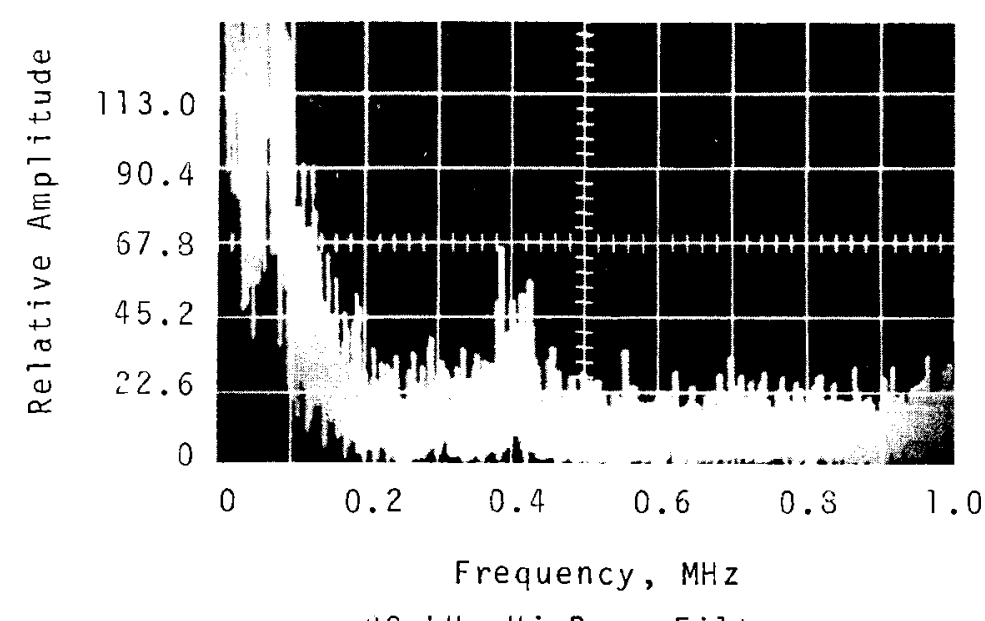

$20 \mathrm{kHz} \mathrm{Hi-Pass} \mathrm{Filter}$

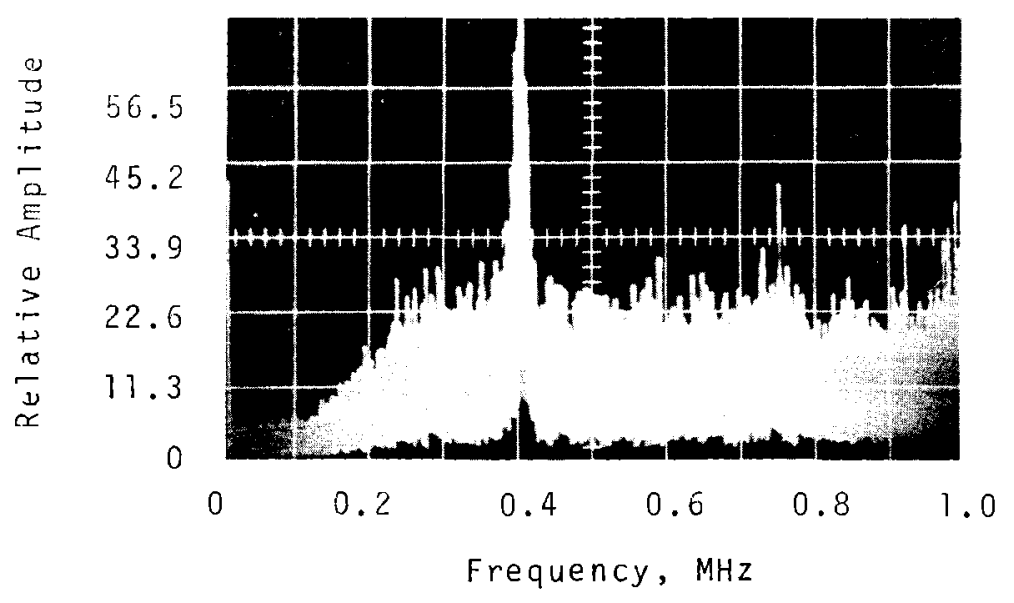

$200 \mathrm{kHz}$ Hi-Pass Filter

Tektronix Type IL5 Analyzer $10^{4}$ Gain

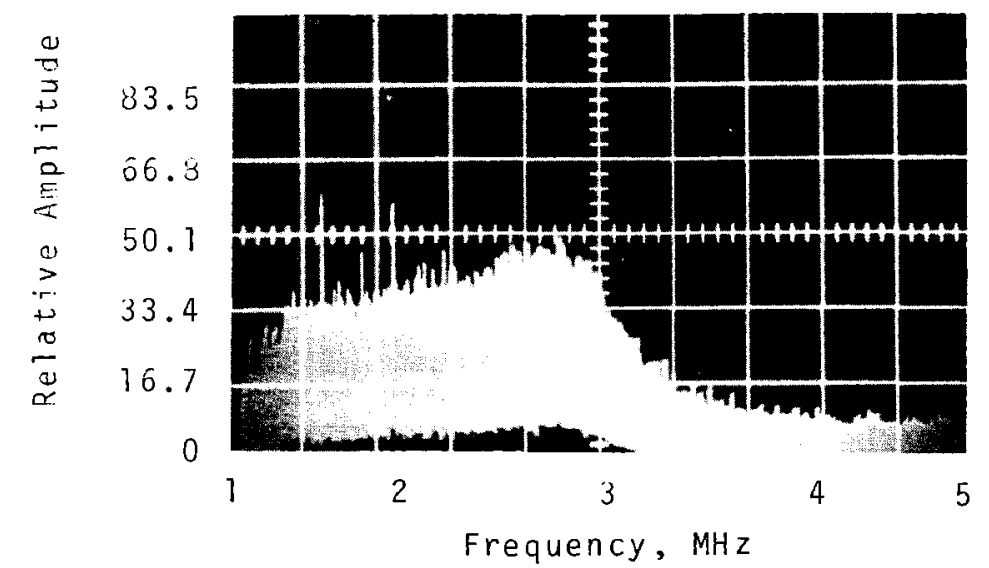

$200 \mathrm{kHz} H i-P a s s$ Filter

Tektronix Type ILlo Analyzer

$$
10^{4} \text { Gain }
$$

FIGURE 3.16. Noise Spectrum Sample-22 in. West Recirculation Header, Dresden I Nualear Power Reactor During Start-up and Normal operation 


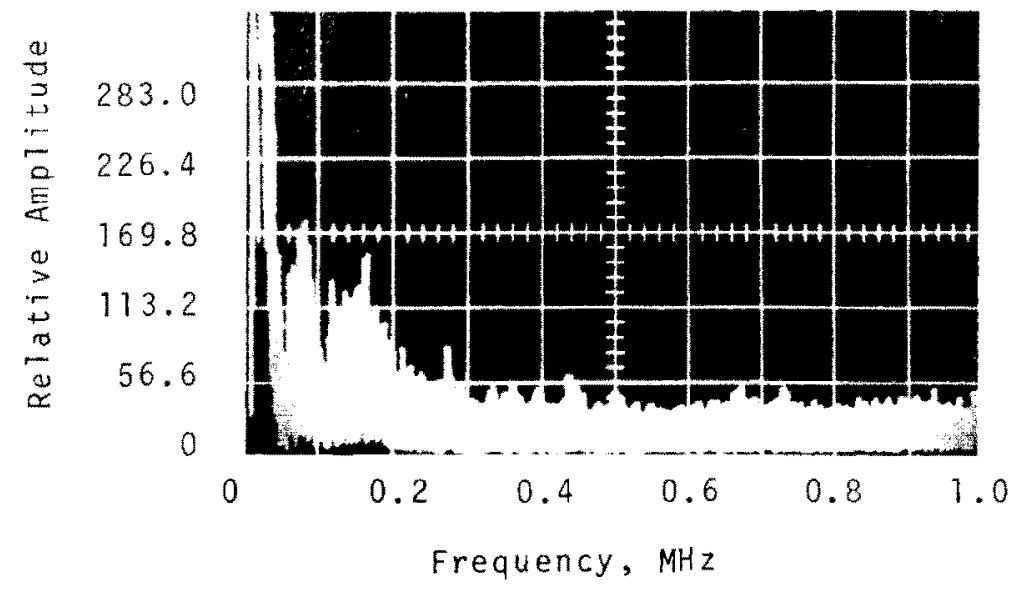

$20 \mathrm{kHz} H \mathrm{Hi}$-Pass Filter

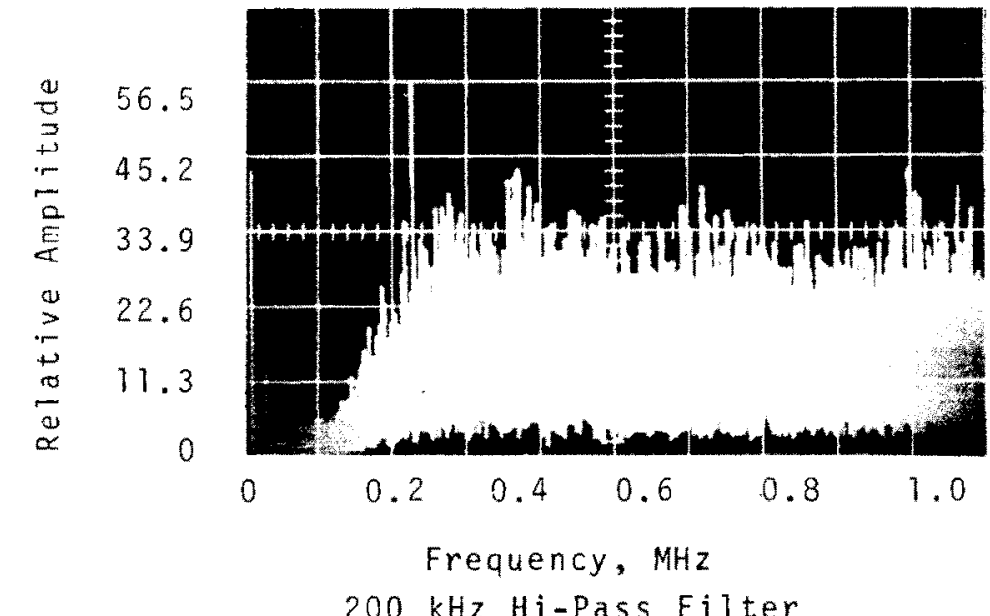

$200 \mathrm{kHz} \mathrm{Hi-Pass} \mathrm{Fijter}$

Tektronix Type IL5 Analyzer

$10^{4}$ Gain

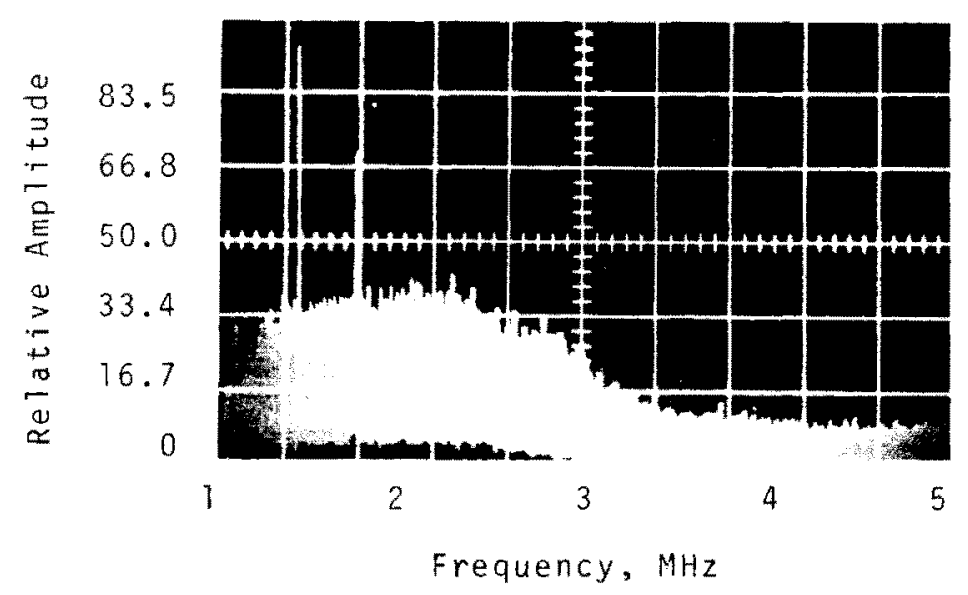

Tektronix Type IL10 Analyzer

$$
10^{4} \text { Gain }
$$

FIGURE 3.17. Noise Spectrum Sample-Control Rod Thimble Adjacent to Vessel Exterior Dresden I Nuclear Power Reactor During Start-up and Normal operation 


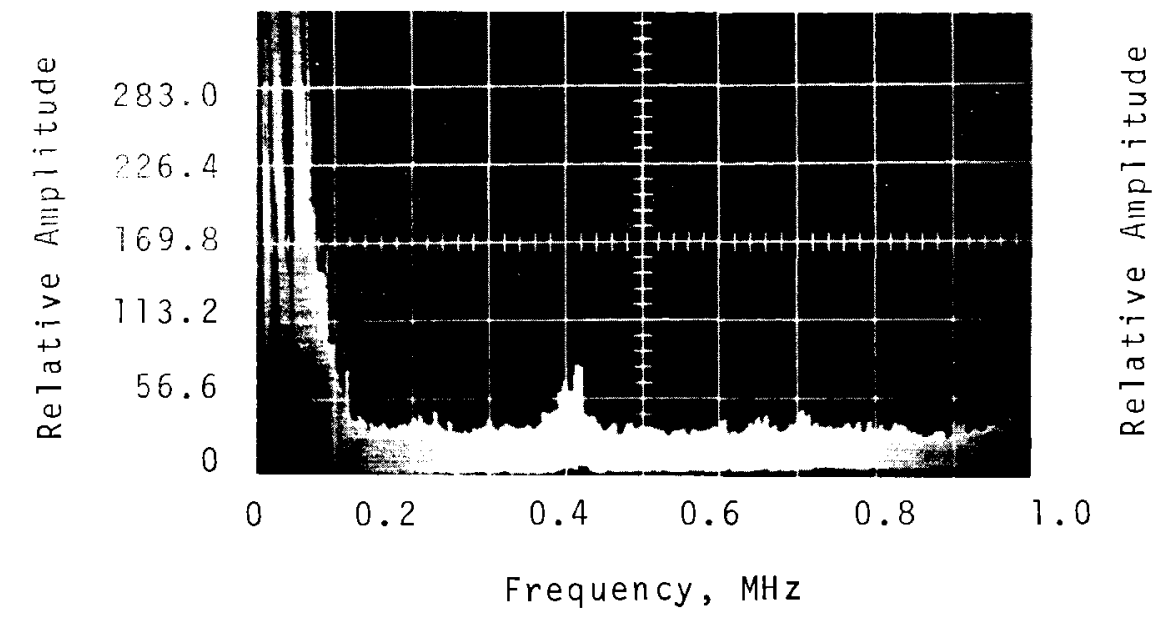

$20 \mathrm{kHz} H i-P a s s$ Filter

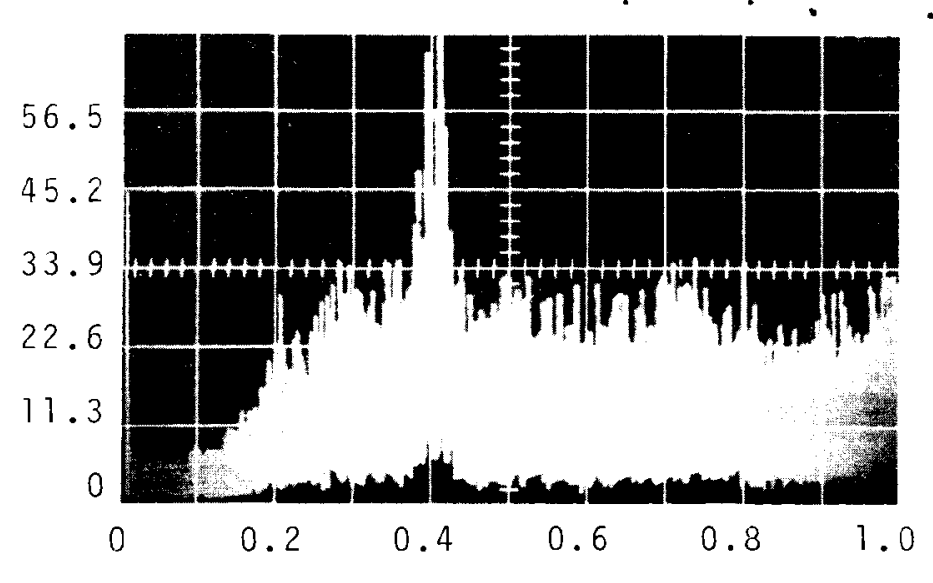

Frequency, $\mathrm{MHz}$

200 ktiz Hi-Pass Filter

Tektronix Type IL5 Andlyzer

Normal Flow-Main Valve Open

$10^{4}$ Gain

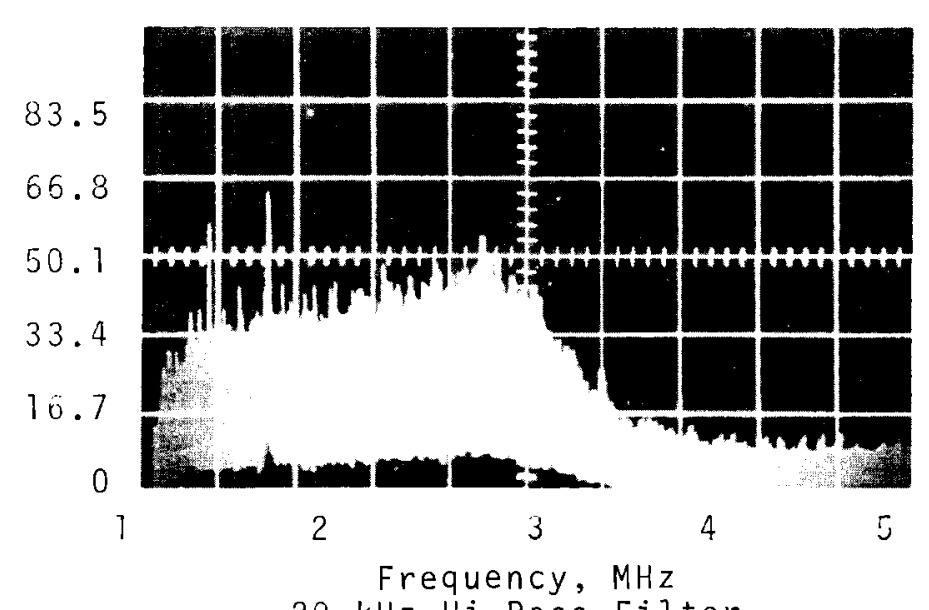

$20 \mathrm{kHz} H i-P a s s$ Filter

Tektronix Type IL5 Analyzer Normal Flow-Main Valve Open $10^{4}$ Gain

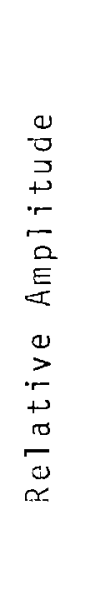

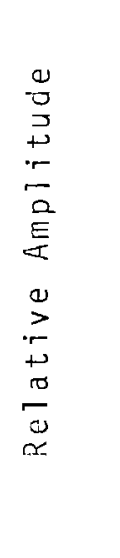

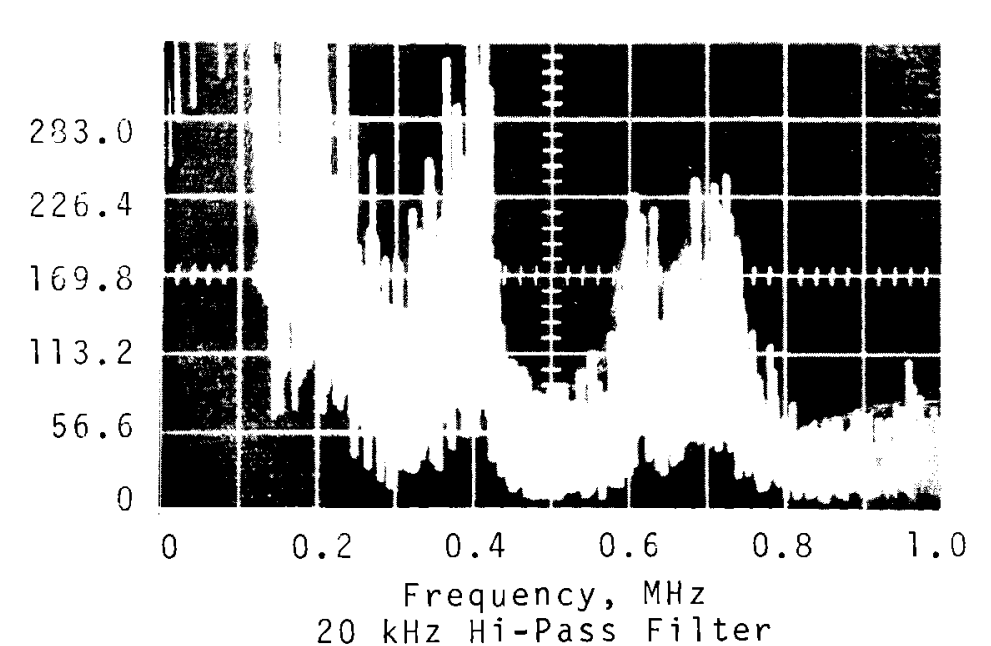

Tektronix Type IL5 Analyzer High Flow-Main Valve Throttled

$$
10^{4} \text { Gain }
$$

FIGURE 3.18. Noise Spectrum Sample-6 in. By-Pass, "D" Secondary Steam Generator in operation 


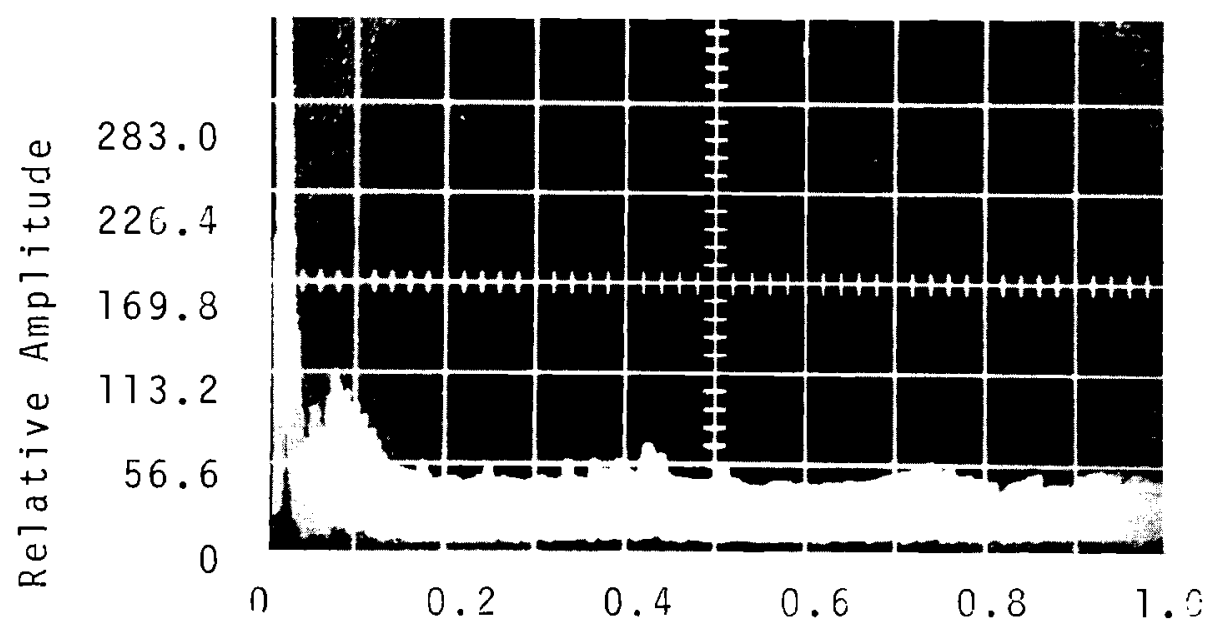

Frequency, $\mathrm{MHz}$

Tektronix Type IL5 Analyzer

$20 \mathrm{kHz} H \mathrm{H}-\mathrm{Pass} \mathrm{Fi} 1$ ter

$10^{4}$ Gain

\section{FIGURE 3.19. Noise Spectrum Sample- \\ Reactor Vessel Head \\ Dresden I Nuclear Power \\ Reactor During Start-up}

unhampered by noise interference except for possible limited periods of very high local-flow velocities (>25 ft/sec). As pointed out previously, however, such a conclusion must be treated somewhat cautiously because it is based on information obtained from one commercial power reactor plus some earlier experience with the Hanford plutonium production reactors. Even on a qualified basis, the information is of considerable value in continued work toward development of a practical system for utilizing acoustic emission as a means of continuously monitoring for crack growth in the pressure boundaries of an operating reactor. It offers encouragement that success can be achieved, and it points to the frequency region where development work on improved detection techniques can be most productively applied. 


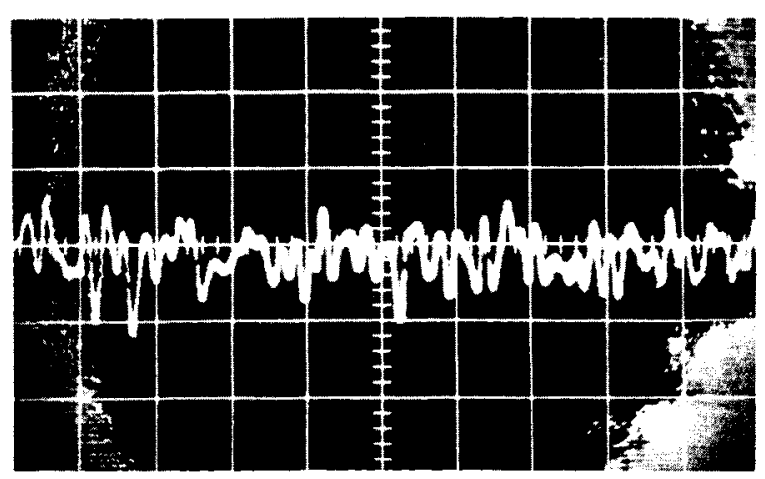

$0.01 \mathrm{~V} / \mathrm{cm}$ Vertical, $2.0 \mu \mathrm{sec} / \mathrm{cm}$ Sweep $10^{3} \mathrm{Gain}$ into the Oscilloscope $200 \mathrm{kHz} \mathrm{Hi-Pass} \mathrm{Filter}$

Measurement System Noise

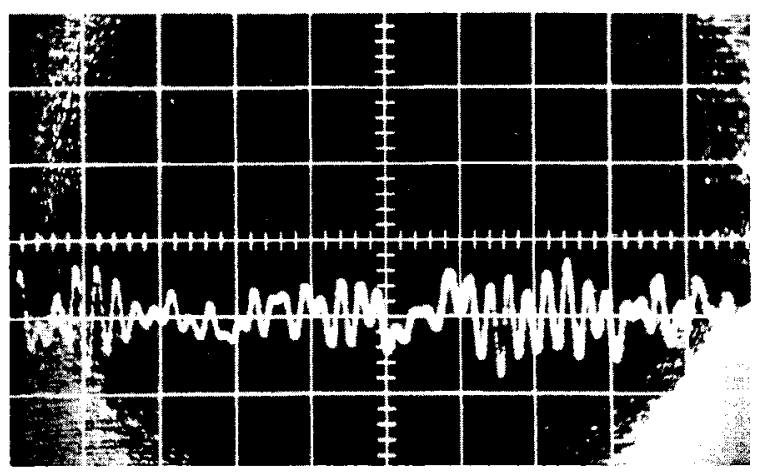

$0.02 \mathrm{~V} / \mathrm{cm}$ Vertical, 2.0 usec/cm Sweep

$10^{3} \mathrm{Gain}$ into the Oscilloscope

$200 \mathrm{kHz} H \mathrm{H}-\mathrm{Pass} \mathrm{Filter}$

Control Rod Thimble Adjacent to Vessel Exterior

FIGURE 3. 20.

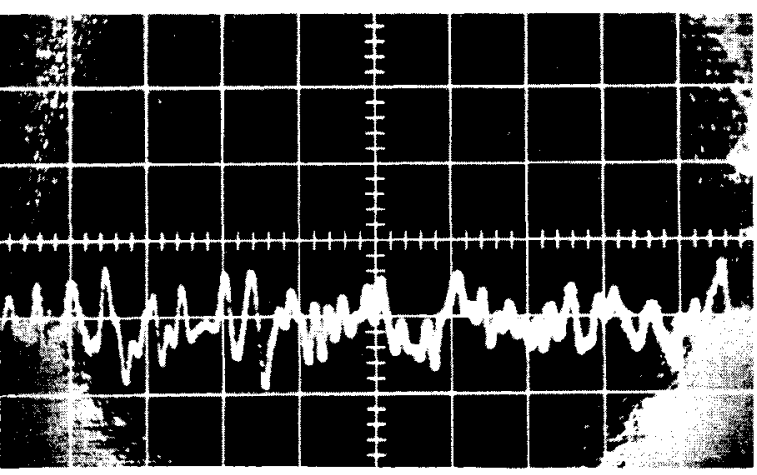

$01 \mathrm{~V} / \mathrm{cm}$ Vertical, $2.0 \mu \mathrm{sec} / \mathrm{cm}$ Sweep $10^{3} \mathrm{Gain}$ into the Oscilloscope

$200 \mathrm{kHz} \mathrm{Hi-Pass} \mathrm{Filter}$

22 in. West Recirculation Header

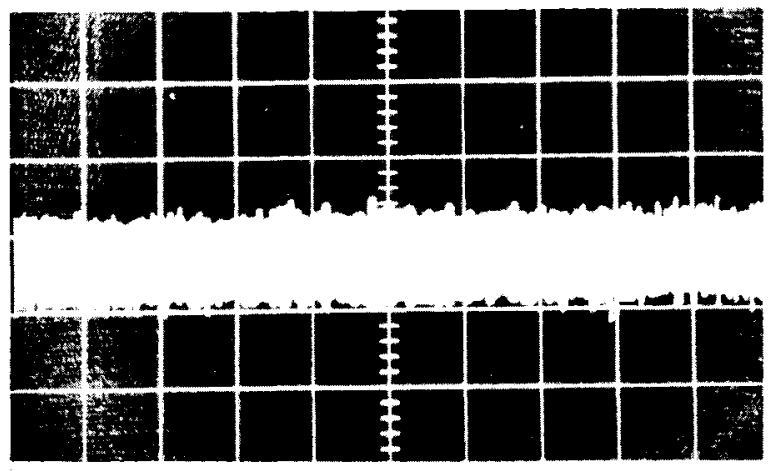

$\stackrel{w}{0}$

$0.02 \mathrm{~V} / \mathrm{cm}$ Vertical, $1 \mathrm{mil}-\mathrm{sec} / \mathrm{cm}$ Sweep

103 Gain into the Oscilloscope

$200 \mathrm{kHz} H \mathrm{H}-\mathrm{Pass} \mathrm{Filter}$

Reactor Vessel Head

$\sum_{\substack{\infty \\ 1 \\ 1 \\ 0 \\ 0 \\ 0}}$ 


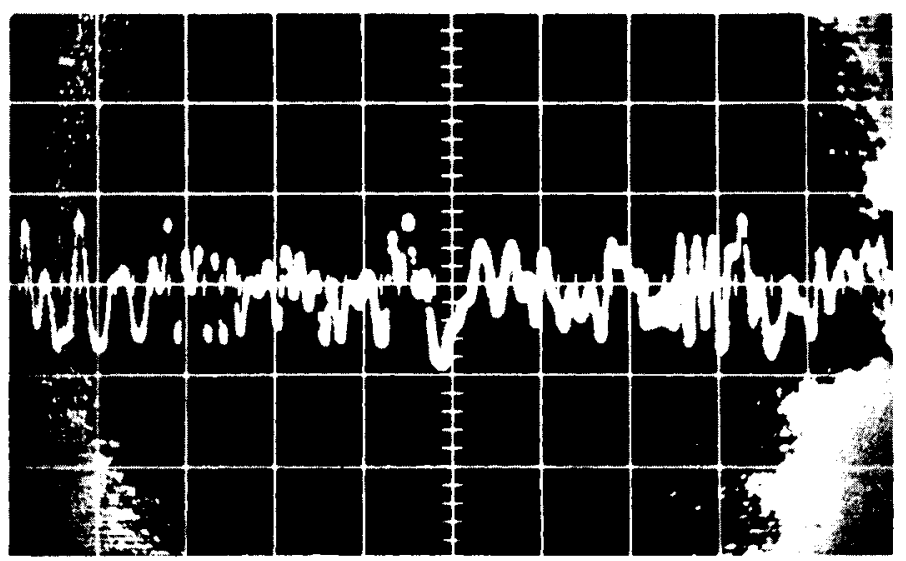

$0.01 \mathrm{~V} / \mathrm{cm}$ Vertical, $2.0 \mu \mathrm{sec} / \mathrm{cm}$ Sweep

$103 \mathrm{Gain}$ into the oscilloscope

$200 \mathrm{kHz}$, Hi-Pass Filter

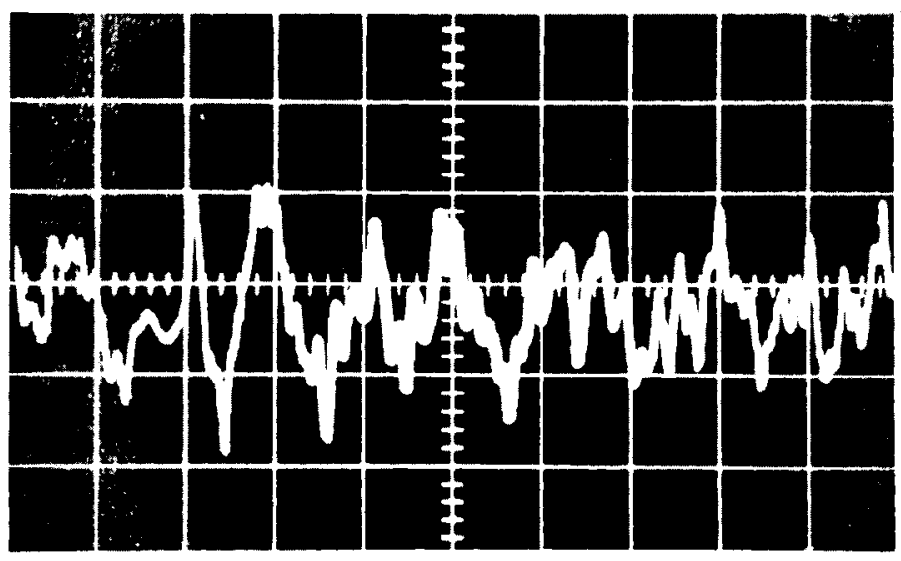

$5.0 \mathrm{~V} / \mathrm{cm}$ Vertical, $0.1 \mathrm{mil}-\mathrm{sec} / \mathrm{cm}$ Sweep $10^{3}$ Gain into the oscilloscope

$20 \mathrm{kHz}$, Hi-Pass Filter

6 in. By-Pass, "D" Secondary Steam Generator

FIGURE 3.21. Video Traces of Noise Signals Dresden I Nuclear Power Reactor During Start-up and Normal

operation 


\section{Work Planned for the Next Quarter}

Work for next quarter includes continued study of wavepropagation characteristics and high-frequency critical-angle detection toward definition of the optimum frequency and technique for on-line plant application. Also, a series of tests will be continued to study frequency classification, event rate, and pulse amplitude for different material conditions.

Transducer development-omnidirectional, critical angle design, and high temperature sensor development and testing will be continued while a study of coupling techniques for high temperature field application will be initiated.

Acoustic emission produced during one pipe fatigue test at General Electric Company's Vallecitos plant will be monitored, and tests to further define capability of acoustic emission detection in-plant will be performed in cooperation with Phillips Petroleum Company. 


\section{ENVIRONMENTAL STUDIES}

R. F. Foster

DISPOSAL OF REACTOR OFF-GAS INTO SOIL SYSTEMS - L. G, KIng

Battelle-Northwest has been conducting research work contributing to the analysis and interpretation of results from a tracer test at a field site within the National Reactor Testing Station (NRTS) in Idaho. During the field test, air containing ${ }^{133}$ Xe as a tracer was injected into the fractured basalt rock between the depths of 110 and $122.5 \mathrm{ft}$ below ground surface via a cased wel1. Samples were collected at various points at the ground surface, in the atmosphere a few feet above ground surface, and at various depths in wells constructed especially for that purpose. Battelle-Northwest has developed mathematical models to describe the gas movement during the injection phase of the field test. Two different approaches to modeling the gas flow have been pursued. The first assumes homogeneity with respect to permeability and allows solutions to boundary value problems to be obtained in closed form. The second approach allows permeability to be a function of space and, hence, relies upon finite difference methods of solution

The homogeneous model was not sufficient for predicting the gas movement in the field. This model adequately represented the total flow rate that could be injected into the ground, but travel times calculated with the model were much greater than measured in the field. The model was extended to include homogeneous, anisotropic media having a horizontal permeability much greater than the vertical permeability The latter model appears to give realistic explanation for observed gas movement.

The finite-difference model with layers of different permeability (homogeneity was assumed within each layer) was 
also not capable of predicting measured travel times but did adequately predict total flow rate of gas during the injection. Details are included in the final reports on this project which terminated at the end of June 1968. The reports are expected to be released in the near future.

SIMULATION MODELING OF THERMAL GENERATION IN SELECTED RIVER SYSTEMS - R. T. JaSke

Operations research with the COL HEAT thermal simulation model to investigate the effects of future nuclear power plants on temperatures of the Upper Mississippi Basin is nearing completion for the trunk stream and several major tributaries. During this report period the following specific accomplishments were made:

- Test simulations of the Minnesota, St. Croix, Chippewa, Wisconsin, Rock, Cedar-Iowa, and Des Moines Rivers were carried out using data collected earlier in the program. The simulations, with the exception of the Chippewa and Wisconsin Rivers, are satisfactory. A paucity of good field data appears to be responsible for the discrepancies in the cases of the Wisconsin and Chippewa Rivers; consequently, a detailed review of the two streams is underway.

- As follow-up report to BNWL-728, "A Test Simulation of the Temperature of the Illinois River and a Prediction of the Effects of Dresden II and Dresden III Reactors,"

is near completion. The report covers the reach between River Mile 230 and River Mile 0 . The report is expected to be issued in october.

Field data have been obtained for a test simulation of the thermal regime of the Phelps County (Nebraska) irrigation canal. The canal extends for approximately $60 \mathrm{miles}$ downstream 
of the Canaday Power Plant, a 100 MW steam plant that uses canal water for direct cooling. This study is expected to provide information of value for possible future use of irrigation waters for cooling of power reactors. 


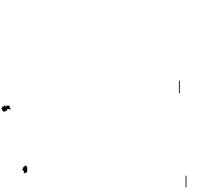




\section{FIXATION OF RADIOACTIVE RESIUUES}

PHOSPHATE GLASS SOLIUIFICATION

Corrosion from Fluoride-Bearing Feed Solutions - P. Fo Maness

Corrosion of the denitrator-evaporator (a11 titanium construction) by fluoride-bearing feed solution was estimated by exposing titanium coupons to $100 \mathrm{gal} / \mathrm{tonne} \mathrm{PW}-1$ solution (meq/P $=1.0)$ containing $0.1 \mathrm{M} H F$. The solution contained $0.5 \mathrm{M} \mathrm{Al}\left(\mathrm{NO}_{3}\right)_{3}$ with an equivalent reduction in the $\mathrm{Fe}\left(\mathrm{INO}_{3}\right)_{3}$ content. The test was made in a11-Teflon ${ }^{(B)}$ equipment with semicontinuous addition of feed to solution concentrated to a boiling point of $133^{\circ} \mathrm{C}$. The exposure time was $19 \mathrm{hr}$. Titanium corrosion rates in the liquid and in the vapor phases were 5.0 and $1.3 \mathrm{mils} / \mathrm{mo}$, respectively. A titanium coupon exposed to the boiling condensate collected from the above test corroded at a rate of $16 \mathrm{mils} / \mathrm{mo}$. Basec upon this value, the fluoride content of the condensate was estimated to be about $5 \times 10^{-3}$.

A phosphate glass run was made with the concentrated feed solution produced above. The run was made at $1100{ }^{\circ} \mathrm{C}$ with semicontinuous feed addition to an alumina crucible equipped with an overflow weir. Platinum specimens were exposed to the melt and to the vapor phase, and a Nionel specimen was exposed in the off-gas line immediately above the condenser. The platinum specimen exposed to the melt corroded at a rate of $0.23 \mathrm{mils} / \mathrm{mo}$ (50 hr exposure) with no evidence of embrittlement. The specimen exposed to the vapor phase evidenced no weight loss. How ever, the specimen fractured on bending, which indicated embrittlement. The Nionel specimen exposed in the off-gas line corroded uniformly at a rate of $6.1 \mathrm{mils} / \mathrm{mo}$. Only about $15 \%$ of the condensate was collected, while the remainder flashed off during feed addition.

(B) Dont Co.s Wilmington, Deiaware 
Radioactive Demonstration

Phosphate G1ass Run PG-6 - J. L. McE1roy, J. N. Hartley, and M. R. Schwab

During Run $P G-6$, waste equivalent to 0.7 tonnes of $20,000 \mathrm{MWd} /$ tonne power reactor fuel was processed to produce approximately $174 \mathrm{~kg}$ of glass product. The 62 liter of radioactive glass produced a self-generating heat density of approximately $131 \mathrm{~W} / 1$ iter $(8100 \mathrm{~W}$ tota 1$)$.

A total of 616 iiters of sulfate-free PW-1 type feed (889 1iters/tonne) containing 2,560,000 Ci of radioactivity, including approximate $1 y, 8,000 \mathrm{Ci}$ of radioruthenium, were fed to the denitrator in $50 \mathrm{hr}$ at an average feed rate of 12.3 liters/hr. Table 5.1 1ists pertinent data for Run PG-6 as well as for al1 WSEP runs to date.

The sulfate-free PW-1 feed used in PG-6 was made by using radiocerium solution from B-plant as a source of radioactivity. Without Purex $1 \mathrm{WW}$ in the feed, no foaming problems occurred in the denitrator-evaporator as had happened in previous runs. The fact that Antifoam $B^{*}$ was not added further supports the previous evidence that small $(<100 \mathrm{ppm})$ quantities of organics (probably dibutyl phosphate, DBP, from degraded tributyl phosphate, TBP) in the Purex 1 WW probably caused foaming in previous runs. The sodium and phosphate concentrations in the $\mathrm{PW}-1$ feed were 2.6 and $6.23 \mathrm{M}$, respectively (at 378 liters/tonne).

Several plugging problems occurred throughout the run, but did not cause any delays. Dip tube and airlift line plugging occurred frequently, and required constant observations and frequent correction to avoid any interruption in the process. The main plugs that occurred during the run were:

* Dow Corning Antifoam B 


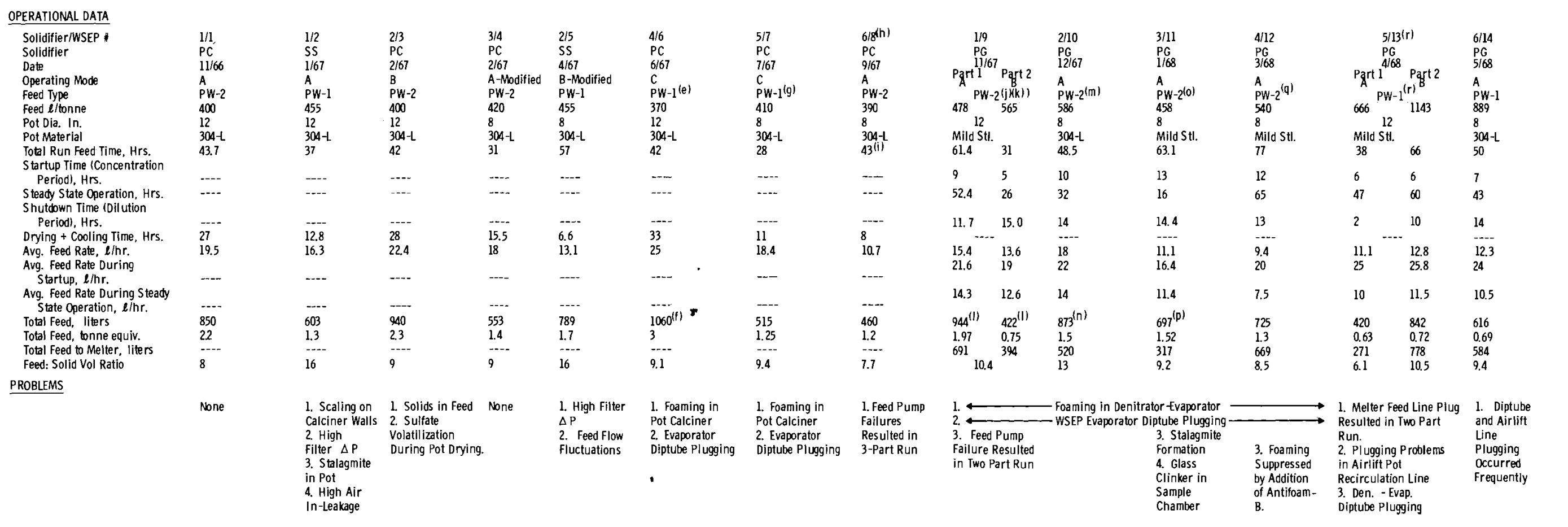

ERACTION OF ACTIVIT DISTRRBUUTE: TOTAL IISS RUIT-RUIAND RU

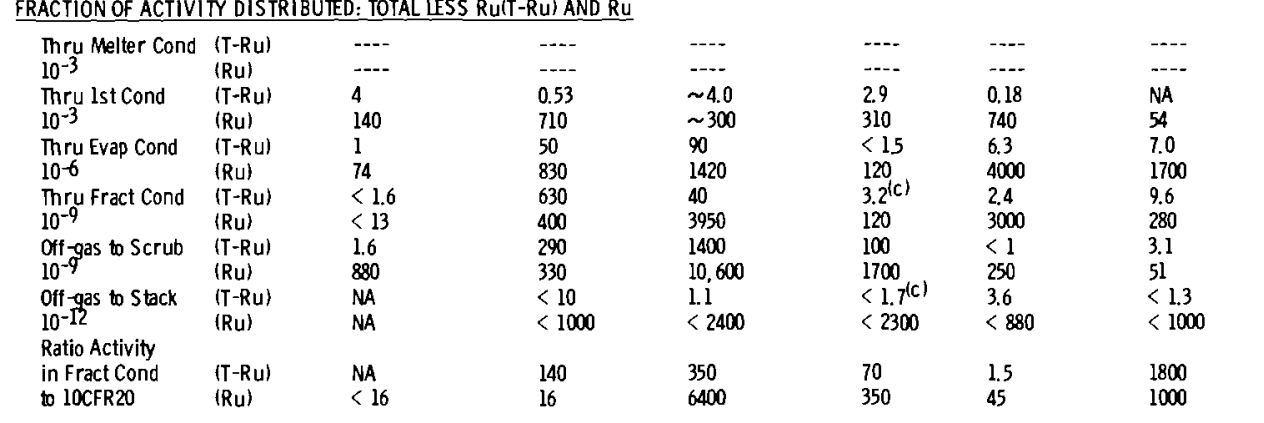

to 100 crR20

FILED POT DAAA
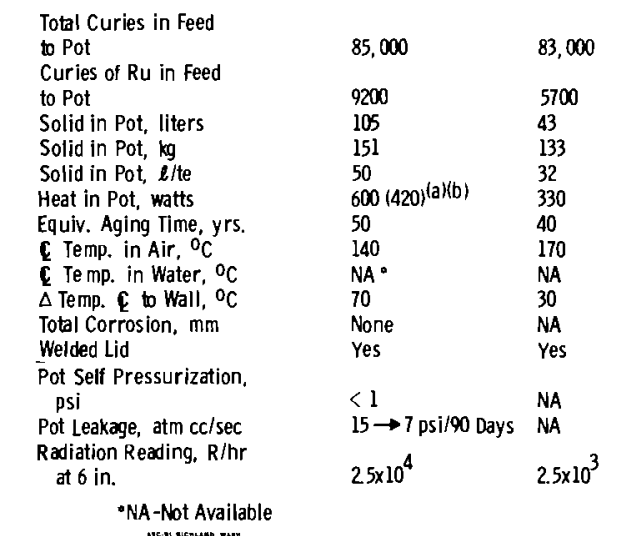

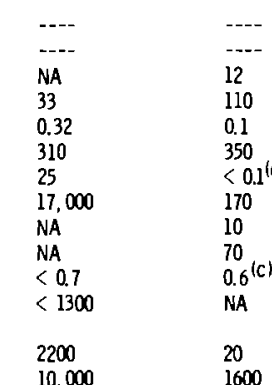

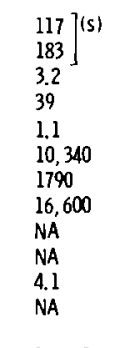

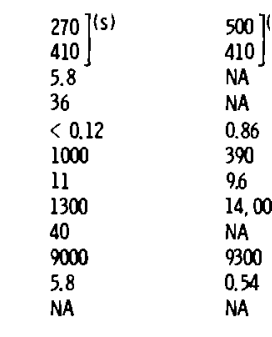

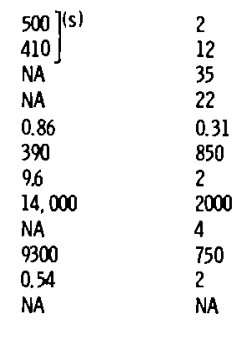

18,000
586
83
43300
1.5
7.5
79
495
49
149

NA
Yes
$N A$
$N A$
$N A$
$N 410^{4}$

$N A$
$N A$
$4.9 \times 10^{4}$

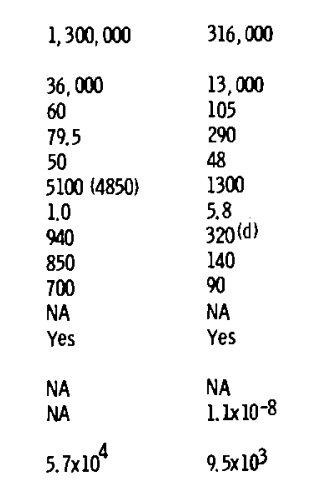

(a) Values in Brackets are trom Pot Calorimetry Oata

(b) Correcteded Because ef forereigh Contanination to give

Approximately Equal to that tor Ru

(d) Values are with Pot Setting in Cool Furnace
(te) $\mathrm{So}$ and $\mathrm{Na}$ were 0.25 and $0.47 \mathrm{M}$ Vice Desired Values
of 0.10 and $0.14 \mathrm{M}$ Respectively

(it) 60 Lhters Expelled trom Pot cue to Fanming

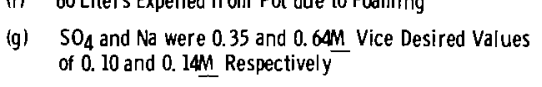

(h) PC-6was a 3 part run. All of Data is for Ist Part

(ii) Feeding Extended to obbin a Maximum fill

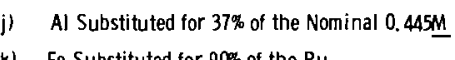

(III) Al Substituted for $65 \%$ of the Noninal $0.455 \mathrm{Fe}$

(n) $27 \%$ of Fotal Feed to Denitrator lost due to foraming

(o) Al Substituted for $40 \%$ of Nominal $0.455 \mathrm{Fe}$ 205 of Nominal Ruthenium Level Added

$50 \%$ of Total Fees to Denitrator ost tue to farming

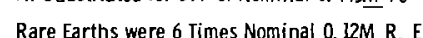

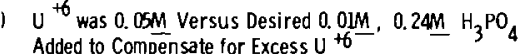

(s) Activity Includes Feed Lossess riom Denitrator
from Ooverflow to Melter Condersate Receiver 
- The denitrator-evaporator airlift air line plugged twice during startup and once during shutdown.

- The airlift pot-weight factor dip tube plugged shortly after startup, and was not unplugged until after the run.

- The denitrator weight factor and specific-gravity dip tubes were kept clear by hourly steam blowdowns, but would start to plug if more than an hour elapsed between blowdowns.

- The airlift recirculation line required frequent backing out of the plug valve as well as acid flushes to remove solids from this area.

During Run PG-6, $1.7 \%$ of the radioactive ruthenium and 1.3\% of other radioactive species fed to the denitrator were volatilized or entrained from the denitrator. Likewise, approximately $4.3 \%$ of the radioactive ruthenium and $0.2 \%$ of al 1 other radioactive species fed to the melter were volatilized or entrained.

The fraction of feed activity in the final condensate stream from the acid fractionator was $2.9 \times 10^{-6}$ for radioactive ruthenium and $3.3 \times 10^{-9}$ for all other radioactive species. This represents activity above CFR20 1imits* by factors of 3200 and 550 , respectively.

With the pot sitting in the cool furnace, the $9800 \mathrm{~W}$ of internal heat produced a centerline temperature of $780{ }^{\circ} \mathrm{C}$ and - a centerline-to-wall temperature difference of $380^{\circ} \mathrm{C}$. These values gave an effective thermal conductivity for the product of $1.0 \mathrm{~W} / \mathrm{m}^{\circ} \mathrm{C}\left[0.61 \mathrm{Btu} /(\mathrm{hr})(\mathrm{ft})\left({ }^{\circ} \mathrm{F}\right)\right]$.

* AEC's Rules and Regulations, 10CER20, Table II, Column II. 


\section{SPRAY SOLIDIFICATION}

Flowsheets for Processing $\mathrm{PW}-4 \mathrm{~m}$ in the Spray Solidifier -

J. E. Mendel

The third high-level radioactive waste composition to be included in the WSEP Program will be PW-4m. It has been defined as the waste resulting from the "clean" reprocessing of fuel with an exposure of 45,000 MWd/tonne at $30 \mathrm{MW} /$ tonne. The principal differences between $\mathrm{PW}-4 \mathrm{~m}$ and the two other WSEP waste compositions are:

\begin{tabular}{|c|c|c|c|c|c|c|}
\hline & \multicolumn{2}{|c|}{$P W-4 m$} & \multicolumn{2}{|c|}{$\mathrm{PW}-1$} & \multicolumn{2}{|c|}{$\mathrm{PW}-2$} \\
\hline & $\underline{\mathrm{wt}} \frac{\mathrm{o}}{\mathrm{a}}$ & mole : & $\mathrm{wt} \%$ & mole $\frac{0}{0}$ & wt: & mole $\frac{\circ}{0}$ \\
\hline FP oxides & 85.7 & 76.7 & 37.2 & 36.2 & 26.4 & 16.4 \\
\hline $\mathrm{Na}_{2} \mathrm{O}$ & 7.6 & 18.3 & 4.8 & 8.0 & 15.1 & 24.4 \\
\hline $\mathrm{Fe}_{2} \mathrm{O}_{3}$ & 3.1 & 2.8 & 54.8 & 53.8 & 18.6 & 11.7 \\
\hline $\mathrm{SO}_{3}$ & - - - & $\ldots$ & & & 36.6 & 45.7 \\
\hline
\end{tabular}

The composition of the simulated $\mathrm{PW}-4 \mathrm{~m}$ being used in laboratory testing is given in Table 5.2 .

Indications are that $\mathrm{PW}-4 \mathrm{~m}$ can be processed by the phosphate glass process without great difficulty. Melts with $\mathrm{M}^{+} / \mathrm{P}$ ratios of 0.9 and 1.0 were smooth and easy to pour at $775{ }^{\circ} \mathrm{C}\left(\mathrm{M}^{+}\right.$included $1.5 \mathrm{M} \mathrm{Na}$ which was added to lower the viscosity and melting point).

The optimum combination of additive fluxing and modifying agents was sought for processing $\mathrm{PW}-4 \mathrm{~m}$ in the spray solidifier process. The goal was to find compositions which form calcines that are not "sticky" at $700{ }^{\circ} \mathrm{C}$ and, thus, will not build deposits on the walls of the spray calciner; yet which melt at approximately $900{ }^{\circ} \mathrm{C}$. Somewhat higher melting points can be accommodated in the spray solidifier process, but experience indicates that a melting point of $900{ }^{\circ} \mathrm{C}$ or below permits optimum operation. Nearly $100 \mathrm{PW}-4 \mathrm{~m}$ melts have been prepared. 
TABLE 5.2. Composition of PW-4m at $100 \mathrm{gar} / \mathrm{tonne}(\mathrm{a})$

\begin{tabular}{ll} 
Inert Chemicals & $\frac{\text { Molarity }}{0.05}$ \\
\hline $\mathrm{Fe}$ & 0.012 \\
$\mathrm{Cr}$ & 0.008 \\
$\mathrm{Ni}$ & 0.001 \\
$\mathrm{Al}$ & $0.322(\mathrm{~b})$ \\
$\mathrm{Na}$ & 0.010 \\
$\mathrm{U}$ & 6.50 \\
$\mathrm{NO}$ & 0.003 \\
$\mathrm{P}$ &
\end{tabular}

Fission Products

$\begin{array}{ll}\mathrm{Rb}(\mathrm{K}) & 0.0141 \\ \mathrm{Cs}(\mathrm{K}) & 0.0783 \\ \mathrm{Sr} & 0.0356 \\ \mathrm{Ba} & 0.0410 \\ \mathrm{RE} & 0.274 \\ \mathrm{Zr} & 0.143 \\ \mathrm{Mo} & 0.130 \\ \mathrm{Tc}(\mathrm{Mo}) & 0.031 \\ \mathrm{Ru}(\mathrm{Mn}) & 0.0816 \\ \mathrm{Rh}(\mathrm{CO}) & 0.0133 \\ \mathrm{Pd}(\mathrm{Ni}) & 0.0425 \\ \mathrm{Ag}(\mathrm{Cu}) & 0.0016 \\ \mathrm{Cd}(\mathrm{Cu}) & 0.0025 \\ \mathrm{Te}(\mathrm{SO}) & 0.0144\end{array}$

(a) Substitutions, as shown in parentheses, are being made for some of the fission product elements.

(b) Nominal Na is 0.10M. Excess is due to adaition of Mo as $\mathrm{Na}_{2} \mathrm{MOO}_{4}$.

Phosphorus, boron, and silicon--singly and in combination-were used as fluxing agents. Lithium, sodium, iron, aluminum, zinc, and molybdenum in various combinations were tested to modify the melt characteristics. 
The relatively high rare earth concentration (35 wt: as oxide) tends to raise the melting point and increase nonhomogeneity in PW-4m melts. To make phosphate-based PW-4m me1ts that could be processed in the spray solidifier, it was necessary to add sodium and iron until the final melt resembled $\mathrm{PW}-1$ spray solidifier product.

Investigation of some borosilicate melts was also started. Although further optimization is required, several $\mathrm{PW}-4 \mathrm{~m}$ borosilicate melts have been prepared which have "stick" temperatures above $700{ }^{\circ} \mathrm{C}$ and which melt in the range of 925 to $975{ }^{\circ} \mathrm{C}$. Corrosion from Fluoride Bearing Feed Solutions - R. F. Maness

A fluoride-bearing PW-2 solution (0.03M fluoride) was concentrated to a boiling point of $128^{\circ} \mathrm{C}$ and fed semicontinuously to a $304 \mathrm{~L}$ SS pot held at $700{ }^{\circ} \mathrm{C}$. The calcine produced was then fed semicontinuously to a $304 \mathrm{~L}$ melter pot held at $850^{\circ} \mathrm{C}$. The off-gas, during both operations, was pulled through a $304 \mathrm{~L}$ sintered stainless steel filter held at $300{ }^{\circ} \mathrm{C}$. The total exposure time was $33 \mathrm{hr}$. The filter evidenced a weight los of $0.5 \%$, but no attack was apparent from microscopic examination. Platinum specimens exposed to the melt and to the vapor phase during the melting operation were unattacked. The fluo* ride content of the condensate collected during the caicination operation was estimated to be $5 \times 10^{-3}$.

Platinum Melter Corrosion - R. F. Maness

The small electric furnace used to operate the spraycalciner melter-freeze valve has been subject to frequent failure. Burners operating on a propane-air mixture could be used to operate this valve; therefore, experiments were made to determine if platinum embrittlement occurred under these operating conditions. Aliquots of PW-2 melt were placed periodically on a section of $10 \mathrm{mil}$ thick platinum 
sheet heated to about $1000{ }^{\circ} \mathrm{C}$ with a torch burning a propaneair mixture. The specimen was allowed to cool to room temperature at $30 \mathrm{~min}$ intervals and was then flexed to determine ductility. After 36 cycles, the specimen was cleaned and examined microscopically. One area of the specimen appeared to contain surface cracks. However, examination of this area after sectioning, polishing, and etching revealed no cracking or other preferential attack. With a Meeker burner used rather than a torch, the experiment was continued on the remaining portion of the specimen. The specimen fractured after two additional cycles. An experiment similar to that described above was made by using, in addition to a propane-air burner, a reducing flame from a small torch burning propane with insufficient oxygen. The platinum specimen fractured after 10 cycles. Ruthenium Volatility Studies - D. W. Brown

The effect of hypophosphorous acid, $\mathrm{H}_{3} \mathrm{PO}_{2}$, on ruthenium volatility in the PW-1 spray solidification process was studied on a laboratory scale. Data indicate that 1M hypophosphorous acid lowers the ruthenium volatility to below the detectable limits of the analysis--in this case, less than $3 \%$ ruthenium. Development Spray Calciner Run DSC-18 - J. D. Moore

A spray solidification run (DSC-18) was made with the cold semiworks spray solidifier to fill a special test pot with simulated PW-2 me1t. The pot will be used for studies of gas evolution from storage pots with molten cores. The 12 in. diam unheated pot was filled uniformly with about 40 liters of melt by batch-dumping from the melter freeze valve and weir during a $29.5 \mathrm{hr}$ run.

The spray calciner, operating at $700^{\circ} \mathrm{C}$, was fed with simulated 137 gal/tonne high sulfate (PW-2) waste at an average rate of 11 iters/hr $(0.5$ tonne/day $)$. This rate reached the 
capacity of the melter operating at a furnace temperature of $925^{\circ} \mathrm{C}$. Air atomization of feed through an internal-mix nozzle produced a fine homogeneous powder feed to the melter. Operation of the system was satisfactory.

After the run, the calciner internal walls were coated with an apparently steady-state layer of powder between $1 / 8$ and $3 / 16$ in. thick, and the calciner filters were covered with a $1 / 16$ in. coating. The filter pressure drop increased gradually from $11 / 4$ to 5 in. of water with a filter blow-back pressure of $35 \mathrm{psig.} \mathrm{For} \mathrm{the} \mathrm{last} \mathrm{quarter} \mathrm{of} \mathrm{the} \mathrm{run,} \mathrm{the} \mathrm{blow-back}$ pressure was increased to $40 \mathrm{psig}$, and the filter pressure drop gradually decreased from 5 to $41 / 4$ in. of water at the end of the run, thereby providing reasonably good control of filter pressure drop. The particulate decontamination factor (DF) across the filters varied from a low of $150,2 \mathrm{hr}$ after the feed was on, to 2600 after $12 \mathrm{hr}$ when a steady-state coating of powder had formed on the clean filters. The DF remained at 2600 to the end of the run.

A new solids feeder was successfully tested for addition of sodium metaphospiate flux to the melter. The feeder consists of two $1-1 / 2$ in. ball valves spaced about 18 in. apart in a pipe connected to a diagonal nozzle in the calciner cone. hie valve handles are coupled together to an air-driven piston wich opens and closes the valves. Wnen one valve is open, the other is closed, thus maintaining a seal of the calciner at al1 times. Sodium metaphosphate chips are fed into the pipe from a vibrating auger feeder. Once every 5 min, a timer actuates the piston which simultaneously opens the bottom valve, closes the top valve, and dumps the accumulated chips into the melter. Total flux addition with this equiprent was within $2 \%$ of the desired amount. IJo solids plugging was encountered. 
Me1t was drained in 4 to 5 1iter batches at a batch rate of about 10 liters/hr without the formation of stalagmites in the product pot. When batch-dumping the melt through the melter freeze valve, foamy melt discharging from the freeze valve bridged across to the freeze valve furnace liner, plugged off the outlet, and burned out the furnace. The foamy melt was caused by evolution of oxides of sulfur when the melt temperature was raised excessively to $910{ }^{\circ} \mathrm{C}$ to drain through the freeze valve. The tip of the freeze valve was too cold to completely melt the plug so the tip was probed with a rod to start the melt flow. Subsequent batch dumping of melt through the weir also indicated that the weir tip was not adequately heated. Heating the weir tip with an oxyacetylene torch or manually rodding the weir tube initiated draining of the melter. Modifications to the freeze valve and weir tube assemblies will be made accordingly.

A11 of the ruthenium in the feed to the calciner was volatilized to the off-gas condensate.

$\underline{\text { Radioactive Demonstration }}$

Run SS-3 - J. L. McE1roy, W. R. Bond, M. R. Schwab, and $J . N$. Hartley

The fifteenth WSEP pilot plant demonstration of the solidification of high-level radioactive wastes was completed with the third spray solidification Run SS-3. During Run SS-3, 362 1iters of high-sulfate waste (at 590 1iters/tonne) containing $333,000 \mathrm{Ci}$ of radioactivity including $26,000 \mathrm{Ci}$ radioruthenium were fed to the spray solidifier in $35.6 \mathrm{hr}$ at an average rate of 10.1 iters/hr (Table 5.1 , page 5.3 for SS-3 data). A total of 40 liters of ceramic solid was produced with an internal heat generation rate of $40 \mathrm{~W} / 1$ iter corresponding to $38 \%$ of thermal maximum for the product. The total of $1600 \mathrm{~W}$ of fission product heat and the centerline-to-wall 
temperature difference of $81{ }^{\circ} \mathrm{C}$ gave an effective thermal conductivity of $1.28 \mathrm{~W} / \mathrm{m}{ }^{\circ} \mathrm{C}\left[0.74 \mathrm{Btu} /(\mathrm{hr})(\mathrm{ft})\left({ }^{\circ} \mathrm{F}\right)\right]$ for the ceramic product.

An internal-mix spray nozzle was used to spray the PW-2 type feed [additives of $1.61 \mathrm{M} \mathrm{H}_{3} \mathrm{PO}_{4}, 1.17 \mathrm{LiOH}, 0.6 \mathrm{M} \mathrm{Ca}\left(\mathrm{NO}_{3}\right)_{2}$, $0.25 \mathrm{~A} 1\left(\mathrm{NO}_{3}\right)_{3}$ at 378 liter/tonne] into the solidifier. Feed atomization with unheated air prevented nozzle plugging as in the previous run, SS-2. In addition to the feed additives, solid sodium hexametaphosphate was added to the melter batchwise to maintain an additive composition of $1.27 \underline{\mathrm{M}} \mathrm{NaPO}_{3}$ at 378 liter/tonne feed concentration, to reduce the melting point to $\sim 700{ }^{\circ} \mathrm{C}$. A gravity flow, mechanically vibrated solids feeder was used to add the solid flux (sodium metaphosphate). A heated air,purge line was added to the solids feeder during the run to minimize condensation of solidifier vapors and subsequent plugging in the solids feed line where it enters the cone of the calciner.

Run SS-3 was plagued by equipment failures, and after several attempts to maintain a continuous operation, the run was terminated due to equipment failures. Early in the run before the feed was started to the solidifier, the freeze valve and weir heaters failed, the feed tank agitator failed, and the feed pump began leaking, in that order. Without adequate feed agitation, the heavy solids in the feed would have settled, thus the run was shut down until the agitator and feed pump were repaired. The run was started without the weir and freeze valve heaters by using a propane torch on the freeze valve to batch drain the product from the melter to the pot receiver. After about $8 \mathrm{hr}$ of feeding, the melter solids addition line plugged at the calciner and the run was shut down. 
Because of a potential for embrittlement in the platinum freeze valve in the presence of a propane flame, the original 12 in. diam pot receiver was replaced with an 8 in. pot, thus shortening the run and requiring only half the original product planned.

During the second part of Run SS-3 (second pot receiver), the feed was shut off intermittently (after 1 to $8 \mathrm{hr}$ of operation) to periodically flush out plugs of entrained calcine in the vent and drain lines from the solidifier condenser (E-111) with nitric acid. Significant quantities of solids in the offgases ( $11 \%$ of the total calcine produced) indicated a failed soliafifier off-gas filter. Failure of one of the $316 \mathrm{~L}$ sintered stainless steel filters has since been visually verified, and investigations to determine the cause of failure are presently underway. Another shutdown was necessary to repair the solidifier vibrator (used to maintain the heated walls of the calcine free from calcine deposition). The run was terminated after about $32 \mathrm{hr}$ of total feed-on time (including about $8 \mathrm{hr}$ with the first pot receiver) when the solidifier off-gas line plugged at the inlet to the solidifier condenser and could not be cleared while "on-1ine."

Approximately, $87 \%$ of the ruthenium in the feed to the solidifier was volatilized. As yet, no quantitative data are available on sulfate losses from the melt. However, on two occasions when the melt temperature exceeded $890{ }^{\circ} \mathrm{C}$, sulfate fumes were observed evolving from the melt as it drained from the melter into the receiver pot.

ADVANCED SOLIDIFICATION TECHNIQUES

Feasibility of Vacuum Batch Transfer of Melts from Simulated Purex-Type Waste - J. N. Hartley

This investigation is being made to provide information for assessing the feasibility of a promising new concept of a 
batch melting solidifier for treating high level radioactive waste. The batch solidifier consists of an evaporator chamber above a batch melter as an integral unit. The waste is concentrated and melted batch-wise, then transferred to the final storage container. Vacuum batch transfer of melt through a heated tube to a final receiving vessel was tested.

Three successful transfers were made by using phosphate glass melts of simulated wastes. A fourth transfer was started by using a sulfate containing ceramic melt from the spray solidifier but due to an equipment failure, was discontinued.

The major features of the vacuum transfer equipment are shown in Figure 5.1. Glass or ceramic is melted by an induction furnace. The molten glass or ceramic is then transferred through a heated tube to a final mild steel receiving pot.

Run VT-1

The first transfer was made by using a sulfate-free (PW-1) phosphate glass melt. A foamup of melt in the receiving pot after transferring $30 \mathrm{~kg}$ of melt caused the transfer to be stopped. The cause of the foamup was an excessive vacuum (29 in. mercury) in the receiving pot. The 13.3 liters of glass product was transferred to the mild steel receiving vessel in $0.65 \mathrm{~min}$ at an average rate of 20.41 iters/min.

The transfer tube was heated to $850{ }^{\circ} \mathrm{C}$ before the transfer was started, and the melt was held at $900^{\circ} \mathrm{C}$. After the trans fer, the unheated receiving pot-wall temperature had increased to $350^{\circ} \mathrm{C}$.

\section{Run VT - 2}

The second vacuum transfer was successfully completed by transferring $44 \mathrm{~kg}$ of $\mathrm{PW}-1$ phosphate glass melt. Thirty liters of glass were transferred in 2.4 min at an average rate of 


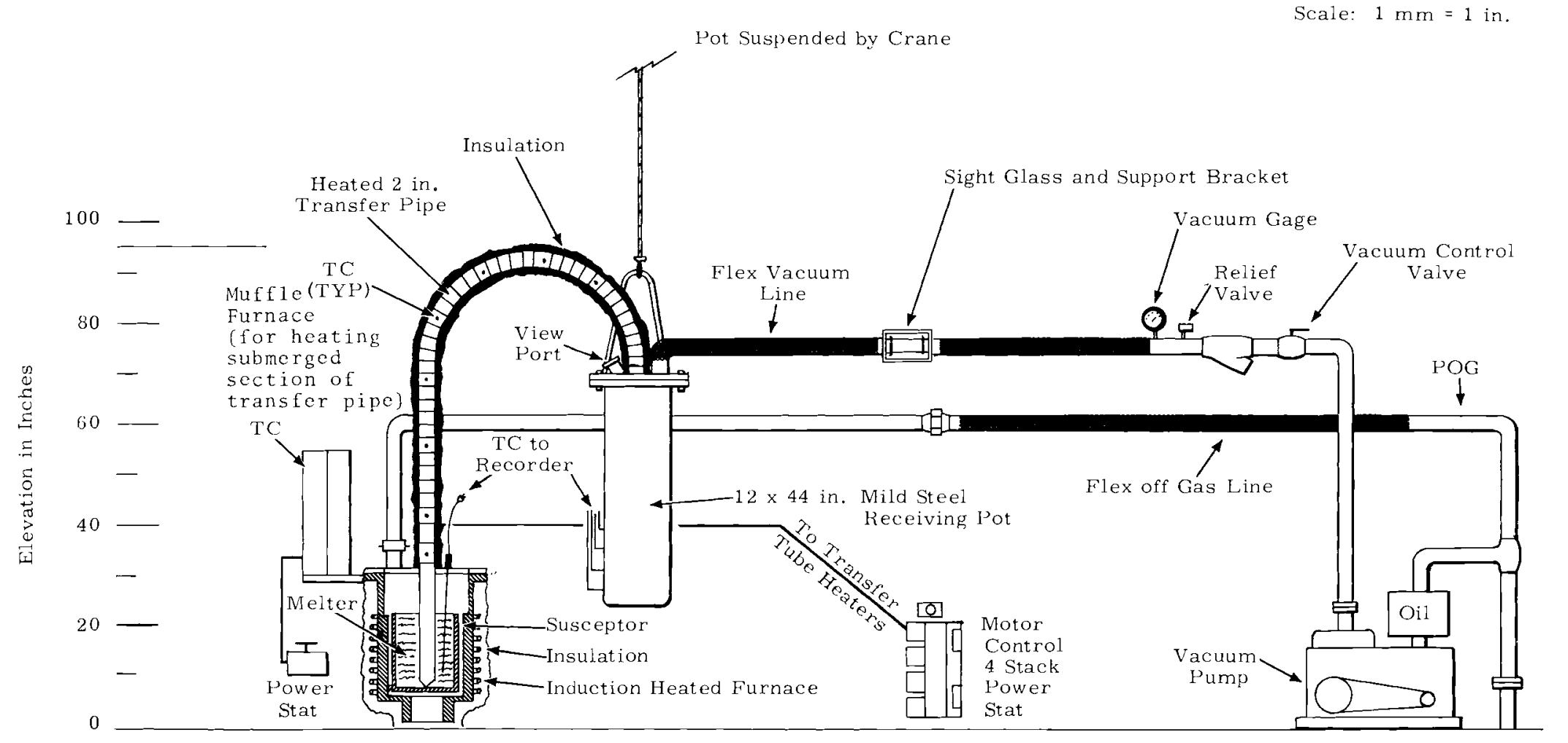

FIGURE 5.1. Vacuum Transfer Equipment Arrangement 
12.5 1iters/min. Fifteen inches of mercury vacuum were used instead of the 29 in. used in the previous run. No transfer problems occurred with the transfer tube heated to $1000{ }^{\circ} \mathrm{C}$, although this was $150{ }^{\circ} \mathrm{C}$ above operating conditions and resulted in a weakening of the $304 \mathrm{~L}$ transfer tube. The me1t was at $935^{\circ} \mathrm{C}$ before the transfer started; after the transfer was complete, the receiving pot wall temperature had increased to $445{ }^{\circ} \mathrm{C}$.

\section{Run VT - 3}

The third transfer was successfully completed by using a phosphate glass melt from a sulfate containing (PW-2) feed. During the transfer, $30 \mathrm{~kg}$ of melt were transferred to a mild steel receiving pot. The 13 liters of glass was transferred in 1.2 min at an average rate of 10.8 liters/min. The transfer rate was about $1 / 2$ the rate in previous transfers because of a heater failure on the tip of the transfer tube where the average temperature was on 1 y $200{ }^{\circ} \mathrm{C}$ as compared to $\sim 850{ }^{\circ} \mathrm{C}$ for the rest of the tube. This caused some buildup of glass in the pipe, but no other problems occurred. The melt was at $925^{\circ} \mathrm{C}$ when the transfer started, with the vacuum at 15 in. of mercury.

Run VT-4

The fourth transfer was started by using a sulfatecontaining ceramic melt from the spray solidifier, but was discontinued due to equipment failure. More experimental work is planned with this type of melt.

DEVELOPMENT STUDIES ON SOLIDIFICATION PROCESSES

Computer Simulation - C. R. Cole, P. C. Owzarski, and J. L. McElroy

The initial simulation of the WSEP off-gas train and pot calciner has been completed. The various elements included in the simulation are illustrated in Figure 5.2. The present 


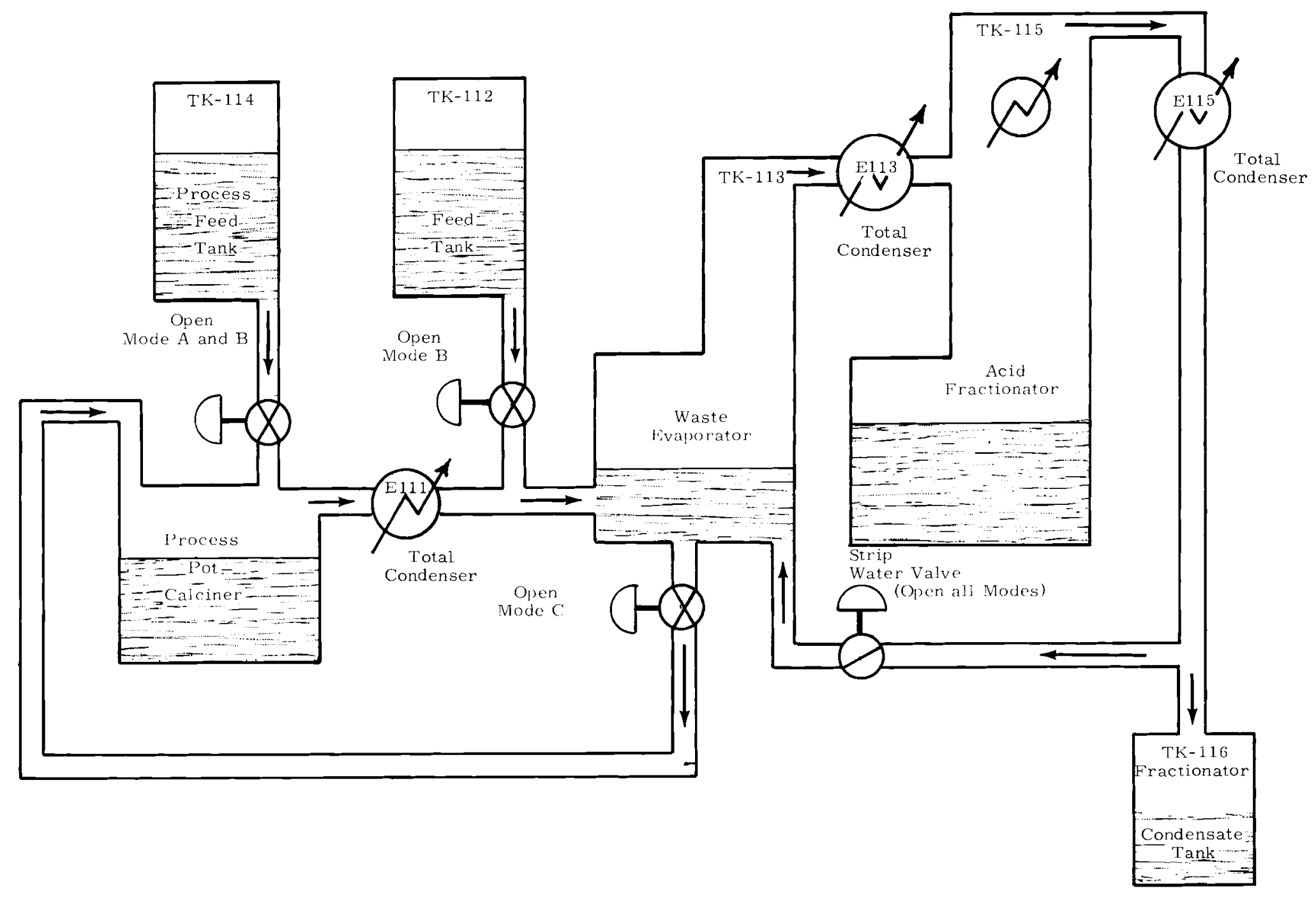

in
i

FIGURE 5.2. Units of the WSEP System which Are Included in the Present Computer Simulation Model 
simulation of the WSEP Plant is capable of any of the three modes of operation (A, B, or C). The present WSEP simulation can be preprogrammed to operate in any desired manner or it can be operated manually as the actual plant might be. The model is now ready to be used to predict the results of any method of operation of the pot calciner.

Heat and material balances are performed in each of the units simulated. Nitric acid separation, where it occurs, is computed from water-nitric acid equilibrium data and enthalpy data on liquid and vapor mixtures of water-nitric acid. Solids entrainment in the units, where it occurs, is assumed to be proportional to a power function of vaporization rate out of that unit and to the solids concentration in that unit. Ruthenium volatility is computed as a power function of the nitric acid concentration in the liquid and is proportional to the ruthenium concentration of the liquid.

The water-nitric acid separation characteristics of the model were verified by comparisons with data from a nonradioactive WSEP run where acid feed of known concentration was fed to the evaporator, and the separation characteristics of the evaporator and fractionator were recorded. Figure 5.3 shows the comparison between the model and the actual WSEP data for this run.

Data from WSEP Run PC-2 were used to adjust the parameters of the model in order to match the observed data on solids entrainment and ruthenium volatility. Figure 5.4 shows a comparison between the actual WSEP data on solids entrainment and ruthenium volatility for Run $\mathrm{PC}-2$ and the simulation's match of this data. 


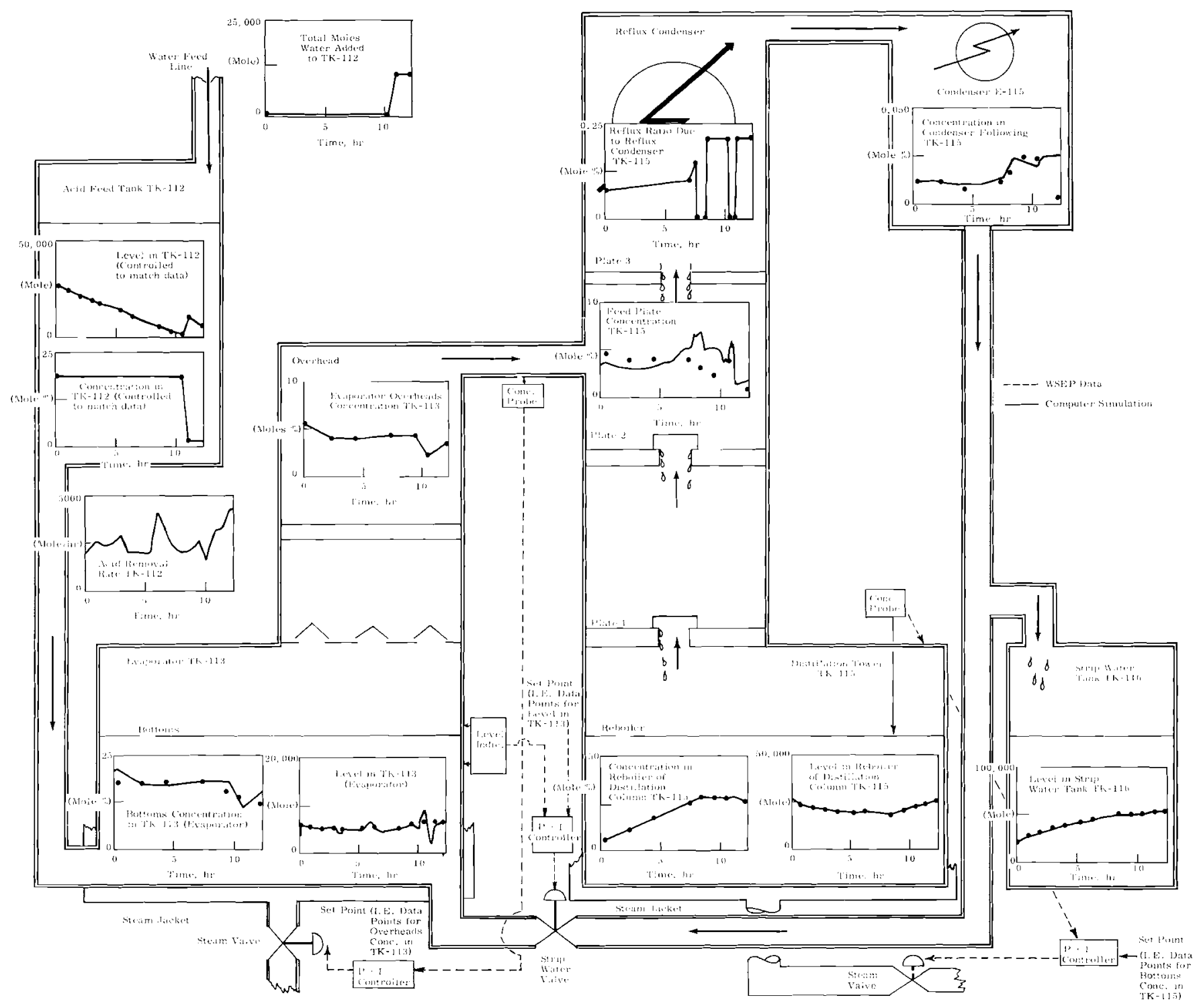

$\underset{\infty}{\stackrel{0}{\infty}}$

0
$Z$
1
1
0
0
0

EIGURE 5.3. Comparison Between the Computer Acid Run Simulation and Actual wSEP Data 
Level of Ruthenium Activity in the Calciner Pot, $\mathrm{Ci}$
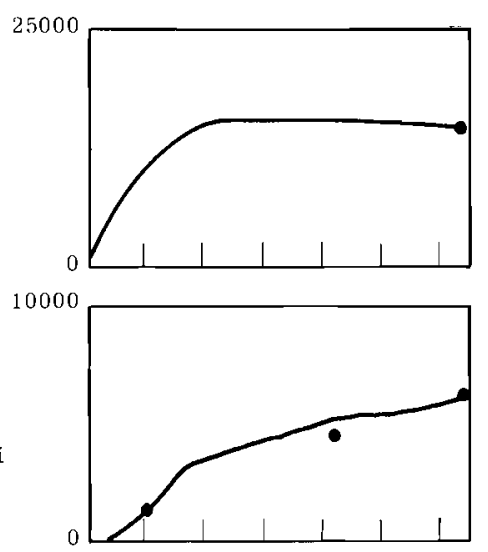

Amount of Ruthenium Activity Volatilized from Calciner Pot, Ci

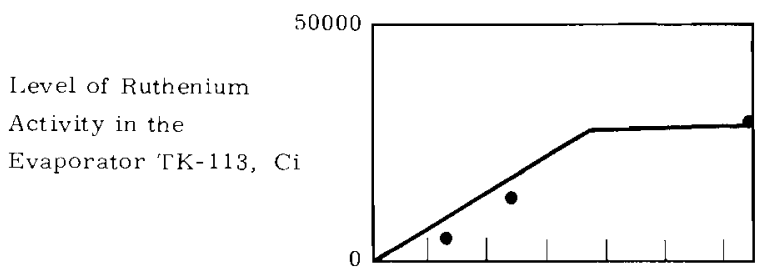

Level of Ruthenium Activity in the Reboiler ' $Г K-115$, Ci

Amount of Ruthenium Activity Volatilized from the Fractionator TK-115, Ci
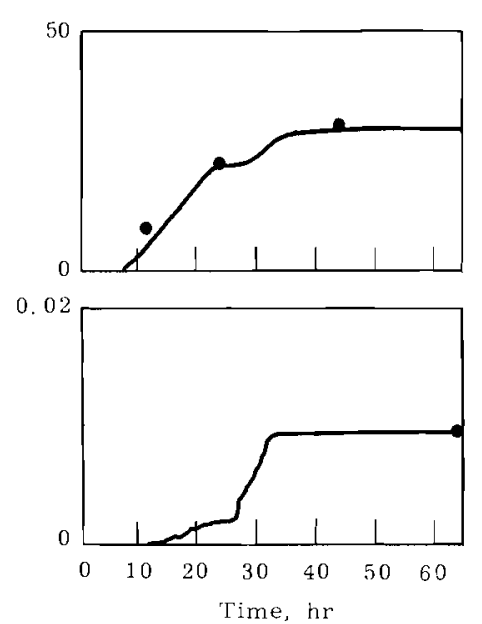
RU'THENIUM
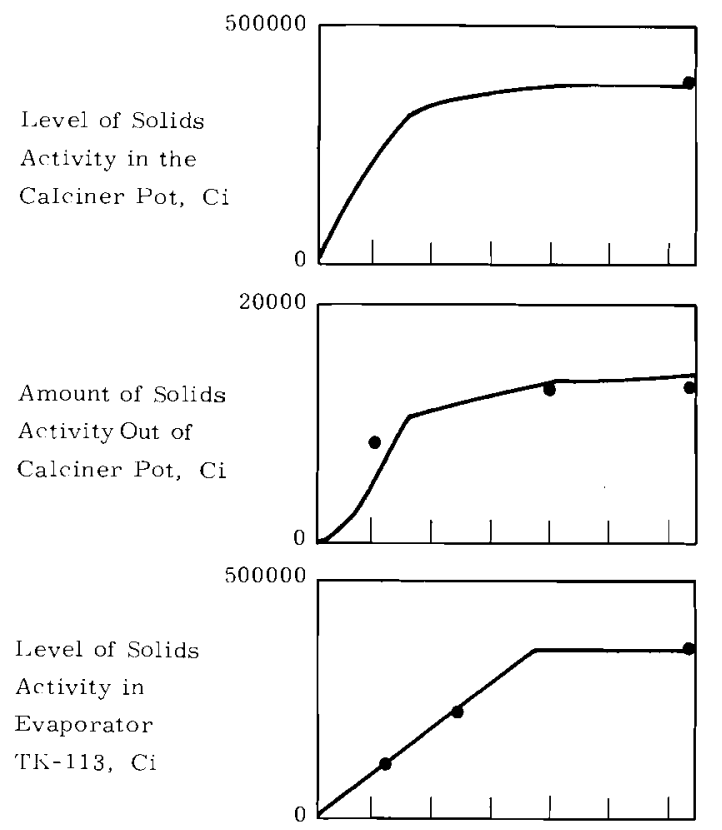

Level of Solids Activity in Reboiler 'T'K-115, Ci

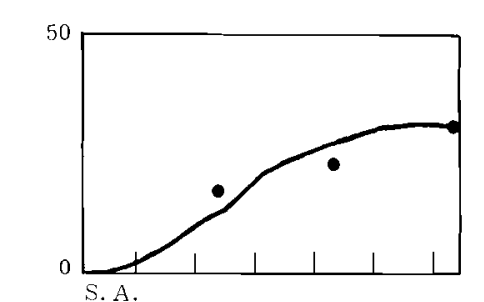

Amount of Solids Activity I eaving the

Fractionator, $\mathrm{Ci}$

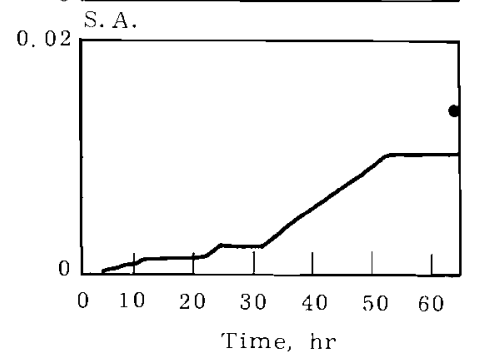

RADIOAC'TIVE SOLIDS

FIGURE 5.4. Comparison Between Actual WSEP Data for Run PC-2 for Solids and Ruthenium Radioactivity Levels and the Levels Computed by the Moder. 


\section{HEAT TRANSFER STUDIES}

Pot Furnace Cooling Capacities - J. D. Kaser

To assist in planning future WSEP runs at higher levels of radioactivity, the steady-state cooling capacities of the induction heated (5A) pot furnace, and the resistance heated (6A) pot furnace were calculated as functions of pot wall temperature. One of these two furnaces contains the 8 -ft-long productreceiving pots during waste solidification in WSEP.

Heat balances between the pot wall and the various surfaces within the furnaces were made by assuming a uniform temperature at each surface and neglecting the heat losses at the top and bottom of the furnaces. Accounting for the effect of two cooling air streams in the furnace (indirect air blasting at the outside of the susceptor wall and direct forced air within the susceptor) resulted in a system of independent nonlinear equations solved by an iterative technique and programmed for the computer.

The results of these calculations are plotted in Figures 5.5 and 5.6. Curves showing calculated wall temperatures for pots hanging in air are included for convenient comparison. Table 5.3 compares relevant WSEP run data with calculated temperatures read from Figure 5.5. When the uncertainties are considered in temperature and heat generation rate measurements and in the values of the heat transfer coefficients used in the calculations, the table shows fair agreement between calculated and observed values. The centerline temperatures were estimated from the calculated pot wall temperatures by using a thermal conductivity value of $0.43 \mathrm{Btu} /(\mathrm{ft})(\mathrm{hr})\left({ }^{\circ} \mathrm{F}\right)$ obtained from preliminary phos phate-glass process run data.

Corrosion experience to date indicates that a stainless steel pot wall probably should not exceed approximately $850{ }^{\circ} \mathrm{C}$ during processing and that a carbon steel pot should not exceed 


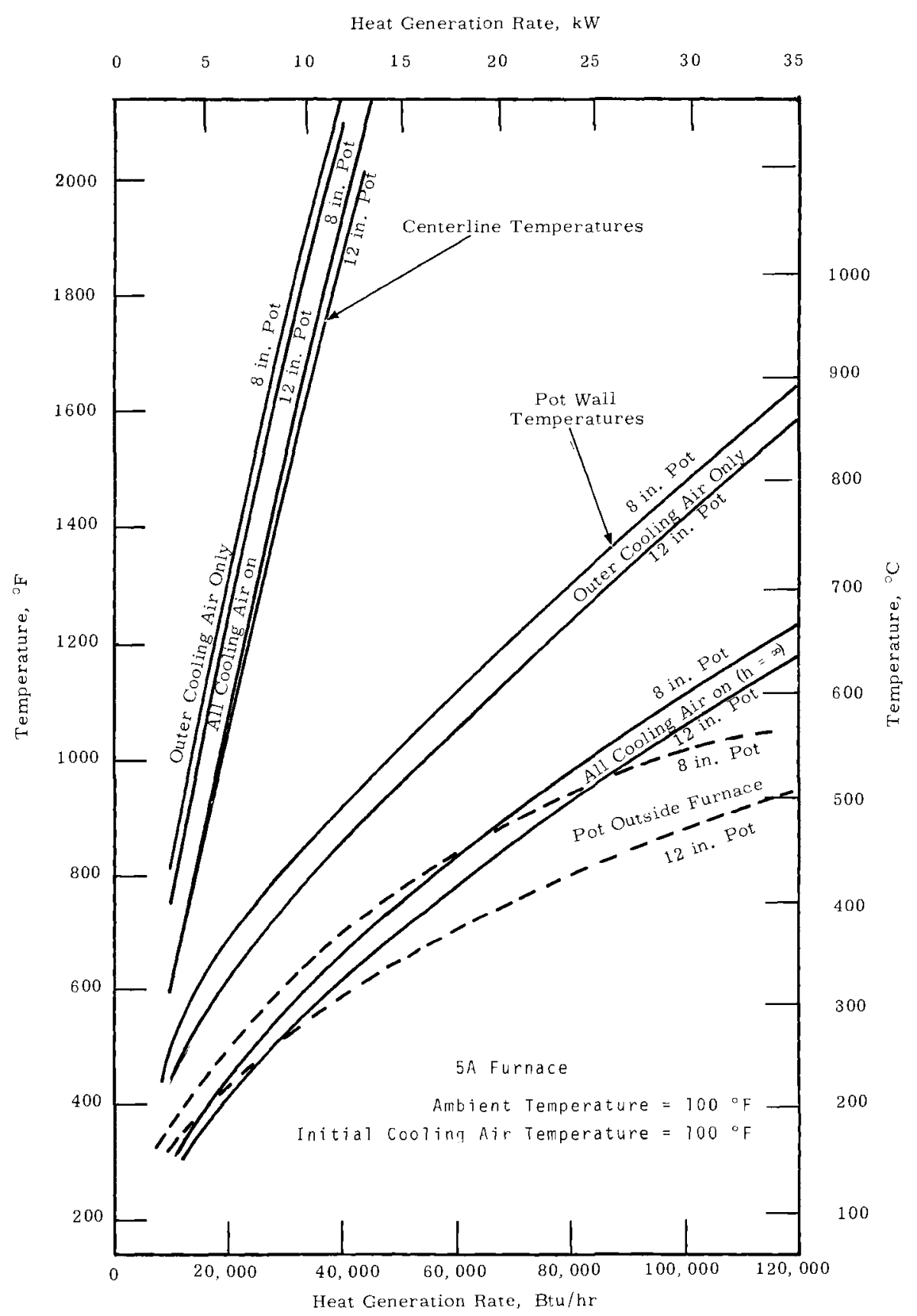

FIGURE 5.5. Steady-State Pot Temperatures During cooling in the WSEP 5 A Furnace 


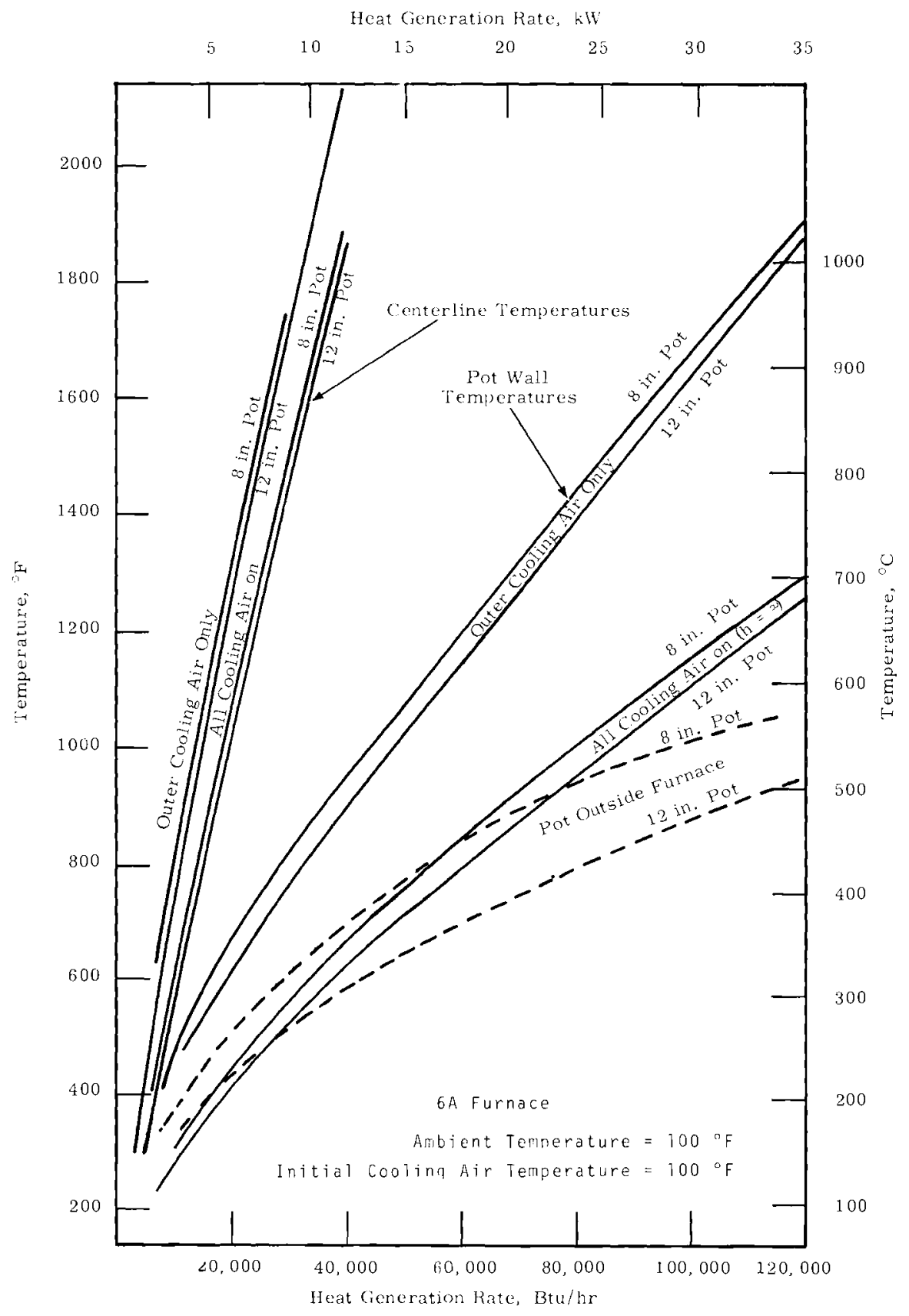

FIGURE 5.6. Steady-State Pot Temperatures During Cooling in the WSEP 6 A Furnace 


\section{TABIE 5.3. Comparison of Measured and Caleulated Pot Temperatures}

WSEP

\begin{tabular}{|c|c|c|c|}
\hline Run & Heat Gen. & Wall Tem & ture \\
\hline No. & Rate, $\mathrm{kW}$ & Observed & Calculated \\
\hline$P C-4$ & 2.6 & 165 & 160 \\
\hline$P C-5$ & 4.3 & 230 & 240 \\
\hline$P C-6$ & 5.1 & 240 & 250 \\
\hline$P G-5$ & 8.8 & 345 & 400 \\
\hline
\end{tabular}

$P G-6$

8.1

420

420

Cooling Condition

Hanging in air outside furnace

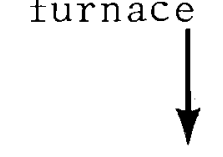

In furnace. Outer cooling air on $1 y$

$700^{\circ} \mathrm{C}$. In these cases, the calculations indicate that heat generation limits for a stainless pot is $33 \mathrm{~kW}$ in $5 \mathrm{~A}$ furnace and about $28 \mathrm{~kW}$ in $6 \mathrm{~A}$ furnace. The corresponding 1 imits for a mild steel pot would be 25 and $20 \mathrm{~kW}$. The highest potential heat generation rate now planned for WSEP is $25 \mathrm{~kW}$, using a stainless steel pot in $5 \mathrm{~A}$ furnace which is within these calculated furnace limits. Since the melting points of the fusible solid wastes range between 700 and $850^{\circ} \mathrm{C}$, the pot cores will remain molten during both furnace cooling and air storage at heat generation rates exceeding 5 to $10 \mathrm{~kW}$.

WASTE FROM CHEMICAL PROCESSING

Waste from Fast Reactor Fuels - E, A. Coppinger

The radioactive waste resulting from chemical processing of fast reactor fuels will be different than wastes from processing of thermal reactor fuels. The higher fuel exposure and specific power in fast reactors will result in much higher fission product contents and heat generation rates in the waste. The fission product spectrum and amounts of neptunium and transplutonium isotopes will also be different in the waste because of the different irradiation conditions, higher Pu/U ratio in 
the fuel, and higher neutron energy in a fast reactor. The reprocessing scheme for fast reactor fuels may also result in differences in the chemical composition of the waste. A very short study was undertaken to provide a limited assessment of the possible aqueous waste resulting from processing of fast reactor fuels.

Approximate heat generation rates, fission product concentrations, and changes in fission product spectrum in fast reactor fuel have been determined and are compiled in Tables 4 through 7. The amounts of neptunium and transplutonium isotopes in a conceptual fast reactor design, obtained from avail. able calculations, are also listed.

Conceptual designs usually divide the fast reactor into three major zones, i.e., the core, axial blanket, and radial blanket. The axial blanket fuel and core fuel are in the same fuel pin in several design concepts. In such cases, the irradiated fuel from the core and axial blanket will be processed together and the waste will contain a blend of radioisotopes and stable fission products from these two fuels. Since the burnup of the axial blanket is typically less than 10,000 MWd/ tonne, the waste from the blended fuel will be fairly similar to the waste from thermal reactor fuel in terms of total fission product content and heat generation rates.

The relative amounts of ${ }^{106} \mathrm{Ru}$ and the potential byproducts, palladium and rhodium, will be significantly increased in wastes from processing of fast reactor fuel. The relative amount of ${ }^{90} \mathrm{Sr}$ will be decreased. The relative amounts of cadmium, tin, antimony, and tellurium will be increased although the total amount of each will still be small. Some of these latter fission products, notably antimony and tellurium tend, like ruthenium to be volatile at high temperatures and could complicate waste solidification processes. 
TABLE 5.4. Approximate Fission product Content in Irradiated Fuel(a)

\begin{tabular}{|c|c|c|}
\hline Element & Fast Reactor Core Fuel (b) & PWR Fue ${ }^{(\mathrm{C})}$ \\
\hline $\mathrm{Se}$ & 166 & 46 \\
\hline $\mathrm{Rb}$ & 609 & 318 \\
\hline $\mathrm{Sr}$ & 1,310 & 837 \\
\hline$Y$ & 677 & 432 \\
\hline $\mathrm{Zr}$ & 7,584 & 3418 \\
\hline $\mathrm{Nb}$ & 60 & 8.8 \\
\hline Mo & 8,800 & 3228 \\
\hline Tc & 2,384 & 789 \\
\hline $\mathrm{Ru}$ & 8,535 & 2068 \\
\hline $\mathrm{Rh}$ & 2,490 & 400 \\
\hline $\mathrm{Pd}$ & 6,660 & 970 \\
\hline $\mathrm{Ag}$ & 756 & 44 \\
\hline $\mathrm{Cd}$ & 440 & 52 \\
\hline In & 42 & 1.6 \\
\hline $\mathrm{Sn}$ & 436 & 48 \\
\hline $\mathrm{Sb}$ & 160 & 15 \\
\hline $\mathrm{Te}$ & 1,666 & 446 \\
\hline Cs & 10,830 & 2567 \\
\hline $\mathrm{Ba}$ & 3,540 & 1350 \\
\hline $\mathrm{La}$ & 3,058 & 1160 \\
\hline $\mathrm{Ce}$ & 7,110 & 2408 \\
\hline $\mathrm{Pr}$ & 3,125 & 1072 \\
\hline $\mathrm{Nd}$ & 10,168 & 3638 \\
\hline $\mathrm{Pm}$ & 1,015 & 124 \\
\hline Sm & 2,470 & 686 \\
\hline $\mathrm{Eu}$ & 407 & 157 \\
\hline $\mathrm{Gd}$ & 323 & 64 \\
\hline $\mathrm{Tb}$ & 30 & 1.4 \\
\hline Dy & 20 & 0.46 \\
\hline
\end{tabular}

(a) Does not include gases or elements present in quantities less than $10 \mathrm{~g} /$ tonne

(b) 100,000 MWd/tonne at $200 \mathrm{MW} /$ tonne, 180 day cooling

(c) 30,000 MWd/tonne at $32.5 \mathrm{MW} /$ tonne, 180 day cooling 
TABLE 5.5. Approximate Amounts of Various Fission

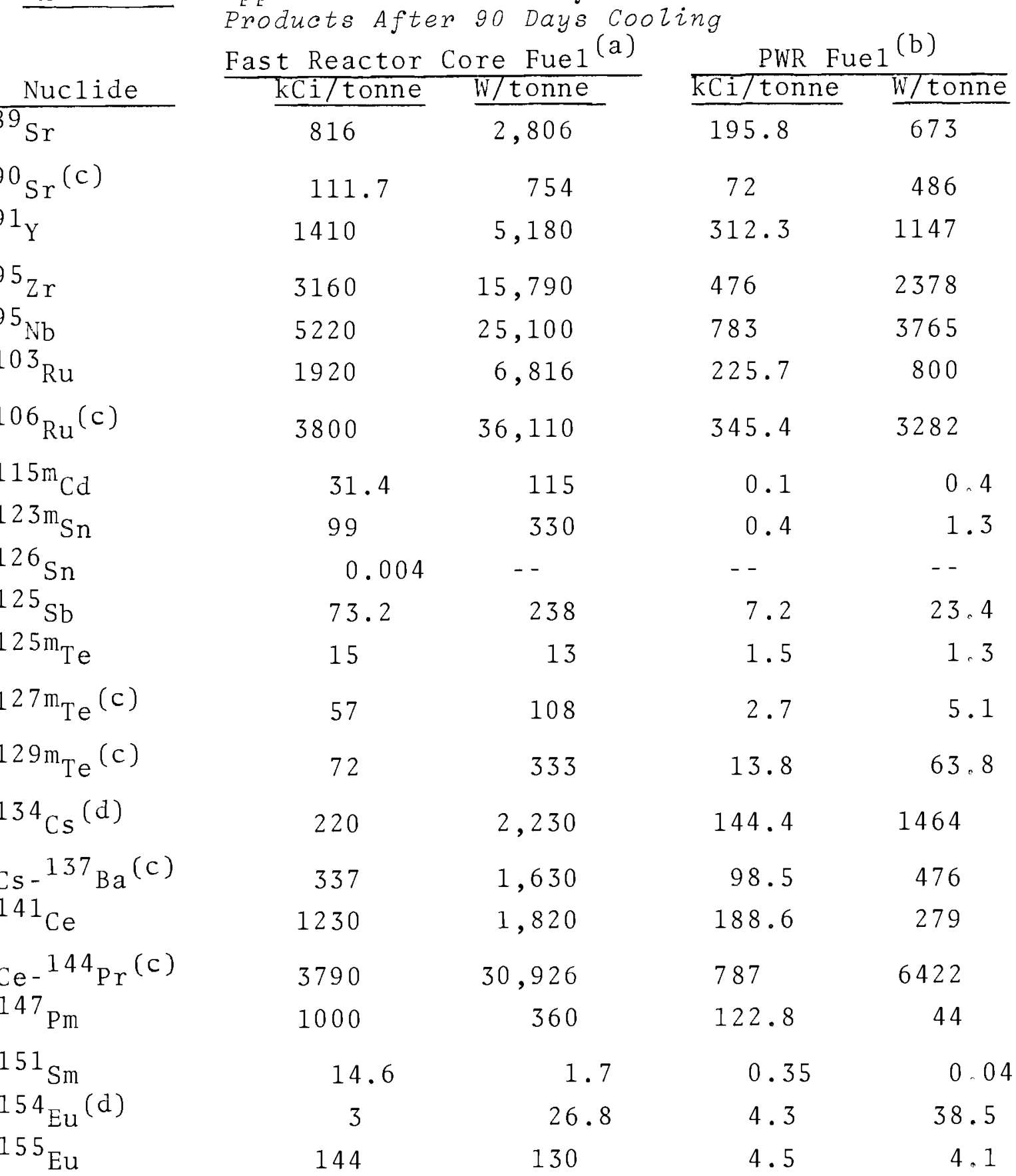

(a) 100,000 MWd/tonne at $200 \mathrm{MW} /$ tonne

(b) 30,000 MWd/tonne at $32.5 \mathrm{MW} /$ tonne

(c) Watts include short-lived daughter

(d) Not fission products. Produced from neutron capture by
$133 \mathrm{Cs}$ and 153 Eu. 
TABLE 5.6. Approximate Amounts of Various Fission Products After 180 Days Cooling

\begin{tabular}{|c|c|c|c|c|}
\hline & Fast Reactor & Core Fuel(a) & PivR Fu & (b) \\
\hline Nuclide & $\mathrm{kCi} /$ tonne & W/tonne & $\mathrm{kCi} /$ tonne & W/tonne \\
\hline $89 \mathrm{Sr}$ & 237 & 815 & 56.8 & 195 \\
\hline $90 \mathrm{Sr}^{(\mathrm{c})}$ & 111 & 749 & 71.6 & 483 \\
\hline $91_{Y}$ & 490 & 1,800 & 108.4 & 398 \\
\hline $95_{\mathrm{Zr}}$ & 1210 & 6,046 & 182.3 & 911 \\
\hline $95_{\mathrm{Nb}}$ & 2346 & 11,280 & 353 & 1697 \\
\hline $103_{\mathrm{Ru}}$ & 404 & 1,434 & 47.5 & 168 \\
\hline${ }^{106} 6_{\mathrm{Ru}}(\mathrm{c})$ & 3200 & 30,400 & 291.2 & 2767 \\
\hline $115 \mathrm{~m}_{\mathrm{Cd}}$ & 7.3 & 27 & 0.02 & 0.07 \\
\hline $123 \mathrm{~m}_{\mathrm{Sn}}$ & 61 & 203 & 0.26 & 0.86 \\
\hline $126 \mathrm{Sn}$ & 0.004 & - & - & - \\
\hline $125 \mathrm{Sb}$ & 68.7 & 223 & 6.8 & 22 \\
\hline $125 \mathrm{~m}_{\mathrm{Te}}$ & 14.9 & 13 & 1.5 & 1.3 \\
\hline $127 \mathrm{~m}_{\mathrm{Te}} \mathrm{c}^{(\mathrm{c})}$ & 31.6 & 60 & 1.5 & 2.9 \\
\hline $129 \mathrm{~m}_{\mathrm{Te}}(\mathrm{c})$ & 11.4 & 53 & 2.1 & 9.5 \\
\hline $134 \mathrm{Cs}(\mathrm{d})$ & 200 & 2,027 & 133.2 & 1350 \\
\hline $\mathrm{Cs}-137 \mathrm{Ba}(\mathrm{c})$ & 335 & 1,620 & 97.9 & 473 \\
\hline${ }^{141} \mathrm{Ce}$ & 180 & 266 & 27.6 & 41 \\
\hline $\mathrm{Ce}-{ }^{144} \operatorname{Pr}(\mathrm{c})$ & 3050 & 24,888 & 632.4 & 5160 \\
\hline${ }^{147} \mathrm{Pm}$ & 950 & 342 & 115 & 41 \\
\hline $151_{\mathrm{Sm}}$ & 14.6 & 1.7 & 0.35 & 0.04 \\
\hline${ }^{154_{\mathrm{Eu}}}(\mathrm{d})$ & 3 & 26.8 & 4.3 & 38.5 \\
\hline $155_{\mathrm{Eu}}$ & 131 & 118 & 4.1 & 3.7 \\
\hline
\end{tabular}

(a) 100,000 MWd/tonne at $200 \mathrm{MW} /$ tonne

(b) 30,000 MWd/tonne at 32.5 MW/tonne

(c) Watts include short-lived daughter

(d) Not fission products. Produced from neutron capture by $133 \mathrm{Cs}$ and $153 \mathrm{Eu}$. 
TABLE 5.7. Neptunium and Transplutonium Isotope Content in Fast Reactor Core Fuel(a)

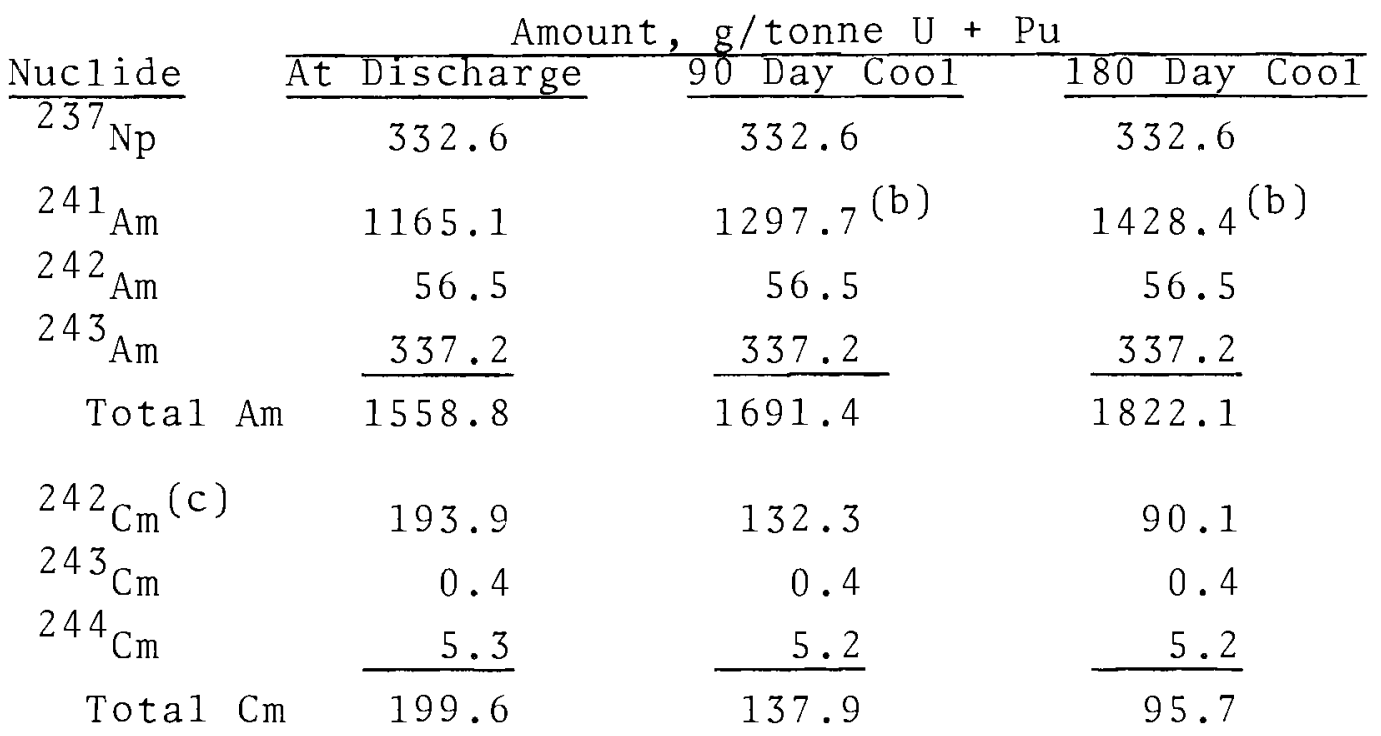

(a) Based on equilibrium core exposure of $110,000 \mathrm{MWd} / \mathrm{tonne}$ at a specific power of $56.5 \mathrm{MW} /$ tonne

(b) The increase in ${ }^{241} \mathrm{Am}$ after discharge results from beta decay of 241 Pu. When plutonium is removed by processing before cooling for 90 or 180 days, the increase in $241 \mathrm{Am}$ content in process solutions stops.

(c) Any ${ }^{242} \mathrm{Cm}$ left in the waste stream after processing decays to $238 \mathrm{Pu}$.

The chemical composition of the waste is difficult to specify quantitatively because of uncertainties concerning fuel composition and the fuel processing scheme. On the basis of a Purex-type process, the aqueous waste could range from relatively "clean" solutions of fission products to solutions containing moderate to high concentrations of sodium, iron, and sulfate. The waste generated during processing of carbide fuels is a possible exception. If carbide fuels are dissolved directly in acid, the waste could contain soluble organic compounds that could complicate waste solidification processes. 


\section{LOW-LEVEL WASTE TREATMENT}

Distillation Demonstration Unit (DDU) - S. J. Dougherty

Assembly of the DDU has been essentially completed, and tests of the apparatus have been conducted to determine any necessary equipment modifications or additions. These tests have been conducted with boiling water at 20 and $50 \mathrm{~mm} \mathrm{Hg}$ pressure and with a boiling acid mixture at $50 \mathrm{~mm} \mathrm{Hg}$. The approximate analysis of the acid mixture was

$$
\begin{aligned}
\mathrm{HNO}_{3}: & 1.0 \underline{\mathrm{M}} \\
\mathrm{H}_{2} \mathrm{SO}_{4}: & 0.5 \underline{\mathrm{M}} \\
\mathrm{H}_{3} \mathrm{PO}_{4}: & 0.19 \underline{\mathrm{M}}
\end{aligned}
$$

The results of these runs have clearly indicated the capabilities of the equipment. The results show that:

- The differential pressure (D/P) cells are an entirely unsatisfactory method for liquid-level measurement at the operating pressures of 10 to $100 \mathrm{~mm} \mathrm{Hg}$.

- Better contact is required between the heaters and evaporator tank.

- When $D / P$ cell and heater modifications are made, the equipment will perform very well.

Although $D / P$ cells are generally considered to be a satisfactory system for liquid-level measurement at atmospheric pressure, they are unsuitable for use in partially evacuated systems, primarily because of the admission of excessive air to the evacuated system. Because of the unsuitability of the $\mathrm{D} / \mathrm{P}$ cells in measuring liquid levels, alternate methods of liquid level measurement will be used.

The poor heat transfer between the heaters and evaporator tank will be solved by placing a heat-conducting substance between the heaters and tank. 


\section{EVALUATION OF SOLIDIFIED WASTE PRODUCTS}

\section{Nonradioactive Lab Studies}

Study of Thermal History of Melts - D. W. Brown

Sixteen phosphate-glass melts were prepared from a solution of PW-2 waste such that each melt had a different thermal history. Characterization tests have been run on these melts, and Table 5.8 summarizes the results. The greatest factor affecting the properties of the melt was the storage temperature. Samples stored at $600^{\circ} \mathrm{C}$ were much more leachable than those stored at $100^{\circ} \mathrm{C}$. Porosity correlates very well to solubility within a storage temperature bracket.

\begin{tabular}{|c|c|c|c|c|c|c|c|c|c|}
\hline $\begin{array}{l}\text { Beaker } \\
\text { No. } \\
\end{array}$ & $\mathrm{M}_{{ }_{0}{ }_{\mathrm{C}}}{ }^{(a)}$ & $\frac{\mathrm{T} \cdot \mathrm{A} \cdot \mathrm{M} \cdot \mathrm{T} ., \text { (b) }^{(\mathrm{r})}}{}$ & $\begin{array}{c}B L E \text { 5.8. Sr } \\
\text { C.R., (c) } \\
\text { degrees/hr }\end{array}$ & $\begin{array}{l}\text { nmary of } \\
\text { S.T. }{ }^{\text {(d) }}{ }^{\text {(d) }} \\
\end{array}$ & hermal History on Me & $\begin{array}{l}\text { Es anc } \\
\text { Drip } \\
\text { Pt. } \\
{ }^{\circ} \mathrm{C} \\
\end{array}$ & $\begin{array}{l}\text { Data } \\
72 \text { hr } \\
\text { Leachability } \\
\text { Loss, } \frac{q}{5} \\
\end{array}$ & $\begin{array}{l}\text { Densit } y \\
\mathrm{~g} / \mathrm{cm}^{3} \\
\end{array}$ & $\begin{array}{c}\text { Porosity } \\
\text { of Sample, } \\
\\
\end{array}$ \\
\hline 2 & 1200 & 1 & 100 & 600 & dull very few holes & 855 & 41.4 & 2.843 & 1.3 \\
\hline 3 & 1200 & 25 & 100 & 600 & dull very few holes & 865 & 35.3 & 2.874 & 2.06 \\
\hline 10 & 1200 & 1 & 30 & 600 & glossy no holes & 872 & 1.9 & 2.882 & 0 \\
\hline 15 & 1200 & 25 & 30 & 600 & glossy cracked & 895 & 7.4 & 2.918 & 0 \\
\hline 7 & 1000 & 1 & 30 & 600 & very dull many holes & 800 & 41.4 & 2.988 & 2.25 \\
\hline 8 & 1000 & 1 & 100 & 600 & very dull many holes & 800 & 33.8 & 2.981 & 3.24 \\
\hline 9 & 1000 & 25 & 30 & 600 & very dull no holes & 795 & 39.3 & 2.977 & 2.4 \\
\hline 16 & 1000 & 25 & 100 & 600 & du11 pin holes & 845 & 35.9 & 2.926 & 2.31 \\
\hline 12 & 1200 & 1 & 30 & 100 & glossy smooth & 875 & 1.2 & 2.906 & 0 \\
\hline 13 & 1200 & 25 & 30 & 100 & glossy smooth & 875 & 1.6 & 2.897 & 0 \\
\hline 14 & 1200 & 1 & 100 & 100 & glossy smooth & 870 & 1.4 & 2.916 & 0 \\
\hline 17 & 1200 & 25 & 100 & 100 & glossy cracked & 870 & 2.2 & 2.909 & 0 \\
\hline 4 & 1000 & 1 & 30 & 100 & dull no holes & 845 & 5.5 & 2.944 & 2.93 \\
\hline 5 & 1000 & 1 & 100 & 100 & glossy cracked & 855 & 4.5 & 2.890 & $\sim 1.0$ \\
\hline 6 & 1000 & 25 & 30 & 100 & glossy smooth & 825 & 5.1 & 2.814 & 2.81 \\
\hline 11 & 1000 & 25 & 100 & 100 & glossy smooth & 915 & 1.5 & 2.897 & 0 \\
\hline
\end{tabular}

(a) M.T. - meit temperature

(b) T.A.M.T. - time at melt temperature

(c) C.R. - cooling rate

(d) S.T. - storage temperature

Study of High Temperature Storage of Solidified Waste Products Containing Sulfate - D. W. Brown

A vessel 12 in. in diameter by 26 in. high has been built and filled $221 / 2$ in. deep with spray solidification sulfatecontaining (PW-2) melt. This will be heated at the center of the melt. The pressure buildup, caused by decomposing sulfate, and the temperature across the melt will be measured. 
product Characterization Laboratory Studies - M. Mularz

Phosphate-glass samples prepared in the laboratory from sulfate-containing (PW-2) feed are being evaluated to characterize the physical properties of the glasses.

Thermal diffusivity will be determined by a rapid thermal pulse method. Linear coefficients of thermal expansion are being measured, and preliminary data indicates a high linear coefficient. Some samples are oozing a clear liquid (presumed to be a phosphate) at elevated temperatures ( 400 to $\left.500{ }^{\circ} \mathrm{C}\right)$.

A prototype drop weight apparatus has been developed for dispersibility measurements. It consists of a 2 in. diam plexiglass tube, a weight with a $1 / 8$ in. diam blunt-end steel tip, and a steel holder for the sample. The tube allows the weight to fall in a straight line with sufficient clearance allowed to prevent drag. When the glass samples break under impact, the particles are collected and classified by weight and size as: greater than sieve size, sieve size, and subsieve size. Analysis of the subsieve sizes will be attempted with a Coulter Counter.

Although the thermal shock apparatus has not been developed as yet, it will consist of a tube furnace capable of $600^{\circ} \mathrm{C}$ and a water bath into which the sample can fall. Thermal conductivity will be determined on samples that are 1 in. long with a 1 in. diam.

Some of the samples are porous and cracked; therefore, in the evaluation of most parameters, the values obtained must be interpreted carefully. 
Product Measurements, Testing and Storage Solids Storage Engineering Testing - V. P. Kelly A-Cell modifications for SSET that are being completed include:

- Design and fabrication of a push-pul1 through-the-wall transfer mechanism.

- Completion of gallery work, which includes correcting problems with manipulator monorail installation.

- Installation of special mounting brackets in cell for waste pot and test pod storage.

- Fabrication of an ion chamber shielding cask for in-cell radiation monitoring.

Completion of these project items is expected by fall.

SSET Equipment and Systems Fabrication and Installation. Fabrication and installation of SSET equipment is proceeding in the effort to activate SSET late this year. Status of the major items of equipment is:

- Construction of 12 standard test pods is complete.

- Construction of four salt storage pods is complete except for assembly. With the exception of assembly of these pods, the full complement of pods for SSETF is now complete.

- Design and fabrication of in-cell transfer hardware and work trays is started.

- Design and installation of items is well along, including (1) emergency in-cell cooling system; (2) emergency test pod cooling system; and (3) auxiliary viewing for both the airlock and $A$ Cell.

- Fabrication of the core driller and a second generation welding turntable is started.

Remote Handling Tests for SSETF. Remote handling design verification testing is in process to verify operability of in-cell components. 
Product Characterization - R. J. Thompson

The following product evaluation data on radioactive WSEP pots were collected during the period:

1. PG-4 Pot Calorimetry--4.2 kW $\pm 10 \%$ (referenced to the shutdown date of $P G-4$ run).

2. Pot pressures for filled pots in Rack 4A Run No. for Pot
a. $\mathrm{PC}-1$
No reading
b. $\mathrm{SS}-1$
1 psig
c. $\mathrm{PC}-2$
$-10 \mathrm{in} . \mathrm{Hg}$
d. $\mathrm{PC}-3$
-28 in. $\mathrm{Hg}$
e. $\mathrm{SS}-2$
1 psig
f. $\mathrm{PC}-4$
12 psig
g. $\mathrm{PC}-5$
-2 psig
h. $\mathrm{PC}-6$
-11 in. $\mathrm{Hg}$
i. $P G-1$
No reading
j. $P G-2$
-30 in. $\mathrm{Hg}$
k. $P G-3$
-24 in. $\mathrm{Hg}$
1. $P G-4$
No pressure (leaky jumper)

The pots from PG-5, PG-6 and SS-3 were welded.

The pot wall thickness scanner is still giving erratic results, but repairs are underway. 
Distr-1

DISTRIBUTION

No. of

Copies

2

AEC Chicago Patent Group

G. H. Lee

R. K. Sharp (Richland)

327

AEC Division of Technical Information Extension

1

AEC Division of Technical Information Extension for retransmittal to:

US/UK, England

A. R. Edwards

3

AEC, RDT Site Representative - PNL

P. G. Holsted (2)

A. W. Waterhouse

1

Aerojet - General

Idaho Falls

W. E. Nyer

1

Aerojet - General

Sacramento

F. J. Climent

7

Argonne National Laboratory

C. E. Dickerman

S. Fistedis

R. O. Ivins

P. Lottes

R. C. Voge 1

LMFBR Program Office

A. Amorosi

L. Baker

61

AEC Library, Washington

Advisory Committee on Reactor Safeguards

F. R. Fraley (17)

Division of Reactor Development and Technology

R. S. Brodsky

J.W. Crawford

R. L. Ednie

D. E. Erb 
No. of

Copies
A. Giambusso

H. L. Hamester

E. E. Kintner

J. A. Lieberman

R. R. Newton (5)

R. E. Pahler (2)

A. J. Pressesky

I. C. Roberts

M. A. Rosen

E. E. Sinclair

S. A, Szawlewicz

G. W. Wensch

M. J. Whitman

Division of Compliance

L. Kornblith, Jr.

Division of Operational Safety

H. Gilbert

Division of Production

G. B. Pleat

Division of Reactor Standards

M. Bolotsky

G. Burley

E. G. Case

A. B. Holt

R. Waterfield

Division of Compliance, Region IV

J. W. Flora

Atomic Energy Commission, RDT Site Representative San Diego

R. H. Ball

Atomic Energy Commission

USAEC Technical Representative

Toronto

H. J. Reynolds

Atomics International

H. Morewitz

Liquid Metals Engr Center

R. W. Dickinson 
No, of

Copies

1

Auburn University

School of Engineering and Engineering

Experiment Station

G. H. Nix

2

Babcock \& Wilcox Co.

Virginia

R. Wascher

Washington

L. R. Weissert

Battelle Memorial Institute

A. R, Duffy

D. L. Morrison/D. L. Ritzman

S. Paprocki

D. N. Sunderman

Batte1le Memorial Institute

Frankfort, Germany

G. Leistner/K. J. Kober

1

1

1

1

1

Bechte1 Corporation

R. F. Griffin

Brookhaven National Laboratory

A. W. Castleman

Canoga Park Area Office

R. L. Morgan

Chalk River Nuclear Laboratories

Chalk River, Ontario, Canada

Station 3

G. Hake

Chicago Operations Office

Atomic Energy Commission

D. M. Gardiner 
Distr -4

No. of

Copies

1

Combustion Engineering

M. F. Valerino

1

Consolidated Edison Company

J. J. Grob

7

Douglas United Nuclear

T. W. Ambrose

N. R. Miller

W. F. Nechodom

J. W. Riches

D. L. Renberger

J. R. Spink

Files

2

General Atomic Division (AEC)

A. J. Goodjohn

3

General Electric Company, APED San Jose

S. Vandenberg

G. E. Wade

E. Zebroski

4

General Electric Company, San Jose (Trumbull)

P. Bray

M. Siegler

W. A. Sutherland

B. Wolfe

1

Harvard Air Cleaning

Laboratory

2

Idaho Nuclear Corporation

J. A. Buckham

C. M. Slansky

2

Idaho Operations Office

Atomic Energy Commission

D. Williams 


\title{
Distr -5
}

\author{
No. of \\ Copies \\ 2 \\ IIT Research Institute \\ E. V. Gallagher \\ T. A. Zaker \\ 2 \\ Atlantic Richfield Hanford Company \\ File \\ G. R. Kie 1 \\ 1 \\ Los Alamos Scientific Laboratory \\ J. H. Russe 1 \\ 1 \\ MPR Associates, Inc. \\ T. Rockwel1 III \\ National Bureau of Standards \\ C. Mueh1hause \\ 1 \\ Naval Ordinance Laboratory \\ J. Proctor \\ North Carolina State University \\ M. N. Ozisik \\ 1 \\ Nuclear Fuels Services \\ R. P. Wischow \\ 13 \\ Oak Ridge National Laboratory \\ R. E. Adams \\ R. Blanco \\ J. Buchanan \\ W. B. Cottre11 \\ D. Ferguson \\ C. E. Miller \\ G. W. Parker \\ L. F. Parsley \\ D. B. Trauger


No. of

Copies

4

1

1

14

2

2

1

2 $\frac{\text { Oak Ridge Operations Office }}{\text { Atomic Energy Commission }}$

D. Cope

E. Delaney

W. L. Smalley

Oregon State University

James G. Knudsen

Pacific Gas and Electric Company

W. Nutting

Phillips Petroleum Company

G. O. Bright

G. F. Brockett

S. Forbes

C. Haire

G. B. Matheny

W. E. Nyer

F. Schroeder

N. K. Sowards

T. R. Wilson

Richland Operations Office Atomic Energy Commission

C. L. Robinson

C. N. Zangar

San Francisco Operations Office Atomic Energy Commission

Lt. Col. J. B. Radcliffe

C. V. Backlund

duPont, Aiken

A. H. Peters

TRW Incorporated

TRW Systems Group

D. B. Langmuir

S. M. Zivi 
No. of

Copies

2

$\frac{\text { University of California, Berkeley }}{\text { Institute of Engineering Research }}$

H. A. Johnson

V. E. Schrock

1

University of Washington

Wells Moulton

6

Westinghouse Electric Co. (APD)

E. Beckjord

D. Fletcher

H. Graves

F. M. Heck

R. A. Wiesemann

Westinghouse Electric Corp. (HTD)

A. Lohmeier

Batte11e-Northwest

F. W. Albaugh

J. M. Batch

D. W. Pearce

J. J. Cadwe 11

L. A. Carter

D. L. Condotta

F. G. Dawson

D. R. de Halas

H. N. Pedersen

L. T. Pedersen

D. L. Reid

W. D. Richmond

G. J. Rogers

L. C. Schwendiman

R. F. Foster

J. C. Fox

J. J. Fuquay

W. A. Haney

H. Harty

J. F. Honstead

R. T. Jaske

R. L. Junkins

H. V. Larson

J. M. Nielson

R. E. Nightingale

H. M. Parker

D. E. Simpson

J. C. Spanner

E. E. Voiland

R. G. Wheeler

N. G. Wittenbrock

D. C. Worlton

Patent Section

Technical Information Files Technical

Publications

R. S. Paul 
